\title{
Target Identification for CNS Diseases by Transcriptional Profiling
}

\author{
C Anthony Altar ${ }^{\star, 1}$, Marquis $\mathrm{P}$ Vawter $^{2}$ and Stephen D Ginsberg ${ }^{3}$ \\ ${ }^{1}$ NeuroDrug Consulting, Garrett Park, MD, USA; ${ }^{2}$ Functional Genomics Laboratory, Department of Psychiatry and Human \\ Behavior, School of Medicine, University of California, Irvine, Irvine, CA, USA; ${ }^{3}$ Center for Dementia Research, Nathan Kline \\ Institute, Departments of Psychiatry and Physiology \& Neuroscience, New York University School of Medicine, Orangeburg, \\ NY, USA
}

Gene expression changes in neuropsychiatric and neurodegenerative disorders, and gene responses to therapeutic drugs, provide new ways to identify central nervous system (CNS) targets for drug discovery. This review summarizes gene and pathway targets replicated in expression profiling of human postmortem brain, animal models, and cell culture studies. Analysis of isolated human neurons implicates targets for Alzheimer's disease and the cognitive decline associated with normal aging and mild cognitive impairment. In addition to $\tau$, amyloid- $\beta$ precursor protein, and amyloid- $\beta$ peptides (A $\beta$ ), these targets include all three high-affinity neurotrophin receptors and the fibroblast growth factor (FGF) system, synapse markers, glutamate receptors (GluRs) and transporters, and dopamine (DA) receptors, particularly the D2 subtype. Gene-based candidates for Parkinson's disease (PD) include the ubiquitin-proteosome system, scavengers of reactive oxygen species, brain-derived neurotrophic factor (BDNF), its receptor, TrkB, and downstream target early growth response 1, Nurr-1, and signaling through protein kinase $\mathrm{C}$ and RAS pathways. Increasing variability and decreases in brain mRNA production from middle age to old age suggest that cognitive impairments during normal aging may be addressed by drugs that restore antioxidant, DNA repair, and synaptic functions including those of DA to levels of younger adults. Studies in schizophrenia identify robust decreases in genes for GABA function, including glutamic acid decarboxylase, HINT1, glutamate transport and GluRs, BDNF and TrkB, numerous 14-3-3 protein family members, and decreases in genes for CNS synaptic and metabolic functions, particularly glycolysis and ATP generation. Many of these metabolic genes are increased by insulin and muscarinic agonism, both of which are therapeutic in psychosis. Differential genomic signals are relatively sparse in bipolar disorder, but include deficiencies in the expression of 14-3-3 protein members, implicating these chaperone proteins and the neurotransmitter pathways they support as possible drug targets. Brains from persons with major depressive disorder reveal decreased expression for genes in glutamate transport and metabolism, neurotrophic signaling (eg, FGF, BDNF and VGF), and MAP kinase pathways. Increases in these pathways in the brains of animals exposed to electroconvulsive shock and antidepressant treatments identify neurotrophic and angiogenic growth factors and second messenger stimulation as therapeutic approaches for the treatment of depression.

Neuropsychopharmacology Reviews (2009) 34, 18-54; doi: 10.1 1038/npp.2008. 172; published online 15 October 2008

Keywords: microarray; gene expression; schizophrenia; bipolar disorder; depression; Alzheimer's disease; Parkinson's disease

\section{INTRODUCTION}

Because of the slow pace of innovations in the therapy of central nervous system (CNS) diseases and a growing elderly population, disabilities due to neurodegenerative and psychiatric diseases now represent the second most frequent cause of morbidity and premature mortality in the

${ }^{*}$ Correspondence: Dr CA Altar, PO Box 498, Garrett Park, MD 208960498, USA, Tel. and Fax: + 1301962 0910, E-mail: tonyaltar@gmail.com Received 31 May 2008; revised 20 August 2008; accepted 21 August 2008
USA. Most psychiatric drugs being approved today are refinements and reformulations of drugs discovered decades ago by serendipitous clinical observations. Bona fide targets for neurological disease are fewer in number, and proof-of-concept studies are rare in neurological practice.

Improved technologies for gene expression analysis of the human brain, confirmation of identified genes by RNA- and protein-based assays, and gene-based compound screening have identified new targets for CNS disease. This mechanistic approach to neuropsychiatric and neurodegenerative 
drug discovery is highlighted in this review, which is limited to genes and their protein products that satisfy at least one of the following criteria: (1) Did their discovery confirm or extend other messenger ribonucleic acid (mRNA)- or protein-based findings? (2) Did they identify proven pathways or targets, or those that are under strong consideration? (3) Did existing, or emerging, drugs confirm the target in proof-of-concept studies? Most of the genes described in this review that met or exceeded these criteria are summarized in Table 1 for neurodegenerative diseases, and Table 2 for psychiatric diseases, in the order that they appear in the text.

\section{Conceptual Approaches}

Traditional CNS drug discovery is a target-oriented 'topdown' approach that screens new compounds based on their interaction with an established receptor or other target. This approach may explain why most new drugs duplicate the efficacy and side effect profiles of their predecessors, and ameliorate only a portion of disease pathology. Most CNS diseases are treated with a combination of drugs, and some of the most effective drugs such as the antipsychotic clozapine (Roth et al, 2004; Altar et al, 1986, 2003a) and the mood stabilizers lithium, valproate, and carbamazepine (Gould et al, 2004) interact with the

TABLE 1: Genes changes in neurodegenerative diseases.

\begin{tabular}{|c|c|c|c|c|}
\hline \multirow[b]{2}{*}{ Gene symbol } & \multirow[b]{2}{*}{ Gene name } & \multirow{2}{*}{$\begin{array}{l}\text { Statistically } \\
\text { significant change }\end{array}$} & \multicolumn{2}{|c|}{ REFERENCES } \\
\hline & & & Initial publication & Confirmation \\
\hline \multicolumn{5}{|c|}{ Alzheimer's Disease } \\
\hline DRD2 & Dopamine receptor 2 & Decreased & Joyce, 1993; Ryoo, 1994 & Ginsberg, 2001 \\
\hline GRIA1 & AMPA1 receptor & Decreased & $\begin{array}{l}\text { Yasuda, 1995; Ikonomovic, } \\
1995\end{array}$ & Carter, 2004; Ginsberg, 2001 \\
\hline GRIA2 & AMPA2 receptor & Decreased & $\begin{array}{l}\text { Yasuda, 1995; Ikonomovic, } \\
1995\end{array}$ & Carter, 2004; Ginsberg, 2001 \\
\hline GRIN1 & NMDA R1 & Decreased & Yasuda, 1995 & Ginsberg, 2001; Jacob, 2007 \\
\hline SLC1A1 & Glutamate transporter EAAT3 & Decreased & Ginsberg, 2001 & Jacob, 2007; Westphalen, 2003 \\
\hline SYP & Synaptophysin & Decreased & Callahan, 1999 & Gutala, 2004; Ginsberg, 2001 \\
\hline SYT1 & Synaptotagmin | & Decreased & Ginsberg, 2001 & Gutala, 2004; Callahan, 1999 \\
\hline CHRNA7 & $\alpha 7$ nicotinic receptor & Increased by ECS & Counts, 2007 & Counts, 2004 \\
\hline 3Rtau/4Rtau & Tau protein isoform & Increased ratio & Ginsberg, 2006 & Ginsberg, 2006 \\
\hline APP & Amyloid precursor protein & Present in SP & Ginsberg, 1999 & Ginsberg, 2004 \\
\hline bax & bcl2-associated x protien & Present in SP & Ginsberg, 1999 & Ginsberg, 2004 \\
\hline bcl-2 & b-cell cll/lymphoma 2 & Present in SP & Ginsberg, 1999 & Ginsberg, 2004 \\
\hline $\begin{array}{l}\text { GRIA1, GRIA2, } \\
\text { GRIA4, and GRIK1 }\end{array}$ & AMPA GluR subunits & Present in SP & Ginsberg, 1999 & Ginsberg, 2004 \\
\hline GFAP & Glial fibrilary protein & Present in SP & Ginsberg, 1999 & Ginsberg, 2004 \\
\hline IL-1 & Interleukin-1 & Present in SP & Ginsberg, 1999 & Ginsberg, 2004 \\
\hline \multirow[t]{2}{*}{ AGER } & Advanced glyucation end-products & Present in SP & Ginsberg, 1999 & Ginsberg, 2004 \\
\hline & receptor & & & \\
\hline \multicolumn{5}{|c|}{ Alzheimer's disease/MCI } \\
\hline TrkA & High affinity NGF receptor & Decreased & Ginsberg, 2001 & Ginsberg, 2001; Boissiere, 1997 \\
\hline TrkB & High affinity BDNF, NT-3 receptor & Decreased & Ginsberg, 2001 & Ginsberg, 2001 \\
\hline TrkC & High affinity NT-3, BDNF receptor & Decreased & Ginsberg, 2001 & Ginsberg, 2001 \\
\hline \multicolumn{5}{|c|}{ Parkinson's disease } \\
\hline $\mathrm{UCH}-\mathrm{L} 1$ & Ubiquitin C-terminal hydrolase L1 & Decreased & Grunblatt, 2004 & Liu, 2002; Choi, 2004 \\
\hline SKP1 & S-phase kinase-associated protein $1 \mathrm{~A}$ & A Decreased & Grunblatt, 2004 & Grunblatt, 2007 \\
\hline EGLN1 & Ion transport & Decreased & Grunblatt, 2004 & Grunblatt, 2007 \\
\hline Nurr-1 & Orphan nuclear receptor & Increased by ECS & Newton, 2003; Altar, 2005 & Chu, 2006; Eells., 2002 \\
\hline BDNF & Brain-derived neurotrophic factor & Increased by ECS & Newton, 2003; Altar, 2005 & Hyman, 1991; Altar, 1994; 2003 \\
\hline TrkB & Tropomyosin receptor-related kinase & Increased by ECS & Nibuya,1995; Altar, 2005 & Hyman, 1991; Altar, 1994 \\
\hline gstm1 & Glutathione-S-transferase & Increased by ECS & Altar, 2005 & Hyman, 1991 \\
\hline $\mathrm{S} 100 \beta$ & S100 calcium binding protein & Increased by ECS & Newton, 2003 & Altar, 2005 \\
\hline \multicolumn{5}{|l|}{ Normal aging } \\
\hline $\mathrm{PKC} \alpha, \beta, \gamma$ & Protein kinase $\alpha, \beta, \gamma$ subunits & Decreased & Lu, 2004 & \\
\hline CALM1 & Calmodulin 1 & Decreased & Lu, 2004 & \\
\hline Tau & tau protein & Decreased & Lu, 2004 & \\
\hline GlurR1 & AMPA receptor subunit & Decreased & Lu, 2004 & Ginsberg, 2007 \\
\hline EAAT2 & Excitatory amino acid transporter 2 & Decreased & Lu, 2004 & Ginsberg, 2007 \\
\hline D1 through D5 & Dopamine receptors 1 through 5 & Decreased & Hemby, 2003 & Ginsberg, 2004 \\
\hline
\end{tabular}

$\ddot{E C S}=$ electroconvulsive shock; $\mathrm{SP}=$ senile plaques. 


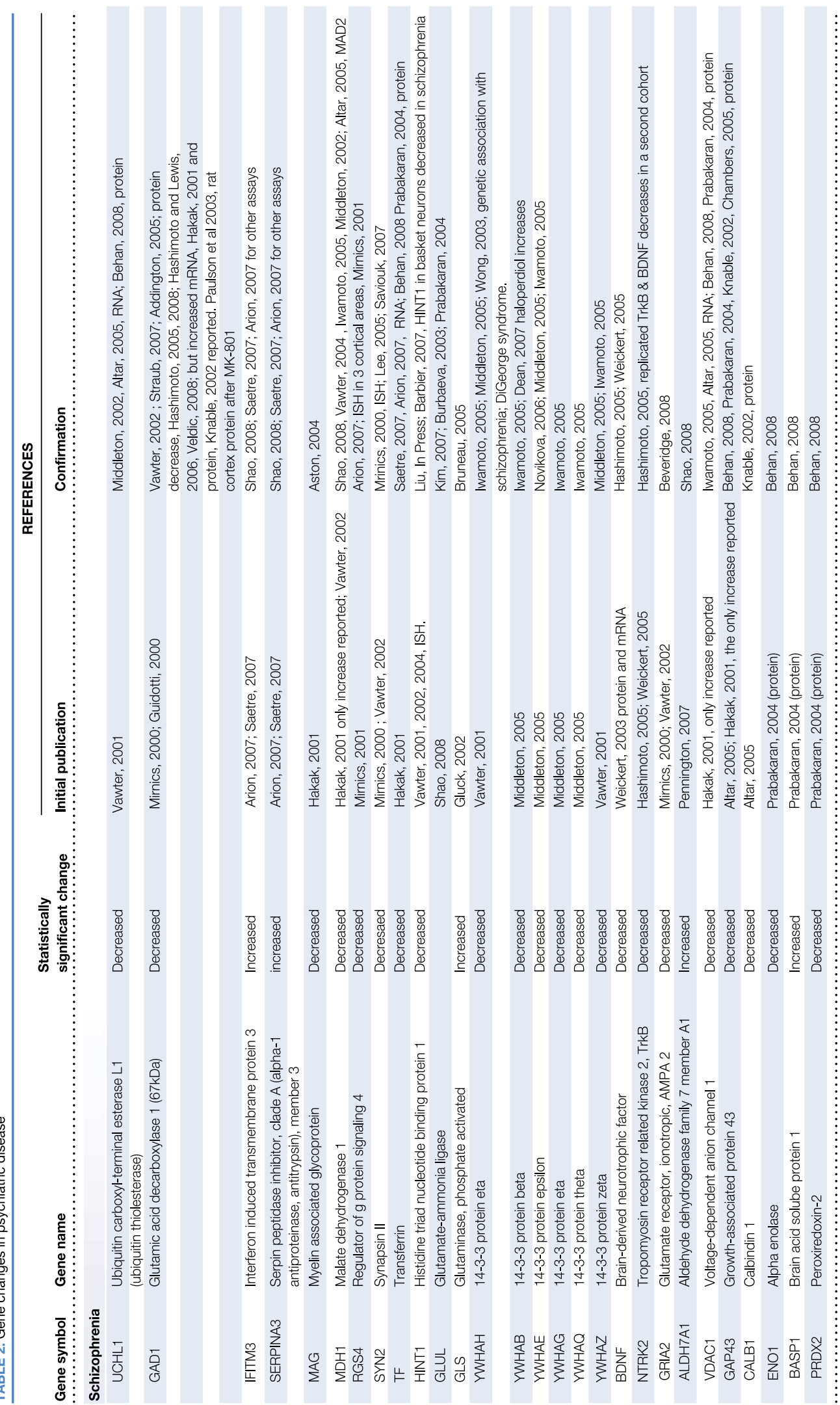




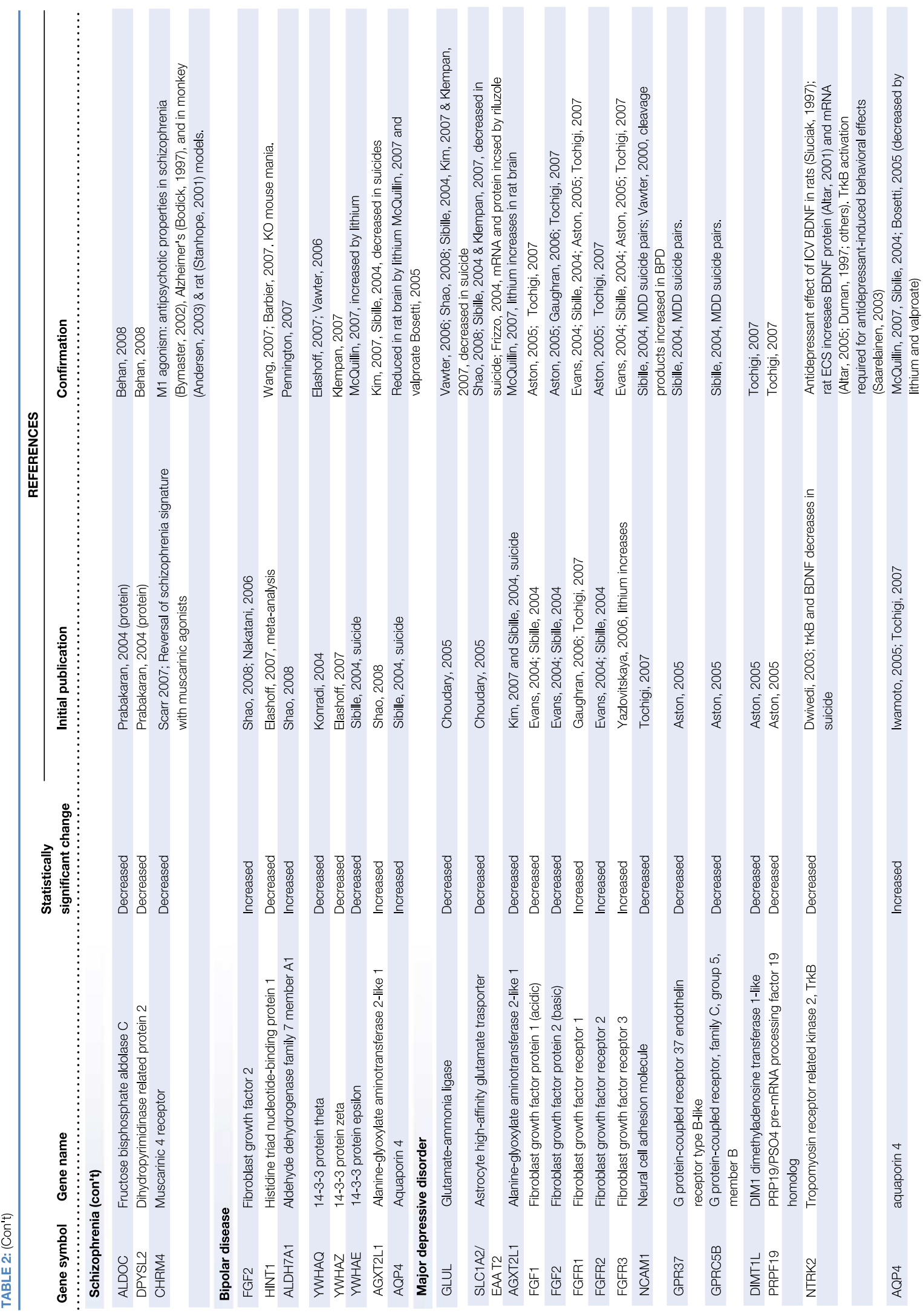


widest number of targets, not the fewest as one might imagine. In addition, family and association studies of DNA haplotypes show that most single gene mutations explain at best only a small portion of the variation in psychiatric, cognitive, or neurodegenerative disorders, and that better genetic association scores are obtained when multiple genes are considered (Tsuang et al, 1999; Pulver, 2000; Plomin and McClearn, 1993; Hauser and Pericak-Vance, 2000; PericakVance et al, 2000). In the absence of a deeper understanding of disease pathology and mechanisms of side effects, CNS drug discovery would remain dominated by the redesign of drugs for familiar targets and reduced approval rates for 'me too' drugs.

The ability to evaluate changes in the expression of the entire genome in brain areas affected by CNS disease and drug effects on multiple pathways is an alternative, 'bottom-up' approach to drug discovery (Palfreyman et al, 2002; Ogden et al, 2004; Le-Niculescu et al, 2007). Most human cells contain a nucleus and, within that organelle, the same DNA. It is the differential expression of genomic DNA, in the form of mRNA, and its transcription into protein, that determines the type and function of each cell. Insights into disease pathology can be revealed by the 'disease signature' (Figure 1), those genes whose expression in the brains of patients differs reliably from those of nonafflicted, matched controls (Palfreyman et al, 2002). The treatment of cultured human neural cells or experimental animals with therapeutic compounds that target the disease can produce a 'drug signature' of genes, the expression levels of which are changed in common in response to multiple therapeutic drugs for that disease. This pharmacogenomic approach to drug discovery is a clear paradigm shift from the conventional method of re-deriving drugs with a known mode of action.

\section{Combining Disease and Drug Signatures for Target and Drug Discovery}

The discovery of genes that change in model systems in response to therapeutic agents, and in a direction that is opposite to their change in disease may provide drugable targets, and novel mechanism(s) which address a broader biochemical basis of disease (Figure 1). The statistical, biological, and pharmacological significance of each of these target genes can be calculated by an algorithm to determine which genes to use in a large-scale mRNA-based drug screening program (Table Box 1). Genes identified in these ways can be used to screen small molecules for activity. New receptor targets can be identified by the pharmacology of novel compounds identified, and, if these are agonists, by the ability of selective antagonists to block their downstream gene effects.

\section{Genomic Tools for Understanding Disease}

High-throughput mRNA technologies (Ginsberg et al, 2006d; Lockhart et al, 1996; Schena et al, 1995; Brown and Botstein, 1999), including microarray platforms, are at the

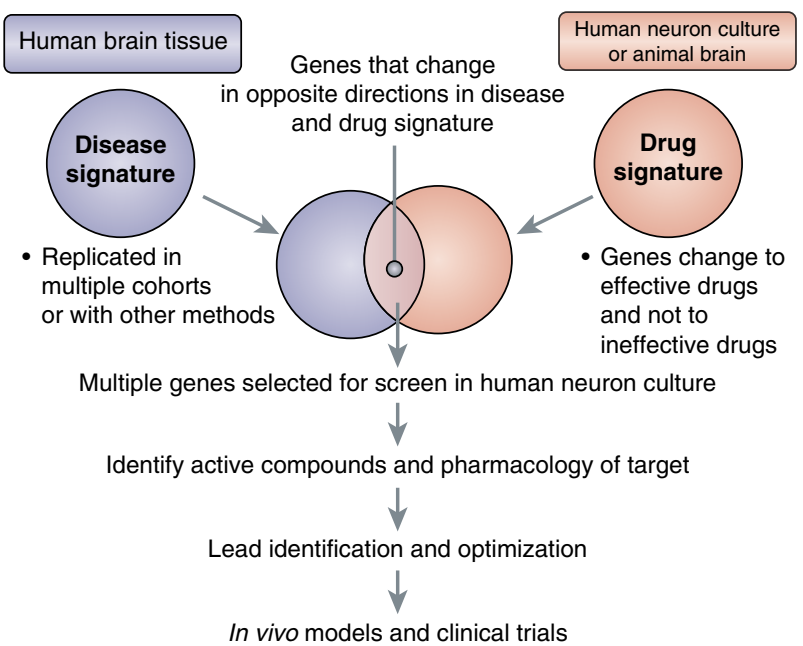

Figure 1. Gene-based drug discovery strategies based on diseasespecific (left) and drug-induced (right) mRNA expression changes. Information from these data, the literature, and other factors described in the text are used to select a smaller set of genes that change reciprocally between human brain and drug-exposed tissue, and are used for gene-based compound screening or identification of specific targets.

center of this paradigm shift. They provide an affordable, simultaneous assessment of gene expression levels in many samples in a single experiment. These technologies remain technically challenging, and require high-quality RNA to measure the relatively small $(20-50 \%)$ changes in brain gene expression (Eberwine et al, 2001; Ginsberg et al, 2004; Jurata et al, 2004). They also require validation by independent methods, including real-time quantitative PCR (qPCR) and measurements of their respective protein products. These methods, and, well-characterized postmortem human brain samples, high-throughput spotted cDNA expression miniarrays, and methods to extract RNA from single neurons and discrete cell clusters in brain, are described below.

\section{TECHNOLOGICAL ADVANCEMENTS FOR THE FUNCTIONAL GENOMICS APPROACH}

\section{Suitable Tissue Sampling}

Human brain tissue. The study of CNS gene changes in neurological or psychiatric cases requires brains collected from well-documented cases. Collections of neurodegenerative disease samples include those of the Multiple Sclerosis Brain Bank and the New South Wales Brain Bank, part of the Australian Brain Bank Network (Sheedy et al, 2008), the University of Miami Brain Endowment Bank, the Center for Neurodegenerative Disease Research at the University of Pennsylvania, the collection at UC Davis, the New York Brain Bank at Columbia University (Vonsattel et al, 2008), the Religious Orders Study at the Rush University Medical Center (Bennett et al, 2002; Mufson et al, 2007a), and the Cognitive Neurology and Alzheimer's Disease (AD) Center at Northwestern University. In Appendix $A$, we include a reference to a comprehensive 
Table Box 1 Algorithm to Prioritize Genes that Change in Disease and Response to Treatment

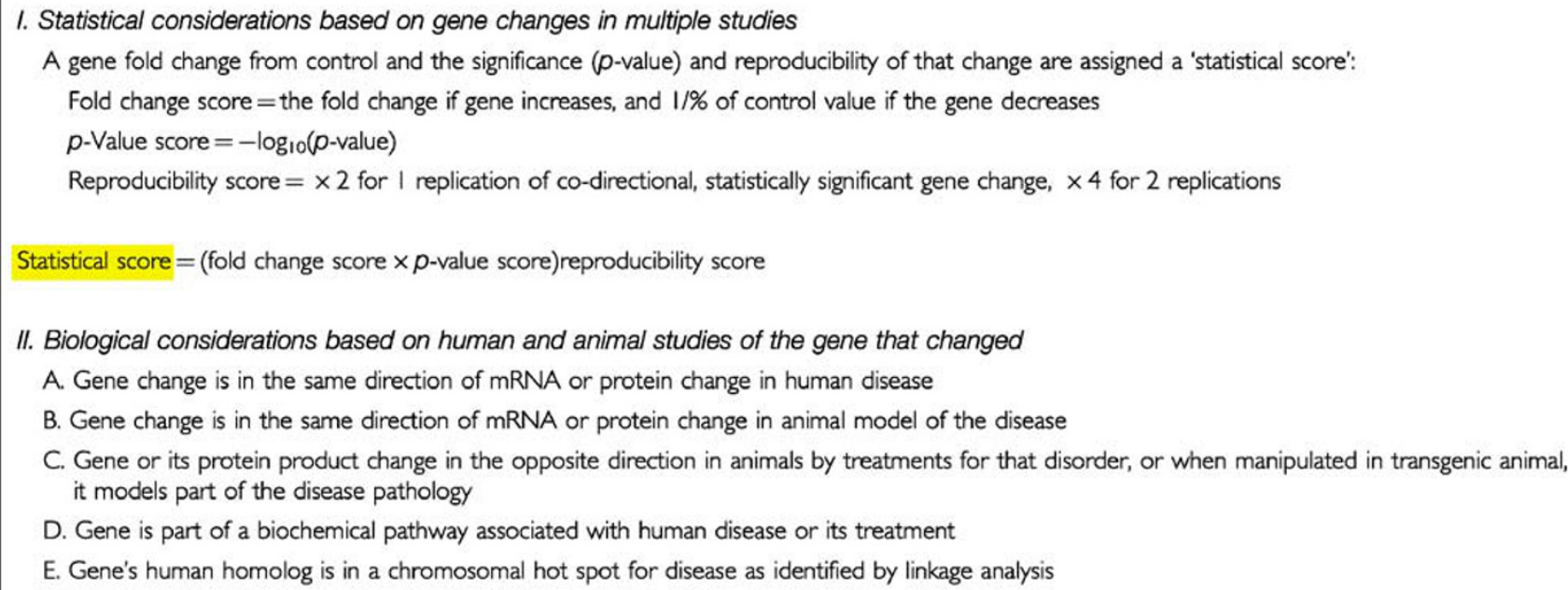

\section{Pharmacological considerations}

The score is based on how 'drugable' the target is, and whether it has received support in the past as a drug target

A. Gene changes in disease or in response to therapeutic agents are found to be under the control of a drugable target (ie, receptor or enzyme antagonist)

B. For antagonist approach, knockout of the target mimics the desired gene changes, or overexpression mimics the disease phenotype. Gene changes are reversed in knockout model by effective drugs.

C. Gene or its protein product is changed by effective treatments for that disorder or when manipulated in transgenic animal, predictably affect disease pathology.

Pharmacological score $=\mathrm{A}(10)+\mathrm{B}(9)+\mathrm{C}(8) ;$ maximum $=27$

The values in parentheses are summed for each criterion that is true for $\mathrm{A}-\mathrm{C}$

Algorithm score $=$ Statistical score+biological score + pharmacological score

Example of a robust gene:

A gene is doubled in bipolar disorder with a $p$-value of $10^{-5}$, and its increase is replicated in two other studies. If the gene fulfills all biological and pharmacological criteria, its algonithm score will be about the maximum, or $(2 \times 5) \times 4+33+27=100$

This algorithm includes features that have been used to identify genes associated with schizophrenia (Altar et al, 2008) and the therapeutic response to ECT (Altar et al, 2005). The statistical, experimental, biological, and pharmacological considerations are quantified and summed to prioritize the significance of each gene as a target for CNS drug discovery.

list of brain banks focused on neurodegenerative diseases and maintained by the National Institute of Neurological Disorders and Stroke (NINDS). Prominent brain collections with an emphasis on psychiatric disease include the Stanley Medical Research Institute (SMRI) (Johnston et al, 1997; Torrey et al, 2000), the collection at UC Irvine (Vawter et al, 2004b; Bunney et al, 2003), the University of Pittsburgh (Mirnics et al, 2000; Mirnics and Lewis, 2001), and the Harvard Brain Tissue Resource Center, which has psychiatric and neurodegenerative disorder collections (Konradi et al, 2004; Benes and Berretta, 2000) (Appendix A).

Requisite clinical information on brain samples includes subtype of the CNS disorder, pathological diagnosis, therapeutic treatments, cause of death, antemortem state, concomitant medical conditions, and lifestyle information such as cognitive performance, smoking, alcohol intake, medication history, and evidence of substance abuse (Torrey et al, 2000; Katsel et al, 2005b). Other necessary measures at autopsy include postmortem interval, brain $\mathrm{pH}$, patient age, sex, and brain weight. Unfortunately, even the best-documented collections contain gaps in such information, such as the amount and frequency of therapeutic and other drug treatments, cognitive status, and state of the illness at the time of death. Other limitations of brain banks can include the dearth of age-matched control cases, particularly in AD, Parkinson's disease (PD), and schizo- 
phrenia research, between-center differences in anatomical dissection methods, or the scarcity of frozen sections, the analysis of which by laser capture microdissection (LCM) can mitigate against variations in dissection methods. The prospective diagnosis and well-planned collection of samples, as exemplified by the Religious Orders Study of the Rush University Medical Center (Mufson et al, 2003), is advantageous in contrast to retrospective disease diagnosis. These advantages include the collection of more accurate patient demographics, finer delineation of patient subtypes, shorter postmortem intervals, and other variables that can be co-analyzed with the results of microarray studies.

In addition to the importance of RNA quality to gene expression profiles, tissue $\mathrm{pH}$ appears to correlate highly with the expression of particular gene classes, including those of metabolic and hydrogen ion transport functions (Johnston et al, 1997; Li et al, 2004; Altar et al, 2005; Vawter et al, 2006b; Knable et al, 2002; Bahn et al, 2001). It remains unknown whether decreases in brain $\mathrm{pH}$ lower the expression of these genes, or whether their decreased expression contributes to brain acidosis during the antemortem agonal period.

Several laboratories have evaluated the effects of different freezing and fixation protocols on RNA quality, ease of tissue microdissection, and success of cDNA array analysis (Bahn et al, 2001; Van Deerlin et al, 2002; Vincent et al, 2002). For example, the agonal state of a patient prior to death can have profound effects on several parameters, including RNA stability and protein degradation, as hypoxia, pneumonia, and protracted coma have been associated with alterations in RNA and protein levels (Li et al, 2004; Barton et al, 1993; Hynd et al, 2003; Tomita et al, 2004). These antemortem variables and postmortem tissue procedures must be considered in molecular studies of human postmortem tissues. Of critical importance is the assessment of RNA quality and quantity, particularly for discrete cell RNA assessments. Acridine orange (AO) histofluorescence provides a rapid assessment of RNA quality in tissue sections. $\mathrm{AO}$ is a fluorescent dye that intercalates selectively into nucleic acids, and has been used to detect RNA and DNA in brain tissues (Ginsberg et al, 1997, 2006d; Vincent et al, 2002; Mikel and Becker, 1991). RNA quality can be obtained with high sensitivity using bioanalysis (eg, 2100 Bioanalyzer; Agilent Technologies). Bioanalysis enables visualization of capillary gel electrophoresis results in an electropherogram and/or digital gel formats. DNA and protein quality and abundance can also be evaluated by bioanalysis (Freeman and Hemby, 2004).

Microaspiration and microdissection of specific cell types. Heterogeneity of neuronal and non-neuronal cell populations characterizes the mammalian brain. Normative brain function and dysfunction, are mediated in large part through gene expression, and ultimately protein expression, within these interconnected cells. The collection of specific cell types from brain is challenging, but often necessary, as evidenced by the limitations of studying relatively large 'blocks' of brain tissue for gene expression experiments. These blocks contain not only the neurons of interest but also unaffected neurons and other cell types, including astrocytes, glia, and vascular tissues. The unaffected cells will most likely greatly outnumber the affected cells and obscure the disease signature. This problem can be circumvented by two recently developed methods for collecting homogeneous cell populations from thin sections.

Single-cell microaspiration entails visualizing cell(s) using an inverted microscope connected to a micromanipulator, microcontrolled vacuum source, and an imaging workstation on an air table. Individual cells can be aspirated from the tissue section and placed in microfuge tubes for RNA amplification. Microaspiration can accurately dissect neurons, neuropil, or dendrites identified by a specific immunostain with minimal disruption of the surrounding neuropil (Ginsberg et al, 2006d; Hemby et al, 2002, 2003; Crino et al, 1998; Ginsberg and Mirnics, 2006). This is demonstrated for a $\mathrm{p} 75^{\mathrm{NTR}}$-immunoreactive cholinergic neuron in the nucleus basalis of an $\mathrm{AD}$ patient (Figure 2). The mRNA of single or pooled cells can be measured by qPCR, or amplified for subsequent microarray analysis.

LCM enriches the detection of cell-specific genes from populations of cells (Ginsberg et al, 2006d; Jurata et al, 2004; Altar et al, 2005; Luo et al, 1999) (Figure 3). LCM employs a high-energy laser source that separates desired cells from the remaining tissue section, and facilitates transfer of the identified cells for analysis (Bonner et al, 1997; Emmert-Buck et al, 1996). Positive extraction LCM, as
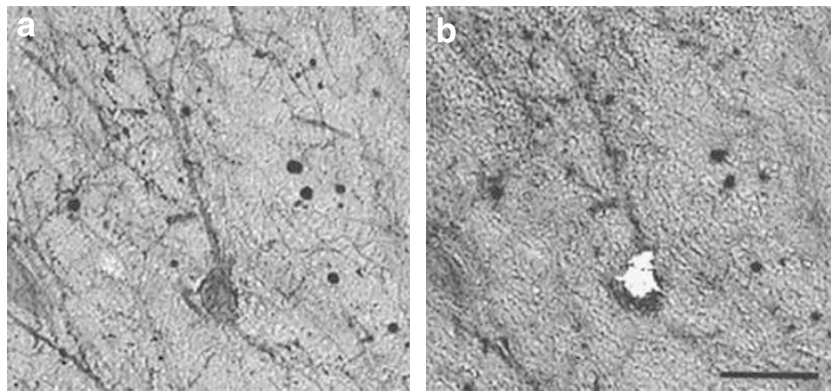
C Classes of transcripts - Cytoskeletal elements
- Glutamate receptors
- Dopamine receptors
- Immediate early genes
- Cell death genes
- Neurotrophins
- Neurotrophin receptors
- Protein phosphatases
- Protein kinases
- AD linked genes
- Synapse-related mRNAs

Figure 2. Single-cell microaspiration and classes of transcripts on a custom-designed cDNA array. (a) A p75 $5^{\text {NTR }}$-immunoreactive neuron in the nucleus basalis of an AD patient is shown. (b) Same section as (a) following single-cell microaspiration. (c) Classes of transcripts analyzed in single-cell preparations using a custom-designed cDNA array platform ( $n=576$ genes). Scale bar: $50 \mu \mathrm{m}$. Adapted from Ginsberg et al (2000) with permission. 

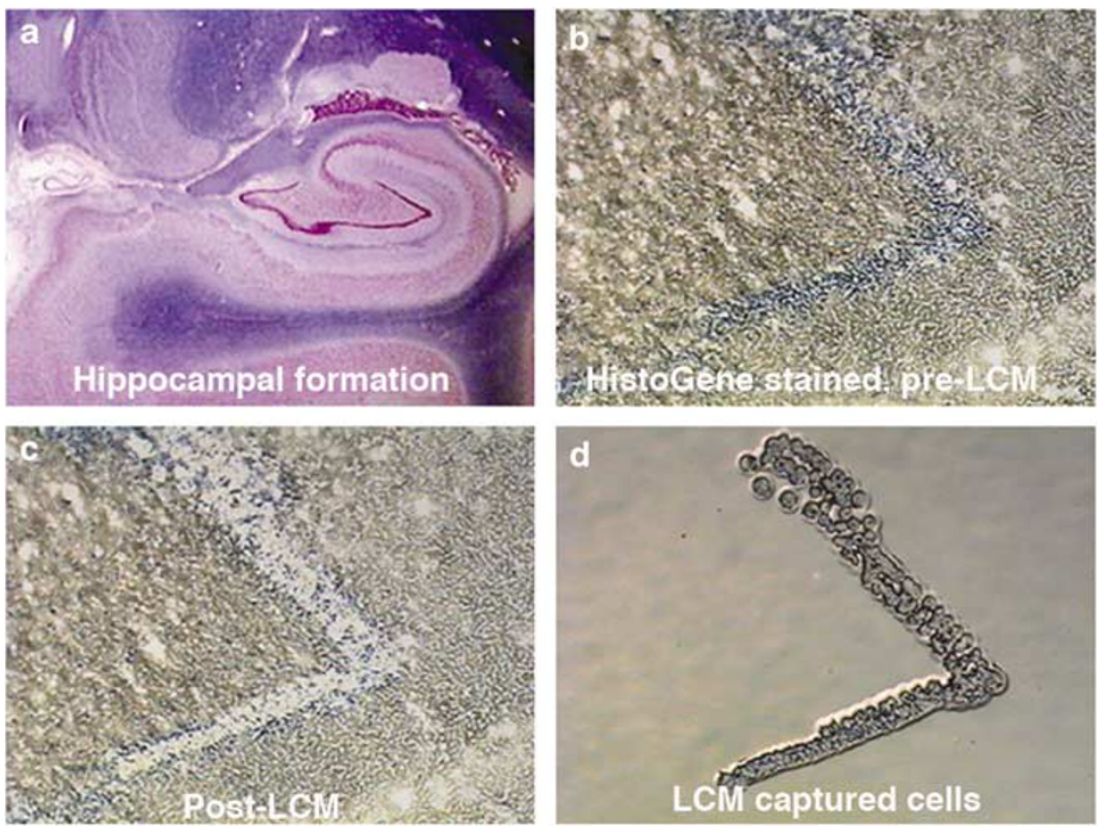

Figure 3. LCM is used to collect dentate neurons from the human hippocampus (shown in lower power, top left) (a). The top right micrograph (b) is an enlargement that shows the blue-stained dentate neurons before LCM. In the lower right (d), the LCM captured neurons are isolated and gene expression is measured in cDNA produced from their amplified RNA. The 'hole' after LCM can be seen in the lower left micrograph (c).

exemplified by the PixCell IIe system from Arcturus (MDS Analytical Technologies, Sunnyvale, CA), directs a laser beam' onto the cells of interest for the purpose of microaspiration (Figure 3). Negative extraction LCM, or non-contact laser extraction, employs a laser source to cut around the area of interest within a tissue section, and the circumscribed material is catapulted into a microfuge tube. This method is utilized by the PALM system (PALM Microlaser Technologies, Bernried, Germany) (Ginsberg et al, 2006d). Both positive and negative extraction methods allow captured cells and their processes to be examined microscopically to confirm the identity and quality of isolated cell population(s). Single cells as well as dozens to hundreds of cells can be collected by LCM instrumentation. RNA, DNA, and protein extraction methods can be performed on microdissected cells (Fend et al, 1999; Goldsworthy et al, 1999; Simone et al, 2000), although LCM is used primarily for RNA extraction and subsequent cDNA microarray analysis. Positive extraction methods have an advantage of allowing for relatively quick and consistent microaspiration of desired cells. Negative extraction can be more time consuming, but can precisely control the cells or areas in a tissue section that are microdissected and catapulted.

\section{RNA Detection and Verification}

cDNA- and oligonucleotide-based gene microarrays are slightly different technologies for quantifying mRNA for each gene represented on the array (Jurata et al, 2004). Commercially available microarrays contain probes for 15000-30000 different mRNA species, and allow gene expression from much of the human genome to be measured in each sample in the course of several days of experiments.

cDNA arrays. cDNA arrays have been widely used to profile human brain tissue in the study of psychiatric and neurodegenerative disorders (Ginsberg et al, 2004, 2006b, c; Mirnics et al, 2000; Altar et al, 2005; Middleton et al, 2002; Vawter et al, 2001; Ginsberg, 2007; Colangelo et al, 2002; Lukiw, 2004). cDNA arrays are constructed with picoliter spots of double-stranded PCR products amplified from cDNA libraries or by plasmid preparation of individual cDNAs and/or expressed sequence tagged (EST) cDNAs. Double-stranded cDNAs/ESTs are printed in a tiny grid pattern on specially prepared glass slides or nylon membranes. The labeling of a control and a disease sample RNA with either of two resolvable fluorescent labeling dyes, such as cyanine 3 and cyanine 5, allows one to simultaneously measure relative gene expression levels in two samples on the same cDNA array. However, the haphazard pairing of control and disease samples and dye bias effects have generated spurious results. Though twice as costly, it is more reliable and statistically more powerful to pair each sample with a common reference derived from similar tissue, such as a pool of the control group samples (Jurata et al, 2004; Altar et al, 2005; Konig et al, 2004). The pairing of each sample with the same internal reference cDNA minimizes false positives due to local background, dye bias effects, or printing inconsistencies between arrays (Jurata et al, 2004).

cDNA arrays are washed to remove nonspecific background hybridization, and a laser scanner images biotinylated/fluorescently labeled probes, whereas a phosphor imager is used for radioactively labeled probes. The specific 
signal intensity (minus background) of RNA bound to each probe is expressed as a ratio of that signal to the total hybridization signal intensity of the array. This minimizes variations across the array platform due to differences in the specific activity of the probe and the absolute quantity of probe present (Ginsberg et al, 2006d; Ginsberg and Mirnics, 2006). An additional advantage of cDNA microarray technology includes the full representation of $3^{\prime}$ ends of genes, which is especially important for detecting the expression of low levels of RNA that require linear amplification prior to microarray analysis (Altar et al, 2005).

Oligonucleotide arrays. Oligonucleotide probes are deposited by a photolithographic printing process that lessens differences between arrays (Lockhart et al, 1996). Oligo arrays have been used by investigators in psychiatric brain research for their extensive coverage of the genome, relatively easy sample processing, and generally reliable data (Prabakaran et al, 2004; Hakak et al, 2001). Each labeled sample is hybridized to its own array for a direct comparison to be made between intensity data of individual samples. As an example, each gene on the Affymetrix GeneChip ${ }^{\circledR}$ (Santa Clara, CA) is represented by eleven 25mer oligonucleotides that are spaced throughout the length of the transcript, and nearly identical oligonucleotides containing a single mismatched base provide information about nonspecific hybridization. Disadvantages of oligonucleotide arrays include decreased sensitivity for detecting samples with a $3^{\prime}$ bias (ie, generated by linear amplification, or predominate in poor quality mRNA), requirement for a relatively large input amount of starting RNA, and their lack of an internal hybridization reference to reduce the effects of local artifacts (Jurata et al, 2004).

Advancements in microarray technology. In addition to RNA that is transcribed from DNA and translated into a protein, the transcriptome includes transcripts that are not translated into protein. These non-coding RNA transcripts include ribosomal RNA (rRNA), transfer RNA (tRNA), short hairpin RNA, short interfering RNA, small nuclear RNA transcripts, microRNAs (miRNAs) and other antisense transcripts with regulatory functions. Fortunately, newer microarray technologies encompass this greater transcriptome breadth with innovations such as the exon array, mRNA array, and ChIP array. These advanced microarray platforms use 20-60 oligonucleotide base pair probes, whereas earlier cDNA platforms generally contained 300600 base pair probes. The shorter oligonucleotides can measure a greater number, and more specific, transcript regions and splice variants of each gene. This improves the sensitivity and specificity of microarrays, and reveals between-individual variations in gene transcription. This is important, as about $40 \%$ of the human transcriptome is composed of alternatively spliced genes. As illustrated for glutathione $S$-transferase M1 (Figure 4), these variations can be measured between individuals. It is likely that a greater understanding of CNS disorders will result from SNP analysis, and other high-throughput evaluations of RNA editing, DNA methylation, transcription factor immunoprecipitation, promoter binding assays, and diversity of

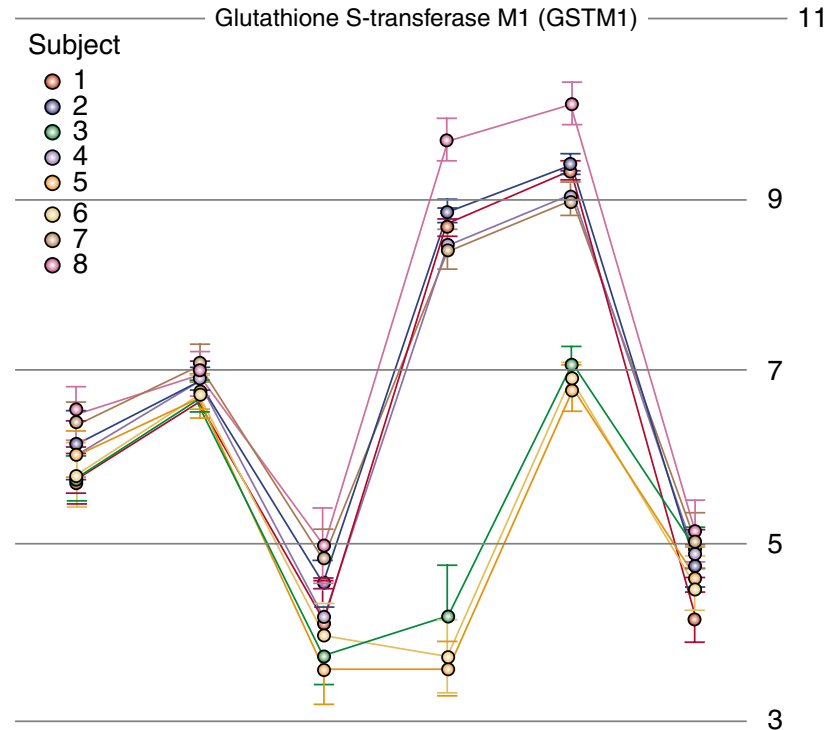

Figure 4. Splicing variations in glutathione $S$-transferase M1 (GSTM1) between eight individuals identified by exon array. The $X$ axis points represent six exons within this gene. The $Y$ axis represents the relative abundance of their expression. Note that the $3^{\prime}$ (left) and $5^{\prime}$ (right) ends of the gene show similar expression levels among people, but the fourth and fifth exons of the GSTM1 gene vary in the expression of this transcript.

transcripts and proteins. Commercial and non-commercial microarray platforms and software sources to conduct microarray gene expression studies are listed in Appendix B.

Processing array data. Microarray data can be processed by calculating the average ratio between control and disease groups, or untreated and treated samples, and analyzed by ANOVA to determine whether the changes are statistically significant. Corrections for multiple testing such as Bonferroni (multiplying a $p$-value by the number of comparisons), or the less stringent Benjamini and Hochberg false discovery rate method, can help reduce the number of false positives that are invariably obtained with microarray experiments (Kaminski and Friedman, 2002; Yang et al, 2002; Reiner et al, 2003).

One common approach is to cluster samples according to their common patterns of differences in gene expression. This can produce the familiar heat map color-coded illustrations that might shed light on clinical sub-populations of disease. More commonly, however, sample clustering reflects confounding variables such as patient drug history or poor RNA preparations. Such confounds can produce equally impressive 'clustering' within just the control group, or within two groups created at random from the pool of all control and patient samples. The absence of such clustering within the control group or mixed groups would increase confidence in the clustering of genes in the control vs experimental group comparison. Gene clustering can define functional relationships among the altered genes when they vary in a similar manner across most or all of the samples of a treatment or disease group $v s$ the controls (Kaminski and Friedman, 2002). 
Pathway analysis tests a list of candidate genes by the Fisher's exact test or hypergeometric distribution for overrepresentation of genes in that pathway relative to the entire set of genes on a microarray platform. The results of such pathway tests are corrected for multiple comparisons to establish the false discovery threshold. Another useful method to identify biological pathways that are implicated by virtue of changes in a large number of their gene members is the Expression Analysis Systematic Explorer (EASE; http://david.abcc.ncifcrf.gov/ease/ease.jsp) (Hosack et al, 2003). EASE can determine whether there is a statistical over-representation of genes involved in a particular biochemical pathway or cellular class defined by Gene Ontology (http://www.geneontology.org/), when compared to the representation of that pathway or class on the array (Altar et al, 2005, 2008). EASE can also be applied to proteins from a proteomic platform, or other highcontent methods. Pathway analyses by EASE, Ingenuity, ermineJ, GeneGO, and other methods are indispensable tools to identify changes in functional pathways from groups of genes with nominal significance and fold changes.

RNA verification. Regardless of how statistically impressive microarray data may appear, it is essential to verify at least a subset of gene expression changes by an independent method. cDNA microarrays can contain large percentages of improperly annotated probes (Kuo et al, 2002; Kothapalli et al, 2002), which can create false-positive gene hits. The nonspecific hybridization or cross-hybridization of closely related genes to oligo or cDNA probes can also yield false positives.

Real-time qPCR. Amplification of genetic signals can be performed at both DNA and RNA levels, and final amplified products are either DNA or RNA. A common method to measure DNA or RNA is the (PCR (Mullis, 1990) and is invaluable in confirming gene changes in postmortem human brain RNA (Johnston et al, 1997). Starting material for PCR reactions can originate from genomic DNA or cDNA reverse transcribed from RNA (eg, RT-PCR). PCR is an effective method to amplify a DNA template. However, PCR is an exponential, nonlinear amplification, and variation can occur within individual mRNA species of different molecular mass or base pair composition. PCRbased methods tend to amplify abundant genes over rare genes and may distort quantitative relationships among gene populations (Phillips and Eberwine, 1996). Real-time qPCR can quantitate PCR product formation during each cycle of amplification and generates fewer concerns than those associated with conventional PCR methods. Other advantages of real-time qPCR include higher throughput, the ability to simultaneously multiplex reactions, greater sensitivity, reduced inter-assay variation, and lack of postPCR manipulations (Bustin, 2002). Fluorescence is generated by labeled nucleotides that are incorporated into the gene-specific PCR product, or a labeled internal probe emits fluorescence on its displacement by the generation of the PCR product. The enhancement of fluorescent signal is monitored at multiple times in each cycle of PCR, thus the name 'real time' is used to distinguish the process from assays that are based on end point analysis.

Real-time qPCR can generate false negatives, primerdimer pairings, variability in cDNA synthesis, and crossreactivity with genomic DNA. These issues can be surmounted by targeting primers near the gene region of interest, incorporating melting curve dissociation analysis for primer-dimer detection, use of DNAse treatments to rid the sample of contamination, resequencing amplicons and, when possible, design of primers spanning two exons.

The comparison of data from different $\mathrm{qPCR}$ studies requires normalization of $\mathrm{qPCR}$ data sets to control for signal fluctuations due to the stepwise qPCR process and sample variability. A normalizing approach can include the use of housekeeping gene(s), total RNA input, or the number of cells used. Selecting an appropriate reference standard for normalization is crucial, as variation in the standard can produce equally significant errors in mRNA quantification as in between-study variations. One common approach is to generate standard curves and cycle threshold $\left(C_{\mathrm{t}}\right)$ values using standards obtained from total brain RNA. The $\Delta \Delta C_{\mathrm{t}}$ is often employed to determine relative gene-level differences normalized by the $\mathrm{qPCR}$ products of housekeeping genes such as glyceraldehyde-3-phosphate dehydrogenase (GAPDH), $\beta$-actin, and cyclophillin as a control (Ginsberg and Mirnics, 2006; ABI, 2004). Alternatively, NormFInder and geNorm are algorithms that identify genes for normalization by ranking genes in the experiment according to their stability of expression (Ohl et al, 2005; Andersen et al, 2004).

\section{High-Throughput mRNA Screening}

The identification of reciprocal gene expression changes in disease and drug signatures has allowed the validation of

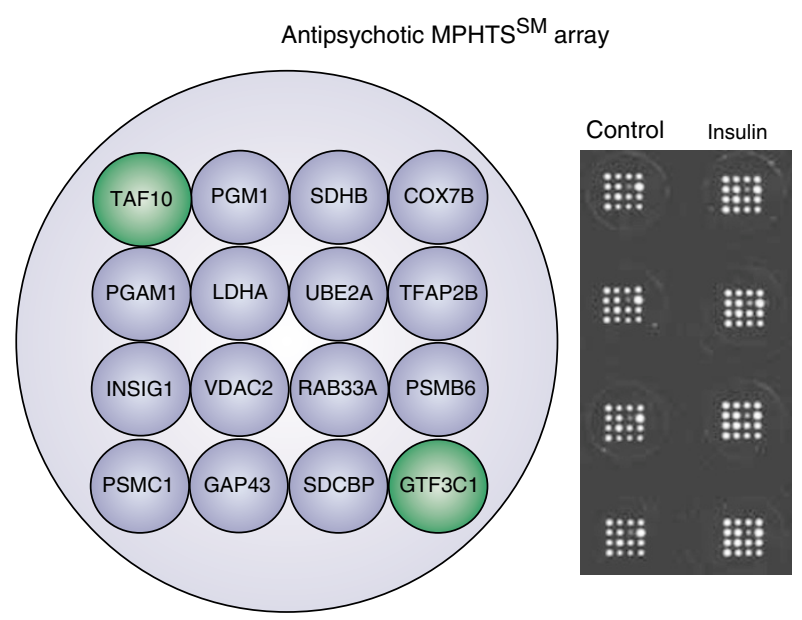

Figure 5. Gene miniarray for antipsychotic drug discovery. Human neuroblastoma cells were cultured for $24 \mathrm{~h}$ in wells of a 96-well plate, in the presence of vehicle or $20 \mathrm{nM}$ human insulin. RNA from the lysed cells was added to the MPHTS ${ }^{\text {SM }}$ plate, which contains the illustrated $4 \times 4$ array of spotted cDNA for the genes. Typical increases by insulin vs the vehicle (control) were observed in quadruplicate by changes in fluorescence for each gene relative to two control genes, TAF10 and GTF3C1. 
gene responses to other drugs using high-throughput methods. One of these, termed a multi-parameter highthroughput screen ${ }^{\mathrm{SM}}$ (MPHTS ${ }^{\mathrm{SM}}$ ), incorporates a miniarray of 16 relatively large hybridization spots (Figure 5) deposited on the bottom of each well in a 96-well format (High Throughput Genomics, Tucson, AZ) (Martel et al, 2002). This platform measures transcript abundance through an RNase protection step, coupled to the hybridization of the protected fragment that is between a specific homing oligo printed in the bottom of each well, and a universal oligo reporter linked to horseradish peroxidase. Detection is accomplished through a chemiluminescent reaction and photon capturing by a CCD camera (www.htgenomics.com). Advantages of MPHTS ${ }^{\text {SM }}$ are that it does not rely on RNA amplification, decreasing cost and signal variability. When genes of moderate to high abundance are used, MPHTS ${ }^{\text {SM }}$ generates intra- and interplate coefficients of variation of around 5 and $10 \%$, respectively. These low levels of variation allow the accurate measurement of $20 \%$ or greater changes in gene expression.

\section{THERAPEUTIC TARGET AND DRUG DISCOVERY}

\section{Neurodegenerative Disease}

Alzheimer's disease. Age is the greatest risk factor for developing mild cognitive impairment (MCI) and AD. The likelihood of developing AD doubles every 5 years after the age of 65 years, so that by the age of 85 years, the risk approaches $50 \%$. Thus, it is highly significant that the number of USA citizens who are 65 years of age or older will double, from the 35 million alive today, by the year 2030 (Plassman et al, 2007). About 4.5 million Americans have $\mathrm{AD}$ today, and this number may reach $11-16$ million by 2050 (Plassman et al, 2007; Wimo et al, 2007). The aging of this population demands greater public health efforts to combat cognitive decline and lessen future costs of caring for people with dementing illness. Although such costs far eclipse those of monetary concern, financial costs alone are estimated to exceed US\$315 billion worldwide in 2005 (Wimo et al, 2007). It is imperative that we learn more about the causes of $\mathrm{AD}$ to develop rational therapies that can delay its onset or progression.

Dementia impairs the ability to learn, reason, make judgments, communicate, and carry out daily activities. The progressive decreases in cognitive and memory functions typically lead to the diagnosis of $\mathrm{AD}$ and, from that point, death within 7-10 years. AD accounts for approximately 50$60 \%$ of dementia cases worldwide. It is a multifactorial disorder, and is likely to originate from complex genetic and environmental risk factors. $\mathrm{AD}$ follows at least a bimodal distribution, whereby rare $(<3 \%)$ autosomal dominant mutations cause early-onset familial forms of $\mathrm{AD}$, whereas the common sporadic form of later-onset $\mathrm{AD}$ is determined by genetic polymorphisms with fairly low penetrance but much higher prevalence (Bertram et al, 2007; Swerdlow, 2007).
The neuropathology of AD is characterized by filamentous material in intracellular and extracellular compartments in the form of neurofibrillary tangles (NFTs). These contain hyperphosphorylated $\tau$. Senile plaques (SPs) consist primarily of amyloid- $\beta(\mathrm{A} \beta)$ peptides, and both markers of $\mathrm{AD}$ are characteristically found in the hippocampal formation and temporal neocortex (Mufson et al, 2003; Ginsberg et al, 1999b; Selkoe, 1997; Trojanowski and Lee, 2005; Hyman and Trojanowski, 1997; Mirra et al, 1991). Among the various neurotransmitter systems that deteriorate as $\mathrm{AD}$ progresses, the most consistent deficits and cell losses are in long projection neurons including those of the cholinergic nucleus basalis (Mufson et al, 2007a,b; Whitehouse et al, 1982) and glutamatergic neurons within the entorhinal cortex and neocortex (Ginsberg et al, 1999b; Hyman et al, 1984). Diagnosis of $\mathrm{AD}$ is confirmed by the postmortem presence of amyloid plaques and NFTs in the brain of a patient who displayed progressive cognitive decline (Hyman and Trojanowski, 1997; Mirra et al, 1991).

A goal of translational profiling has been to identify genes, their regulatory elements, and pathways that contribute to NFT and SP deposition, and the change in the expression of which correlates with cognitive decline in AD. Microarray analysis has been an effective tool to assess transcript levels in animal models and postmortem brain of AD (Table 1) (Ginsberg et al, 2006a, b; Colangelo et al, 2002; Lukiw, 2004; Loring et al, 2001; Blalock et al, 2004; Dickey et al, 2003; Mirnics et al, 2003; Reddy et al, 2004; Miller et al, 2008). The majority of microarray studies of neurodegenerative disease have used gross brain dissections as the basis for expression profiling. Given the limitations discussed earlier about this approach, the microaspiration of neurons, NFTs, and SPs within the hippocampal formation and nucleus basalis of human postmortem tissues and animal models have proven to be an effective paradigm shift. These studies have yielded provocative data sets relevant to the pathophysiology of $\mathrm{AD}$ (Ginsberg et al, 2000, 2004, 2006b).

Genes changed within neurofibrillary tangles: Histopathological and biochemical studies show that hippocampal CA1 pyramidal neurons of the $\mathrm{AD}$ brain bear intracellular NFTs, which have been modeled in mice that overexpress the human $\tau$ protein (Ginsberg et al, 1999b; Trojanowski and Lee, 2005; Gotz, 2001; Andorfer et al, 2005). Microaspiration coupled with microarray analysis was used to uncover mechanisms that might underlie the formation of NFTs (Ginsberg et al, 2000, 2004, 2006b). Relative to non-tanglebearing CA1 neurons obtained from normal control brains, neurons harboring NFTs in AD brains displayed reductions in mRNAs for cytoskeletal elements, dopamine (DA) receptors, glutamate receptors (GluRs), protein phosphatase subunits $1 \alpha$ and $1 \gamma$, kinases, and synaptic-related markers (Ginsberg et al, 2000, 2004; Ginsberg, 2007). In addition, microarray analysis has demonstrated that protein phosphatase $3 \mathrm{CB}$, also known as calcineurin $\mathrm{A} \beta$, is upregulated in NFT-bearing neurons within the $\mathrm{AD}$ hippocampus (Hata et al, 2001). 
a Age (years)
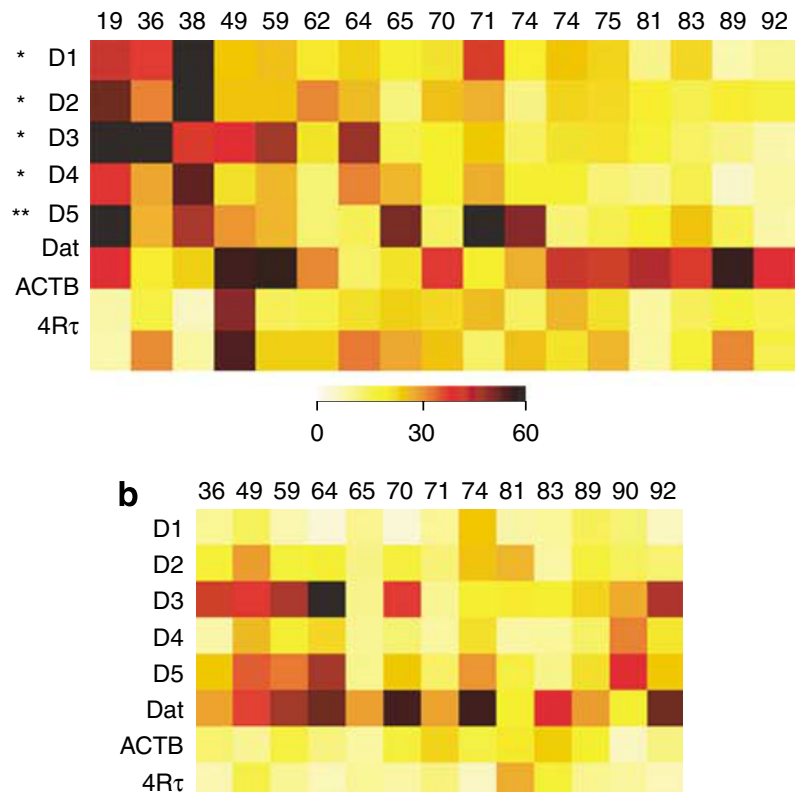

Figure 6. Expression profiling in neurofibrillary tangles (NFTs) bearing CA1 pyramidal neurons in postmortem $A D$ brain. (a) Dopamine (DA) receptors D1-D5 are significantly decreased ( ${ }^{*} p<0.001$; $\left.{ }^{*} p<0.05\right)$ in AD NFT-bearing CA1 neurons as evidenced by representative custom cDNA arrays. (b) Downregulation of several synaptic-related markers ${ }^{*} p<0.01$; including synaptotagmin, SYP, synapsin I, $\alpha$-synculein, and $\beta$-synuclein) is presented in a representative custom cDNA arrays and a histogram. In contrast, the relative expression of $4 \mathrm{R} \tau$ did not vary across the cohort, although the ratio between $3 R / 4 R \tau$ is altered in AD. Adapted from Galvin and Ginsberg (2005) and Ginsberg et al (2000) with permission.

The expression of D1-D5 subtypes of DA receptors, particularly D2, and the DA transporter (DAT) are decreased by 2 - to 4 fold in NFT-bearing neurons in $\mathrm{AD} v s$ non-tangle-bearing neurons in control brains, mRNA (Figure 6) (Ginsberg et al, 2000, 2004). These findings are consistent with the ability of D2 receptor agonists to reverse motor impairments associated with normal aging in rodents (Altar and Marshall, 1988), and decreased D2 radioligand binding in AD hippocampus (Joyce et al, 1993; Ryoo and Joyce, 1994). A variety of behavioral impairments associated with dopaminergic dysfunction are seen in $\mathrm{AD}$ patients, including impaired motor function, anxiety, cognitive decline, hallucinations, and psychosis. The treatment of $\mathrm{AD}$ patients with $\mathrm{DA}$ antagonists such as risperidone has become more common, though controversial, in care facilities for AD patients (Katz et al, 2007). The decreases in DA receptor expression and ligand binding in these patients may be counterintuitive to the use of D2 antagonists, and warrants a closer scrutiny for the basis of their use, or the alternative use of D2 agonists, such as the mixed D2/D3 agonist piribedil, which enhances cognitive skill learning in healthy older adults (Peretti et al, 2004).

Glutamatergic dysfunction in $\mathrm{AD}$ has been assessed at the gene and protein level for two decades. One of the few FDAapproved medications for cognitive decline in $\mathrm{AD}$ is memantine, a non-competitive antagonist of $N$-methyl-D- aspartate (NMDA) receptors (Lipton, 2007). Independent microarray evaluations indicate that hippocampal $\alpha$-amino3-hydroxy-5-methyl-4-isoxazole propionate (GRIA1 and GRIA2, corresponding to AMPA1 and AMPA2, respectively) and NMDA receptor (eg, GRIN1) subunits, and select glutamate transporters (eg, SLC1A1, or EAAT2, a neuronal specific glutamate transporter) are downregulated during the progression of $\mathrm{AD}$, consistent with earlier pharmacological binding, immunoblot, and immunocytochemical evaluations (Ginsberg, 2007; Ginsberg et al, 2000, 2006b; Westphalen et al, 2003; Jacob et al, 2007; Yasuda et al, 1995; Ikonomovic et al, 1995; Carter et al, 2004). The vulnerability of cortical and hippocampal glutamatergic synaptic machinery, including these ionotropic GluRs and glutamate transporters, is consistent with the roles that excitotoxic mechanisms have been proposed to play in the pathogenesis of AD (Ginsberg et al, 1999b; Trojanowski and Lee, 2005; Hyman et al, 1984; Carter et al, 2004), and merit further consideration as drugable targets (Rothstein, 2003).

Genes related to synaptic function, particularly those for presynaptic vesicles and postsynaptic docking machinery, are another class of genes shown by microarray analysis to be relevant to $\mathrm{AD}$ pathogenesis (Ginsberg, 2007; Loring et al, 2001; Miller et al, 2008; Ginsberg et al, 2000; Yao et al, 2003; Blalock et al, 2003). Indeed, the losses of synapses and the nerve terminal-specific protein, synaptophysin (SYP), correlate better with cognitive decline than do increases in amyloid load or $\tau$ pathology (Heffernan et al, 1998; Shimohama et al, 1997; Sze et al, 1997, 2000). Decreased synapse-related markers are consistently observed in NFTbearing CA1 neurons. These include SYP, synaptotagmin I, synapsin I (SYN I), $\alpha$-synuclein, and $\beta$-synuclein (Ginsberg et al, 2000, 2004, 2006b) (Figure 7). Decreases in SYN I, II, and III were also found in the entorhinal cortex of $\mathrm{AD}$ patients (Ho et al, 2001). SYP decreases in AD hippocampus have been confirmed by qPCR and in situ hybridization (Gutala and Reddy, 2004; Callahan et al, 1999). These and other genes that encode for synapse-specific proteins may help evaluate the efficacy of therapeutic compounds in animal models, postmortem human tissues or in patients, based on the use of imaging biomarkers.

Genes changed within cholinergic basal forebrain neurons: Degeneration of the cholinergic basal forebrain (CBF) system is an early event in $\mathrm{AD}$ pathogenesis, and probably contributes to the cognitive abnormalities seen in MCI and AD (Mufson et al, 2003; Whitehouse et al, 1982; Bartus, 2000). One likely suspect for CBF neurodegeneration is nerve growth factor (NGF), a neurotrophin (NT), the administration of which, similar to that of brain-derived neurotrophic factor (BDNF), or NT-3, promotes their survival in a variety of animal lesion models. NGF is synthesized and secreted by cortical and hippocampal cells, and binds to the high-affinity NGF receptor, trkA, and lowaffinity NGF receptor, $\mathrm{p} 75^{\mathrm{NTR}}$ that are highly enriched in somatic and synaptic sites within CBF neurons (Mufson et al, 2003, 2007a; Sofroniew et al, 2001). 

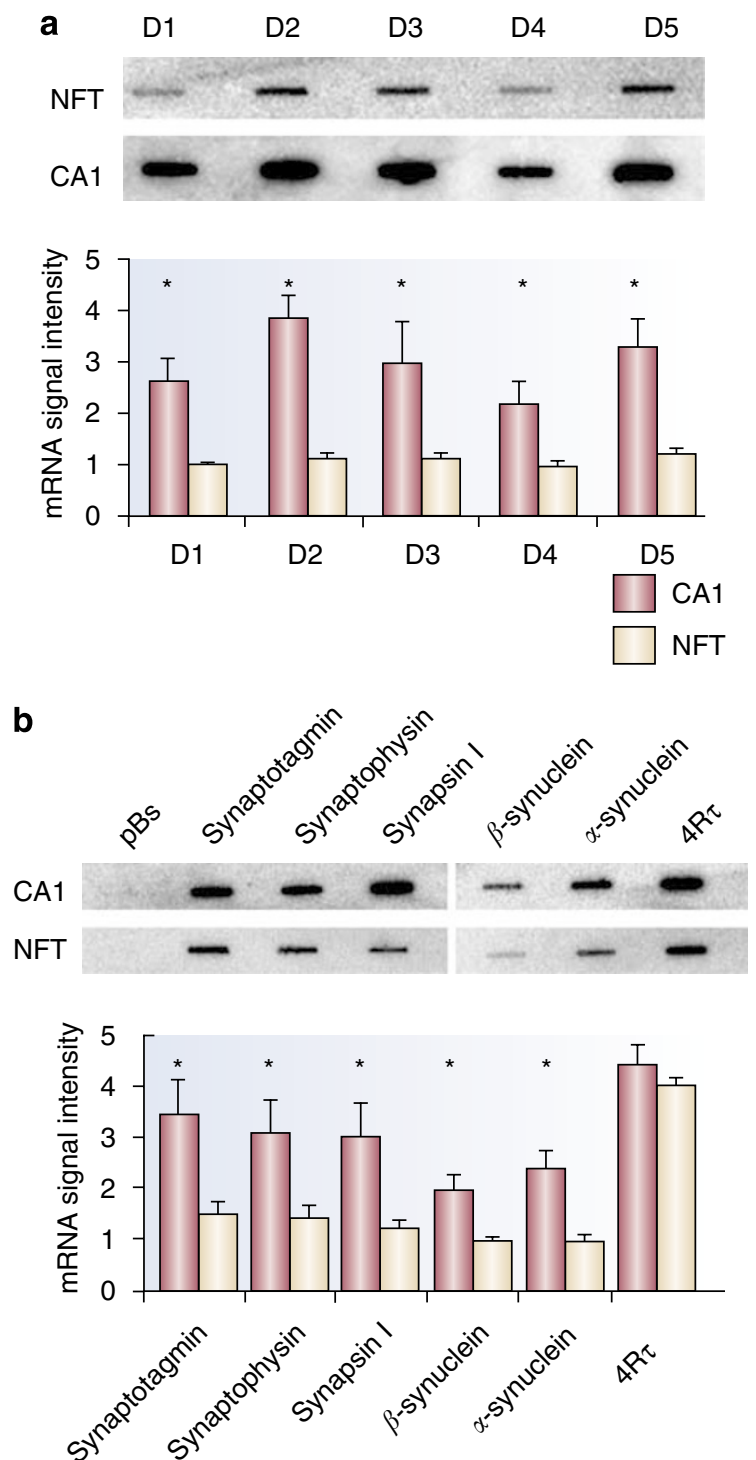

Figure 7. D1-D5 receptor expression levels in normal aging. The colorcoded heatmap illustrates differential regulation of each receptor within individual CA1 pyramidal neurons and entorhinal stellate cells across a normal aged cohort. (a) Relative expression levels of the DA receptors, dopamine transporter (DAT), $\beta$-actin (ACTB), and 4-repeat $\tau(4 \mathrm{R} \tau)$ within individual CA1 pyramidal neurons microaspirated from postmortem human brains (aged of 19-92 years) (Hemby et al, 2003). Significant downregulations of DRD1-DRD5 were found $\left({ }^{*} p<0.001\right.$. No differential regulation of DAT, ACTB, and $4 \mathrm{R} \tau$ was observed, indicating a relative specificity of age-related transcript decline. (b) In contrast to the observations in CA1 pyramidal neurons, no differential regulation of DA receptors was observed within individual entorhinal cortex stellate cells. Adapted from Galvin and Ginsberg (2005) with permission.

Individual cholinergic neurons collected from the nucleus basalis of $\mathrm{AD}$ patients were evaluated with custom-designed cDNA arrays (Figure 2) and changes were verified with realtime $\mathrm{qPCR}$ and in situ hybridization. CBF neurons displayed decreases in the expression of the receptors for NGF, BDNF, and NT-3, namely, TrkA, TrkB, and TrkC, respectively (Ginsberg et al, 2006b, c; Counts et al, 2007). Moreover, an EST targeted to the extracellular and tyrosine kinase domains were decreased for each Trk gene (Ginsberg et al, 2006c). These results have been validated by $\mathrm{qPCR}$ in the basal forebrain of $\mathrm{AD}$ patients and are consistent with in situ hybridization studies of Trk receptors (Ginsberg et al, 2006c; Boissiere et al, 1997). Moreover, increases in the expression of the $\alpha-7$ nicotinic acetylcholine receptor (CHRNA7) were seen during the progression of $\mathrm{AD}$ in these studies. Interestingly, an intermediate reduction in the NT receptors was observed in MCI. In contrast, mRNAs for p $75^{\text {NTR }}$ choline acetyltransferase (ChAT), the other nicotinic and muscarinic acetylcholine receptor subunits, or GAPDH, were not changed across clinical conditions (Ginsberg et al, 2006b, c; Counts et al, 2007). These decreases in TrkA, TrkB, and TrkC mRNA during prodromal stages of $\mathrm{AD}$ are associated with cognitive decline, as measured by a Global Cognitive Score and the Mini-Mental State Examination (Ginsberg et al, 2006c; Mufson et al, 2007b). These results suggest that the decreases in high-affinity NT receptor expression in CBF neurons occur during the early stages of cognitive decline and are associated with the clinical presentation of the disease. Thus, Trk defects may be molecular markers for the transition from normal cognitive function to $\mathrm{MCI}$, and from $\mathrm{MCI}$ to $\mathrm{AD}$. Interestingly, recent SNP analysis of the CHRNA7 haplotype in a large population of aged subjects concluded that genetic variation in CHRNA7 influences susceptibility to AD (Carson et al, 2008). These results also provide support for the development of agonists and/or modulators of CHRNA7 as a potential pharmacotherapeutic treatment for $\mathrm{AD}$.

On the basis of animal model and clinical studies, the delivery of NGF (Mufson et al, 2007a; Bartus, 2000; Tuszynski, 2007) or BDNF (Morse et al, 1993) has been proposed as treatments to prevent or delay the onset of $\mathrm{AD}$. There are significant limitations for NGF or BDNF delivery to the CNS, including their failure to cross the blood-brain barrier and, during intracranial delivery, poor bioavailability, poor bioavailability, their in vivo instability, and proliferative effects (Bartus, 2000; Kaplan and Miller, 2000). CNS transplantation with cells that secrete NTs is technically challenging and faces the same limitations as infused NTs. Because of these limitations, small molecule partial agonist activators of Trk receptors have been designed and tested for the treatment of AD (Skaper, 2008; Mocanu et al, 2008). A high-throughput screening assay of small-molecule agonists for the TrkA receptor has identified gambogic amide, an alkaloid used in traditional Chinese medicine (Jang et al, 2007). It selectively binds TrkA (but not TrkB and $\operatorname{TrkC}$ ), phosphorylates TrkA tyrosine residues, and activates the Akt and MAPK TrkA-mediated NGF signaling pathways. Gambogic amide attenuates excitotoxic damage to cells and promotes neurite outgrowth in PC12 cells (Jang et al, 2007), making this a lead for chemical modification and potential for $\mathrm{AD}$ clinical trials.

No mutations have been described in the low molecular weight microtubule-associated protein $\tau$, the principal component of NFTs in AD (Ginsberg et al, 1999b; Hyman and Trojanowski, 1997; Mirra et al, 1991). However, mutations in the $\tau$ gene cause frontotemporal dementia (Goedert and Jakes, 
2005), suggesting that post-transcriptional alterations in $\tau$ expression may contribute to tauopathies, including $\mathrm{AD}$ and related dementing disorders. Gene expression profiling within single nucleus basalis and CA1 hippocampal neurons revealed an increase in the expression of the three-repeat $\tau(3 \mathrm{R} \tau)$ to four-repeat $\tau(4 \mathrm{R} \tau)$ mRNAs during the progression of $\mathrm{AD}$, but not during normal aging (Ginsberg et al, 2006a). An increase in the proportion of $3 \mathrm{R} \tau / 4 \mathrm{R} \tau$ mRNA was found in $\mathrm{MCI}$ and $\mathrm{AD}$ relative to those with normal cognition (Ginsberg et al, 2006c), suggesting that this dysregulation impacts neuronal function and marks a transition from normal cognition to prodromal $\mathrm{AD}$. An increase in the $3 \mathrm{R} \tau / 4 \mathrm{R} \tau$ expression ratio may increase neuronal vulnerability, a model worth further evaluation as agents that regulate this pattern of $\tau$ expression might be beneficial.

Genes changed within Senile plaques: The biochemical composition of SPs is well known, but little data exist on the non-proteinaceous components of these lesions. The presence of mRNA, rRNA, and tRNA was evaluated in SPs using AO histofluorescence, alone or in combination with thioflavine-S staining and immunocytochemistry in $\mathrm{AD}$ brains and related neurodegenerative disorders with abundant SPs (Ginsberg et al, 1997, 1998). Quantitative analyses demonstrated that about $55 \%$ of thioflavine-Sstained SPs also contain AO histofluorescence (Ginsberg et al, 1997, 1998), indicating that RNA species are localized to a significant population of SPs. The sequestration of RNAs prompted single-cell gene expression analysis of SPs in $\mathrm{AD}$ hippocampus. Expression profiles of SPs were compared with individual CA1 neurons and surrounding neuropil of control brains (Ginsberg et al, 1999a). Results indicate that the expression profiles amplified from SPs are predominantly neuronal. SPs harbor two distinct populations of expressed genes. One cluster of transcripts contains high abundance genes including amyloid- $\beta$ precursor protein (APP), bax, Bcl-2, AMPA GluR subunits and $\tau$ (Ginsberg et al, 1999a, 2004). A second grouping of transcripts contains low abundance genes including glialenriched mRNAs such as glial fibrillary acidic protein (GFAP), interleukin-1 (IL-1), and the receptor for advanced glycation end products (AGER) (Ginsberg et al, 1999a, 2004). Combined single-cell expression profiling, in situ hybridization, and PCR data sets indicate that multiple mRNA species are found in individual, extracellular SPs. SPs appear to sequester the remnants of degenerating neurons and their processes, including mRNA, and these properties can be studied in animal models of cerebral amyloid overexpression (Dickey et al, 2003; Reddy et al, 2004).

Parkinson's disease. PD is the second most frequently occurring age-related chronic neurodegenerative disease, with both common sporadic and rare familial forms. Clinical symptoms include resting tremor, bradykinesia, hypokinesia, and postural disturbances. Key pathological features are the loss of dopaminergic neurons within the substantia nigra pars compacta (SNPC), loss of striatal DA, and other neurotransmitters including serotonin and norepinephrine, and the presence of inclusions known as Lewy bodies that consist of $\alpha$-synuclein (Fearnley and Lees, 1991).

Genes changed in PD: Expression profiling studies have revealed downregulation of genes critical to mitochondrial function and energy synthesis and maintenance, supporting several lines of evidence from animal models that experimental perturbations such as complex I inhibitors of the respiratory chain and mitochondrial poisons result in a $\mathrm{PD}-$ like pathology in the SNPC (Table 1) (Mandel et al, 2003; Grunblatt et al, 2001; Greene et al, 2005; Napolitano et al, 2002; Patel et al, 2008). Mechanisms underlying these reductions may involve mitochondrial function itself, which increases reactive oxidative species and promote oxidative stress and mitochondrial failure, leading to synaptic loss and neurodegeneration, which have also been reflected in transcript alterations in microarray analysis of PD (Miller et al, 2006; Vogt et al, 2006).

Microarray analysis of RNA harvested from the SNPC of PD cases identified decreased transcripts for the ubiquitinproteosome system (eg, SKP1, UCHL1) and ion transport (eg, EGLN1), among others (Grunblatt et al, 2004). Another microarray analysis of postmortem SNPC tissue from PD patients identified increases in other ubiquitin-proteosome system components when compared with age-matched controls, including the $70 \mathrm{kDa}$ heat-shock protein (HSPAlA) (Hauser et al, 2005). A twofold decrease in the expression of the PARK5 familial PD-linked ubiquitin carboxyl-terminal hydrolase L1 (UCHL1) gene is observed within the SNPC of PD patients (Liu et al, 2002), and a proteomic assessment in postmortem PD brains found downregulation of UCHL1 protein (Choi et al, 2004). Moreover, UCHL1 itself is a target for protein oxidation (Choi et al, 2004), suggesting a link among mitochondrial dysfunction, oxidative stress, and reduced proteasomal activity, all of which have been implicated in several recent microarray studies in rodent and non-human primate models of PD (Greene et al, 2005; Iwata et al, 2007; Duke et al, 2006; Chin et al, 2008; Miller et al, 2004). These observations suggest that a common final pathway for buffering cellular toxicity of misfolded proteins may be dysfunctional in PD. Interestingly, transcripts and their expressed proteins involved in ubiquitin-proteasome and mitochondrial functions are also downregulated in two models of PD, 1-methyl-4-phenyl-1,2,3,6-tetrahydropyridine (MPTP) and methamphetamine delivery (Chin et al, 2008), further validating the human microarray studies and lending additional genomic and proteomic credence to the use of these versatile models for the assessment of molecular and cellular pathogenesis in PD.

Genes changed by anti-Parkinsonian therapies: It is interesting that over half of all $\mathrm{PD}$ patients receiving electroconvulsive therapy (ECT) for psychiatric depression also show improvement in Parkinsonian symptoms (Faber 
and Trimble, 1991). The mechanism of this anti-Parkinsonian effect of ECT is unknown; however, microarray profiling in a rodent model of ECT, electroconvulsive shock (ECS), reveals ECS increases in genes that could ameliorate DA deficiencies (Altar et al, 2004; Newton et al, 2003). Nurr1, which is elevated after acute and chronic ECS (Altar et al, 2005), is an orphan nuclear receptor required for the differentiation of mid-brain dopaminergic neurons. Hemizygous Nurr1 deletions decrease limbic and cortical DA levels (Eells et al, 2002). Nurr1 expression is decreased in nigral neurons that contain Lewy bodies in PD brains (Chu et al, 2006). ECS also increases BDNF, TrkB, early growth response 1 (EGR1), glutathione $S$-transferase, $S$ adenosylmethionine decarboxylase, arc, fibroblast growth factor (FGF) receptor-1, heme oxygenase-3, and S100 calcium-binding protein, in addition to Nurr-1 (Altar et al, 2004, 2005). The protein products of each of these genes could enhance DA functions or neuronal protection in PD.

Few studies have employed microarrays to profile mRNA changes to L-dopa, DA agonists, or other drugs or surgical approaches used to treat PD. Such studies would be of interest as they may identify gene overlaps with those that change in response to ECS or those that are reciprocally changed in PD. One such gene is Nurr-1, which increases in SH-SY5Y neuroblastoma cells exposed to the D2/3 receptor agonist, pramipexole, as do DAT and VMAT2 (Pan et al, 2005). Interestingly, the Nurr-1 increase is mediated by the D3 receptor, which can be blocked by nafadotride, a D3 receptor antagonist (Pan et al, 2005). Another overlapping gene is EGR1, the gene and protein products of which are increased in rat frontal cortex by 4 -week treatment with Abilify, a partial D2 agonist (Cheng et al, 2008).

Rats with extensive dopaminergic lesions induced by neurotoxins including 6-hydroxydopamine (6-OHDA) or MPTP have been evaluated for specific striatal gene expression changes following L-dopa. In most cases, L-dopa challenge was associated with the production of dyskinesias or self-injurious behaviors and those studies will not be summarized here. More moderate, and subchronic, doses of L-dopa that more closely model anti-Parkinsonian treatment regimens induce a variety of mRNA changes in the lesioned hemisphere. These include increases in the receptor activity-modifying protein, RAMP1 in striatum (Lee et al, 2008), the vesicular GABA transporter (vGAT) in the striatonigral pathway (Wang et al, 2007a), striatal glutamic acid decarboxylase 67 (GAD67), but not GAD65, dynorphin, enkephalin (Tronci et al, 2007), secretogranin II, preproenkephalin A, secretoneurin (Medhurst et al, 2001), c-jun and c-fos (Svenningsson et al, 2002), and a reversal of the decrease in striatal Src, Lyn and PKC expression induced by 6-OHDA (Napolitano et al, 2006). Cannabinoid receptor 1 was another gene among the 10 genes increased in rats by the D2 partial agonist Abilify (Cheng et al, 2008), and is increased in the 6-OHDA striatum by L-dopa (Zeng et al, 1995). The pattern of mRNA changes after other D2 agonists, such as apomorphine, pergolide, bromocriptine, and SKF 38393 are far less studied and complex (Granata et al, 1996). They appear to preferentially affect the DAdenervated striatum, possibly due to D2/D3 receptor supersensitivity. More analysis is needed to relate changes in striatal and nigral gene expression to this class of drugs that account for differences in their degree of agonism, tolerance, and pharmacokinetic properties.

A candidate approach for treating $\mathrm{PD}$, adenosine $\mathrm{A}(2 \mathrm{~A})$ receptor antagonism, potentiates L-dopa-induced c-fos expression and contraversive rotations (Fenu et al, 1997). $\mathrm{A}(2 \mathrm{~A})$ antagonism also reverses the increased expression of PPE in 6-OHDA-denervated rat striatum, thus demonstrating that this approach normalizes the activity of striatopallidal enkephalin-containing neurons (Aoyama et al, 2002). The upregulation of c-fos by ECS and by L-dopa and $\mathrm{A}(2 \mathrm{~A})$ antagonism in $\mathrm{PD}$ lesion models is consistent with a PKC- or PKA-mediated activation of gene expression in the treatment of PD (Figure 13).

\section{Normal Aging}

The longevity of a given species is a product of several parameters, including frailty (ie, intrinsic vulnerability to death) and senescence (ie, the rate of change in frailty over time) (Gems and McElwee, 2003; de Magalhaes, 2004). About half of the variation in human lifespan is attributable to genetic variation (Pletcher and Stumpf, 2002), but individual genes directly responsible for these aging events have been difficult to identify. Telomere shortening with age reduces the proliferative capacity of somatic cells and has been linked to premature aging (Zucchero and Ahmed, 2006). Other genes appear to underlie aging in invertebrate and mammalian systems, where mutations in genes including daf-2, daf-16, and IGF-1 have been shown to extend lifespan (Vijg and Suh, 2005; Kirkwood, 2005; Golden and Melov, 2004; Kenyon et al, 1993; Chen et al, 2007). The majority of these genes encode protein regulators or modifiers of energy utilization. In contrast, mutations in genes that encode proteins responsible for DNA repair or cell cycle control accelerate the aging process (Vijg and Suh, 2005). Association studies have used population-based genomic approaches to compare the prevalence of genetic markers between long-lived and randomly chosen individuals (Hauser and Pericak-Vance, 2000). Potential markers are then identified by linkage disequilibrium, the nonrandom inheritance of alleles located in proximity to each other in the genome. The prevalence of a marker in long-lived individuals is evidence that the marker may either be a causal genetic variant or linked nearby to a causal variant. Fortunately, highthroughput technologies have enabled the creation of public databases that annotate relevant genes and expression profile data in aging paradigms. For example, the Human Ageing Genomic Resources (HAGR) provides online resources for the biology of aging (http://genomics. senescence.info) (Raghothama et al, 2005; de Magalhaes et al, 2005). Several databases are available for public queries 
on nematode aging including WormBase (http://wormbase. org) (Hunt-Newbury et al, 2007; Rogers et al, 2008).

Oxidative stress. Age-related accumulation of reactive species of oxygen and nitrogen, which increase lipid peroxidation, and heightened oxidative damage, have been well documented (Sohal and Weindruch, 1996; Barja, 2004; Serrano and Klann, 2004). The aging brain is associated with heightened apoptosis and immune activity that lead to the accumulation of misfolded proteins, which confer their own set of negative sequelae to affected cells. Microarray studies have identified altered regulation of markers of oxidative damage during the aging process in humans and animal models (Blalock et al, 2003, 2004; Reddy et al, 2004; Prolla, 2002; Lee et al, 2000; Brooks et al, 2007). An Affymetrix array analysis of frontal cortex of 30 normal male subjects aged from 26 to 106 years indicated that mRNA expression profiles were most consistent for subjects $<40$ years old, with another relatively homogeneous expression profile occurring in subjects $>70$ years old (Lu et al, 2004). The greatest variability in expression levels was found in the 40- to 70 -year-old subjects, suggesting that the rate of change in expression levels advances throughout middle age. The middle age and aged groups showed an upregulation of cortical genes and pathways related to oxidative damage and inflammation, and downregulation of genes associated with DNA repair and synaptic function, particularly for vesicular transport and neurotransmission (Miller et al, 2008; Blalock et al, 2003; Brooks et al, 2007; Lu et al, 2004). Promoter analysis assays and evaluation of RNA structure demonstrated oxidative damage to DNA and RNA during senescence ( $\mathrm{Lu}$ et al, 2004; Abe et al, 2002; Shan et al, 2003), and abnormal processing of proteins has been observed from oxidized mRNAs expressed in vitro (Shan et al, 2003). Importantly, microarray analyses in AD, $\mathrm{PD}$, and motor neuron disease have consistently shown dysregulation of genes related to oxidative stress (Altar et al, 2005; Blalock et al, 2003; Grunblatt et al, 2004; Brooks et al, 2007; Manczak et al, 2004; Matzilevich et al, 2002), making this class of transcripts one of the most important to evaluate for therapeutic interventions in aging paradigms. The products of these genes can help scavenge free radicals and protect cellular membranes, avoid DNA and RNA damage, and promote the DNA/RNA repair mechanisms (Galvin and Ginsberg, 2005).

$D A$ receptors. Single-cell RNA was amplified and evaluated by custom-designed cDNA arrays for changes in over 200 genes in hippocampal CA1 pyramidal neurons and entorhinal cortex layer II stellate cells from normal persons who died at 19-95 years of age (Hemby et al, 2003). A dramatic age-related decline was found for all five DA receptor mRNAs in CA1 pyramidal neurons, but not in entorhinal cortex stellate cells (Figure 7) (Ginsberg et al, 2004; Hemby et al, 2003). No age-related decrement in other mRNAs was observed in CA1 pyramidal neurons, including the cytoskeletal elements $\beta$-actin, $3 \mathrm{R} \tau$, or $4 \mathrm{R} \tau$ (Hemby et al, 2003) (Figure 7).

Alterations in hippocampal DA function impact cognitive and mnemonic functions, and disruption in the functional integrity of hippocampal DA neurotransmission correlates with the pathophysiology of neurodegenerative disorders including $\mathrm{AD}$ and neuropsychiatric disorders such as schizophrenia. Deficits in dopaminergic neurotransmission may also contribute to cognitive decline associated with normal human aging and in animal models (Volkow et al, 1996; Rinne et al, 1990; Amenta et al, 2001). Aging may be a factor responsible for cell-type-specific downregulation of many genes ( $\mathrm{Lu}$ et al, 2004), with downregulation of DA receptor gene expression contributing to deficits in learning and memory, anxiety, and depressive-like syndromes during aging. It is of interest that the D2/D3 agonist piribedil, which increases cognitive skill learning in aged adults (Peretti et al, 2004), restores the $21 \%$ decrease in brain protein synthesis rates in aged rats as compared with those of middle-aged rats (Bustany et al, 1995).

\section{Psychiatric Indications}

Schizophrenia. Schizophrenia is a severe and life-long psychiatric disorder characterized by illogical, delusional, or paranoid thoughts (positive symptoms), and cognitive deficits, including impairments in working memory, attention, and executive function. The positive symptoms constitute the more overt manifestations of psychosis and are typically the first to draw attention to the disorder. The cognitive components are perhaps more variable, yet more enduring, and, in many respects, are more disabling. Negative symptoms, including social withdrawal, flattened affect, and decreased initiative, characterize most schizophrenic patients to some extent, and constitute the majority of symptoms in about 15\% of schizophrenics (Bleuler, 1950; Kraeplin, 1919).

Similar to most psychiatric illnesses, neither the cause nor the mechanism(s) underlying the pathophysiology of schizophrenia are clear, and much of what is known is inferred from the response, or non-response, of patients to pharmacologic therapies. Most antipsychotic drugs are more effective in ameliorating the positive symptoms than the negative symptoms (Altar et al, 2003a). Examples include the 'typical' antipsychotics haloperidol and chlorpromazine, and the 'atypical' antipsychotics clozapine, thioridazine, olanzapine, ziprasidone, and aripiprazole, which produce fewer adverse side effects, such as Parkinsonian-like symptoms (Altar et al, 2003a; Taylor et al, 2008). Atypical antipsychotics may improve cognitive deficits, although as determined by a meta-analysis of neuropsychological change to clozapine, olanzapine, quetiapine, and risperidone in schizophrenia, the effects are small (Woodward et al, 2005). The following summarizes genes and functional classes of transcripts associated with schizophrenia and potential targets for therapeutic development.

Gene changes in schizophrenia brain: Several groups initially compared the gene expression profiles in postmortem dorsolateral prefrontal cortex (DLPFC) dissected en bloc from control subjects and age- and sex-matched schizophrenic cases (Vawter et al, 2001, 2002a, 2004b; Mirnics et al, 2000; Middleton et al, 2002; Hakak et al, 2001). Not a single gene 
change was consistently replicated among all three groups, and several genes including malate dehydrogenase 1 cytosolic (MDH1) and SERPINI1 (neuroserpin) were found to change in opposite directions (Hakak et al, 2001; Vawter et al, 2002a). Gender differences in the expression of MDH1 and neuroserpin may have contributed to this result, as both genes are more highly expressed in male subjects as compared with female subjects with schizophrenia and in women $v s$ men among the controls (Vawter et al, 2004a).

Subsequent microarray studies of schizophrenia incorporated improvements including better case-control matching, and validation with $\mathrm{qPCR}$, in situ hybridization, and
SNP analysis (Altar et al, 2005; Arion et al, 2007; Aston et al, 2004; Haroutunian et al, 2007; McCullumsmith et al, 2007; Hashimoto et al, 2008; Mexal et al, 2005; Middleton et al, 2005; Mirnics et al, 2001; Katsel et al, 2005a; Iwamoto et al, 2005; Iwamoto and Kato, 2006; Shao and Vawter, 2008; Saetre et al, 2007; Benes et al, 2007). These studies revealed consistently modest effect sizes $(20-40 \%)$, but statistically significant changes for genes in multiple cortical and hippocampal regions. Many abundantly expressed genes showed robust, co-directional changes in schizophrenia when compared with controls in two or more studies (eg, UCHL1, GAD1, GAD2, interferon-induced transmembrane

Table Box 2 Protein Changes Concordant in Two Studies of Schizophrenia (Prabakaran et al, 2004; Behan et al, 2008) Compared to Results for the Same Gene Found in Microarray Studies

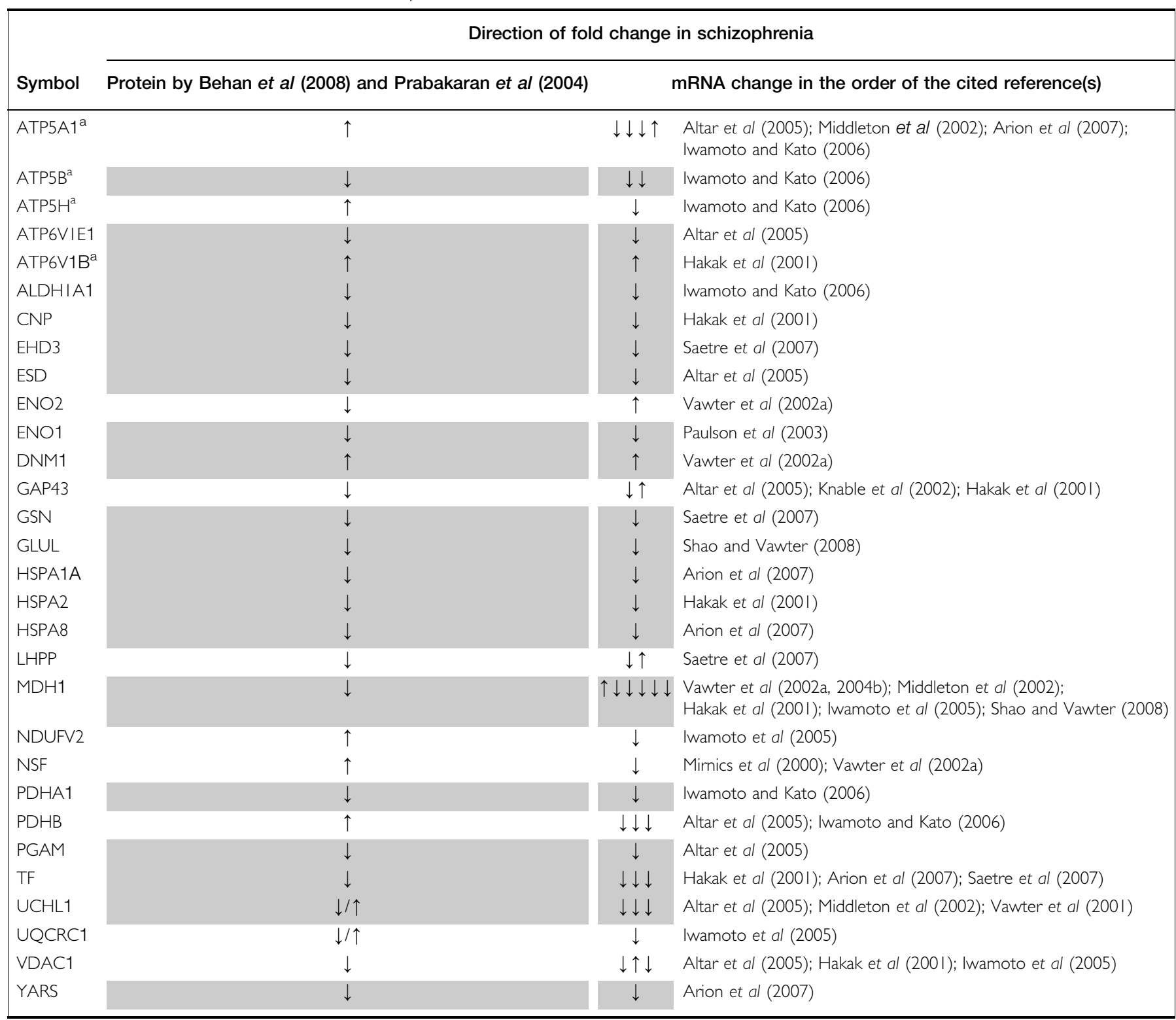

${ }^{a}$ A finding by Behan et al (2008), without a result from Prabakaran et al (2004). BASPI was increased, and PRDX2, ALDOC, and DPYSL2 were decreased in both studies, but without confirmatory findings.

Arrows indicate direction of significant fold change in each listed study, in the same order as the listed studies. Gray-filled boxes indicate concordant mRNA expression and protein changes. 
protein 3 (IFITM3), MAG, MDH1, SYN3, TF, YWHAH, and RGS4) (Table 2). Changes in some genes were confirmed by other techniques such as proteomics (Table Box 2), in situ hybridization, or RT-PCR. The subtraction of the estimated effects of comorbid alcohol and substance abuse, gender, age, and $\mathrm{pH}$ on gene expression reduced the number of significant genes for schizophrenia (Shao and Vawter, 2008). Nevertheless, decreases in prefrontal cortex and cerebellar GAD67 protein and mRNA were replicated in patients with schizophrenia or bipolar disorder (BPD) with psychosis, and these decreases were unrelated to postmortem intervals, dose, duration, or presence of antipsychotic medication (Guidotti et al, 2000). Decreases in genes related to mitochondria, oligodendroglia-myelin pathways, metabolism, ubiquitin-proteasome function, chaperone functions, and immune responses and apoptosis pathways were confirmed in prefrontal cortex (Hakak et al, 2001; Arion et al, 2007; Haroutunian et al, 2007; Shao and Vawter, 2008; Saetre et al, 2007; Tkachev et al, 2003; Shao et al, 2008) and hippocampal dentate granule neurons (Altar et al, 2005). These initial expression studies showed that disease-specific effects would require the analysis of larger sample numbers, additional brain regions, and possibly more homogeneous tissue or cell-specific sampling. Prominent and concordant gene expression differences found in at least two microarray studies of schizophrenia are described in the following sections (Table 2).

HINT1 (histidine triad nucleotide-binding protein 1), parvalbumin, and GAD67. HINT1 gene expression was decreased in three postmortem schizophrenia microarray studies (Vawter et al, 2001, 2002a; Ryan et al, 2006). In situ hybridization showed HINT1 to be reduced by $35 \%$ in cortical layer VI and by $21 \%$ in layer II-V neurons (Vawter et al, 2004b). Interestingly, HINT1 is co-expressed in parvalbumin-containing interneurons (Liu et al, 2008), and parvalbumin expression is decreased in schizophrenia prefrontal cortex and correlates strongly with the decreased densities of GAD67 mRNA-positive neurons (Hashimoto et al, 2003, 2008; Lewis and Moghaddam, 2006). Either clozapine or haloperidol increases GAD67 expression, as shown by ISH in rat neocortex (Zink et al, 2004). An HINT1 knockout mouse model displays mania-like behaviors, and is more behaviorally responsive to amphetamine than are wild-type mice (Barbier et al, 2007). The normal presence of HINT1 in human and animal GABAergic basket interneurons (Liu et al, 2008; Barbier et al, 2007) may explain its reduction in schizophrenia, as the immunoreactivity of parvalbumin and the GABA membrane transporter, GAT2containing basket, and chandelier cells in layers III and IV are decreased in schizophrenia (Beasley and Reynolds, 1997). HINT1 is a member of the histidine triad superfamily of nucleotide hydrolases (Brenner, 2002), complexes with transcription factors MITF or USF2 and lysyl-tRNA synthetase, and lysyl-AMP may be a native substrate for HINT enzymes (Chou and Wagner, 2007). HINT1 may be involved in postsynaptic phosphorylation of neurotransmitter receptors (Guang et al, 2004).
14-3-3 gene family. The 14-3-3 proteins are involved in intracellular signaling, cell division, cell differentiation, apoptosis, ion channel functioning, and neurotransmission (Berg et al, 2003). Their first mode of action was identified with serotonin- $N$-acetyltransferase, a pineal gland enzyme that is catalytically inefficient for melatonin synthesis. After phosphorylation, however, the 14-3-3 protein binds to and stabilizes the enzyme's active conformation (Ganguly et al, 2001; Obsil et al, 2001). It was then discovered that the 14-33 proteins also activate tyrosine hydroxylase, tryptophan hydroxylase (TPH), and inhibitors of protein kinase C, including HINT1 (Bridges and Moorhead, 2005). In rat brain, 14-3-3 family members associate and colocalize with GABA receptors (Couve et al, 2001), disrupted in schizophrenia-1 (DISC1) (Taya et al, 2007), CHRNA $\alpha 4$ subunit (Jeanclos et al, 2001), and TPH2 (Winge et al, 2008). There are seven 14-3-3 genes: $\beta$ (YWHAB), $\varepsilon$ (YWHAE), $\eta$ (YWHAH), $\gamma$ (YWHAG), $\sigma$ (YWHAS), $\theta$ (YWHAQ), and $\zeta$ (YWHAZ). The 14-3-3 proteins are present in synaptic membranes and isolated synaptic junctions and may influence neurotransmission by regulating exocytosis or phosphorylation of synaptic proteins (Martin et al, 1994), including the NMDAR2A receptor by YWHAH (Pozuelo Rubio et al, 2004).

The 14-3-3 gene expression studies indicate that YWHA$B,-E,-G,-H,-Q$, and $-Z$ are decreased in the DLPFC of schizophrenia cases (Table 2). Drug interactions with specific 14-3-3 family members may have antipsychotic benefits. Mechanisms to increase 14-3-3 may include the use of acetyl-L-carnitine, which increases YWHAG (Traina et al, 2004), or fluoxetine, which induces YWHAZ and YWHAE (Cecconi et al, 2007). Haloperidol increased YWHAB in monkey DLPFC and but does not alter YWHAG or YWHAZ in rat brain (Wong et al, 2003; Dean et al, 2007). It will be of interest to screen antipsychotic drugs for their effects on the 14-3-3 subtypes. Decreases in the $\eta$ protein (YWHAH) were also found in the middle temporal gyrus and cerebellum of schizophrenia cases (Vawter et al, 2001) and confirmed in DLPFC in two other cohorts of schizophrenics (Middleton et al, 2005; Iwamoto et al, 2005). Interestingly, the YWHAH gene is located at 22q12.2, close to the DiGeorge region 22q11.2. This deletion is the next highest risk factor for schizophrenia after having a schizophrenic identical twin, and shows a significant association with schizophrenia for two polymorphisms (Wong et al, 2003). Altogether, these studies indicate that YWHAH, YWHAB, YWHAE, YWHAG, YWHAQ, and YWHAZ are decreased in the DLPFC of schizophrenia. The YWHAE protein was decreased in the DLPFC of two cohorts of schizophrenic cases (Novikova et al, 2006), reinforcing the mRNA decreases in this gene family (Vawter et al, 2001, 2002a; Middleton et al, 2005).

YWHAH and YWHAZ are reported to be susceptibility genes for schizophrenia (Bell et al, 2000; Jia et al, 2004; Toyooka et al, 1999; Wong et al, 2005), but three additional studies provide no such evidence for YWHAH (Wang et al, 2005; Hayakawa et al, 1998; Duan et al, 2005). A 
resequencing of YWHAH, YWHAZ, and other 14-3-3 proteins for more rare polymorphisms may determine whether functional polymorphisms are associated with schizophrenia. Interestingly, a systems biology approach identified YWHAZ to be decreased in frontal neocortex of aging and $\mathrm{AD}$ cases, and that it is a 'hub gene' candidate for further analysis in the pathogenesis of age-related neurodegeneration (Miller et al, 2008).

Synapse-related genes. Decreases in genes that encode for synaptic-related markers (Mirnics et al, 2000; Vawter et al, 2002b) were initially reported for SYN2, NSF, GRIA2, and SYT5, but were not found in more recent studies that used larger commercial microarrays and better parametric statistical approaches. SNP or protein confirmation has nonetheless been obtained for SYN II (Lee et al, 2005; Saviouk et al, 2007), ionotropic GluR AMPA2 (GRIA2) (Beveridge et al, 2008), and GAD67 (GAD1) (Guidotti et al, 2000; Hashimoto et al, 2003; Straub et al, 2007; Addington et al, 2005). The use of dissected brain blocks may explain the lack of additional confirmation for decreases in SYN II reported in earlier microarray studies (Gray et al, 2006; Imai et al, 2001).

GABAergic genes. An analysis of all postmortem studies of schizophrenia conducted in specimens from the Stanley Neuropathology Consortium revealed that three genes expressed in GABA neurons, namely reelin (RELN), parvalbumin (PV) and GAD1, had the most abnormal transcript and protein levels (Torrey et al, 2005). GAD1 and other markers of GABAergic neurotransmission are also downregulated in DLPFC, as determined by microarray analysis (Hashimoto et al, 2008). The cellular specificity of gene expression changes in schizophrenia was reinforced by the large and highly significant decreases in GAD1 expression found in the stratum radiatum, pyramidale, and oriens (Benes et al, 2007), but not in whole hippocampus (Konradi et al, 2004). GAD2 is decreased in stratum oriens (Benes et $a l, 2007)$ and GAD1 is decreased in schizophrenia neocortex (Mirnics et al, 2000; Vawter et al, 2001; Akbarian et al, 1995). As noted in this review, some inconsistencies in gene changes between microarray studies probably resulted from between-study differences in the gender of samples or agonal state (Lewis and Moghaddam, 2006).

Protein changes in schizophrenia brain: Some microarray-based mRNA changes in schizophrenia DLPFC have been confirmed by proteomic studies conducted in the same region. We compared two proteomic studies of frontal cortex in schizophrenia (Prabakaran et al, 2004; Behan et al, 2008) in which about 119 proteins were changed in either study. Confirmation of many of those protein changes, particularly in metabolic, immune, and oligodendroglia groups, were provided by up to three expression studies (Table Box 2). The protein glutamate-ammonia ligase (GLUL; Figure 10) was also decreased in Brodmann areas 10 (BA 10) (Burbaeva et al, 2003) and BA 9 (Prabakaran et al, 2004) in schizophrenia. Interestingly, multiple thalamic nuclei showed increased expression of the GLUL transcript (Bruneau et al, 2005). In addition, four proteins $(\alpha$-enolase 1, peroxiredoxin-2, fructose bisphosphate aldolase $\mathrm{C}$ and dihydropyriminidase-related protein 2) decreased in both proteomic studies, and brain acid-soluble protein 1 increased in both studies (Table Box 2).

Genes for synaptic proteins were decreased in schizophrenia neocortex (Mirnics and Lewis, 2001), and comprised 7 of 15 genes, the protein levels of which were changed in another cohort (Mirnics and Lewis, 2001; Pennington et al, 2007). Metabolic- or mitochondrialassociated proteins comprised 25 of the 51 genes that were changed in BPD (Middleton et al, 2002; Pennington et al, 2007) and these decreases in functional gene classes were also found by Middleton et al (2002).

A more comprehensive survey of gene changes in schizophrenia was provided by the SMRI gene expression database (Elashoff et al, 2007) (http://216.55.162.172/index.html). The SMRI combined and analyzed multiple microarray investigations of the DLPFC from schizophrenia, BPD, and control cases provided by the groups of CA Altar, S Bahn, H Chen, SE Dobrin, A Fienberg, T Kato, $\mathrm{P}$ Sklar, MP Vawter, and LT Young. A relative risk score for the over-representation of genes in each disease and pathway was used to rank pathway terms for their disease association. Pathways significant in the SMRI genomic database (at a false discovery of $p=0.05$ ) using adjusted individual microarray studies (Higgs et al, 2006) for schizophrenia include: generation of $\mathrm{A} \beta$ peptides by presenilin 1 (PS1), regulation of MAP kinase pathways through dual specificity phosphatases, oxidative phosphorylation, ATP synthesis, and ribosomal pathways. A compelling mediator of the MAP kinase could be BDNF, which, along with its high-affinity receptor, TrkB, is expressed at lower levels in schizophrenia prefrontal cortex, as determined by in situ hybridization of different cohorts (Weickert et al, 2003; Hashimoto et al, 2005). Decreases in $\mathrm{BDNF}$ were localized to large pyramidal neurons in cortical layers III, V, and VI (Weickert et al, 2003).

Immune genes in schizophrenia: Three independent groups found immune response pathway genes to be overrepresented in postmortem schizophrenia DLPFC (Arion et al, 2007; Shao and Vawter, 2008; Saetre et al, 2007). The proteins encoded by genes for IFITM3 and serpin peptidase inhibitor, clade A ( $\alpha-1$ antiproteinase, antitrypsin), member 3 (SERPINA3) are involved in immune responses and are stimulated by cytokines (Andreu et al, 2006; Baker et al, 2007). Increases in mRNA for IFITM 3 and SERPINA3 were also found in two schizophrenia cohorts (Saetre et al, 2007), in BA 9 (from the University of Pittsburgh Brain Bank), in BA 8 and BA 9 (from the Harvard and Stanley Brain Banks), and from the left side of the superior frontal gyrus (Arion et al, 2007).

IFITM3 and SERPINA3 are expressed in oligodendrocyte and endothelial cells, and their transcription is induced by the inflammatory cytokines TNF- $\alpha$, IFN- $\alpha$, and IFN- $\gamma$ (Saetre et al, 2007). Increases in proinflammatory markers 
such as IL-6 are found in cerebrospinal fluid during exacerbations of psychotic disorders (Garver et al, 2003). The ability of haloperidol, risperidone, and clozapine to decrease proinflammatory markers in blood and microglia cell cultures (Kato et al, 2007; Moots et al, 1999; Song et al, 2000) suggests that decreases in inflammatory response might lessen schizophrenia. Lifetime antipsychotic level is associated with an increase in v-erb-b2 erythroblastic leukemia viral oncogene homolog 2, neuro/glioblastomaderived oncogene homolog (ERBB2) transcripts in schizophrenia (Shao and Vawter, 2008), and ERBB2 protein in rat hippocampus (Chong et al, 2008). Neuregulin 1 (NRG1) and ERBB4 receptors are increased in schizophrenia in DLPFC (Chong et al, 2008). If either can cross the blood-brain barrier, the ERBB2 receptor antibody trastuzumab (Sastry and Sita Ratna, 2004) or the anti-inflammatory agent erythropoietin (EPO) (Ehrenreich et al, 2004, 2008) could be evaluated as treatments for schizophrenia by blocking excess immune activation (Hanson and Gottesman, 2005).

Gene changes as a basis for drug discovery: On the basis of an evaluation of gene expression in single stellate cells collected from the entorhinal cortex of normal controls and schizophrenic cases (Ginsberg et al, 2004; Hemby et al, 2002), and genomic profiling of dorsal root ganglia neurons collected by LCM (Luo et al, 1999), LCM was used to separate hippocampal dentate gyrus granule cell neurons from surrounding tissue (Figure 3) and profile gene expression with cDNA microarrays (Judd and Akiskal, 2003). These studies identified far more gene decreases in schizophrenia than expected by chance, and replicated $37 \%$ of these genes and $29 \%$ of the upregulated genes in a second cohort (Figure 8). Importantly, almost every gene that changed in both cohorts did so in the same direction. Functional groups of gene decreases were found to be highly significant by EASE analysis and survived Bonferroni correction for multiple comparisons. These functional groups included those involved in protein turnover (proteasome subunits and ubiquitin), similar to gene decreases found in the DLPFC (Vawter et al, 2001), and mitochondrial oxidative energy metabolism (including isocitrate, lactate, malate, $\mathrm{NADH}$, and succinate dehydrogenases; complexes I-IV, cytochrome $C$ oxidase, ATPase, and ATP synthase), as observed for mitochondrial gene decreases in adult rat brain of offspring born to vitamin Ddeficient dams (Eyles et al, 2007). These mRNA decreases were also found in the frontal cortex of schizophrenics (Middleton et al, 2002) and so too for many of the proteins they encode, and in different patient cohorts (Prabakaran et al, 2004; Whatley et al, 1996), and independent of patient medication status. In addition, chronic treatment of rats with clozapine failed to lower these genes in LCM-captured dentate granule neurons (Altar et al, 2005). In fact, MAD1 and other metabolic genes were unchanged or increased in brain by haloperidol treatment of monkeys or rodents (Middleton et al, 2002; Whatley et al, 1996).

\section{Many gene changes replicated in 2 schizophrenia cohorts}
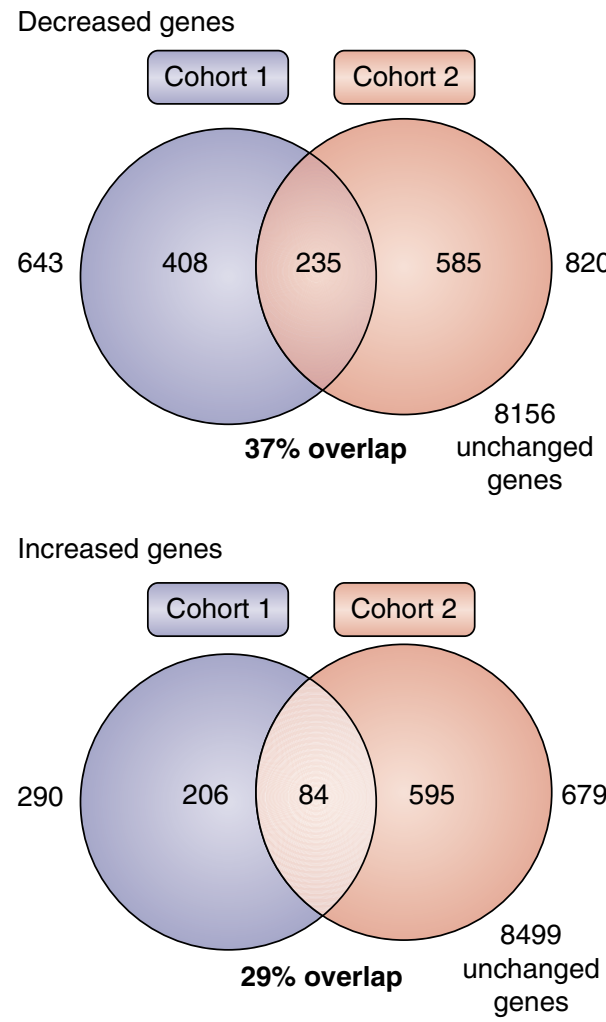

Figure 8. Overlap in genes decreased (top) and increased (bottom) between two cohorts of schizophrenic cohorts and controls, $n=9$ controls and 8 schizophrenics (cohort 1), and 15 controls and 14 schizophrenics (cohort 2). Over $95 \%$ of the genes that changed $(p<0.05$ ) in both cohorts changed in the same direction (Altar et al, 2005).

Insulin/IGF-1 and muscarinic signaling: Many of the genes decreased in schizophrenia encode for mitochondria, carbohydrate metabolism, ubiquitin-proteosome pathways, ATP production, and hydrogen ion transport proteins and were also found by microarray studies to be decreased in skeletal muscle of diabetic rodents (Yechoor et al, 2002). Rome et al (2003) used microarrays to demonstrate the upregulation of many of these same genes by insulin in human skeletal muscle. These similar data sets indicated that brain insulin signaling might be deficient in schizophrenia. The insulin signaling pathway has been shown to be deficient in schizophrenia brain (Zhao et al, 2006) and olanzapine treatment elevates insulin mRNA in the frontal cortex of rats by 3.7 -fold, the largest increase among all genes tested (Fatemi et al, 2006).

Using human SH-SY5Y neuroblastoma cell cultures, human insulin or insulin-like growth factor 1 (IGF-1) increased the expression of genes involved in mitochondrial function, the ubiquitin-proteosome pathway, glucose and energy metabolism, synaptic function, and hydrogen ion transport (Altar et al, 2008). These cells did not respond to IGF-2, BDNF, haloperidol, clozapine, or many other pharmacologically active compounds. These effects were 


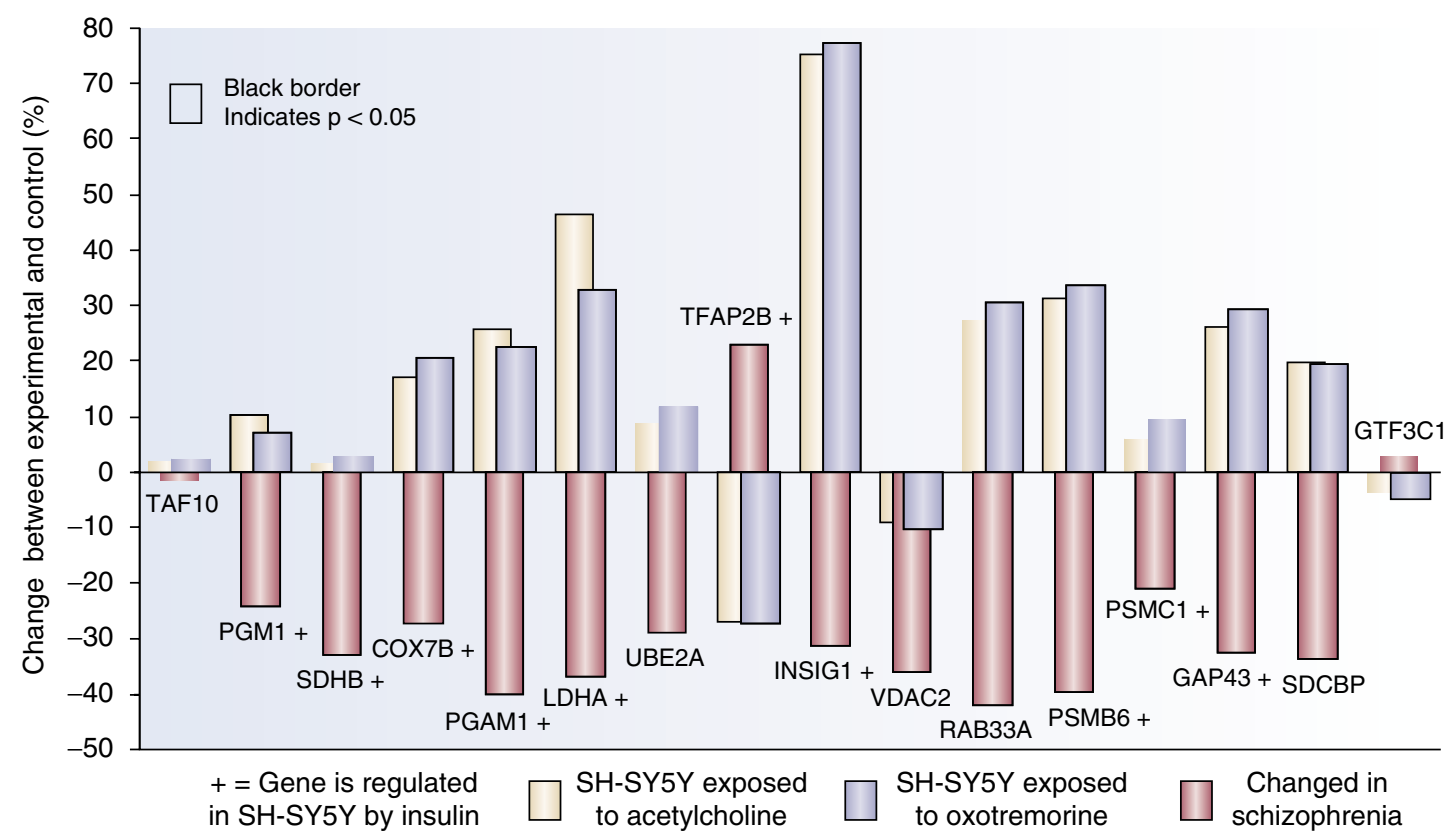

Figure 9. Reversal of schizophrenia gene signature (red bars) (Altar et al, 2005) by muscarinic agonists, $25 \mu \mathrm{M}$ acetylcholine (yellow bars) and $25 \mu \mathrm{M}$ oxotremorine (blue bars; Altar et al, 2008). A '+ ' next to gene names signifies that it changed in response to insulin, and in a direction similar to the muscarinic agonists. Black border around bars indicates a significant change from vehicle control, $p<0.05$.

consistent with the demonstration that insulin phosphorylated its receptor in the SH-SY5Y cells and, similar to IGF-1, increased the phosphorylation of the insulin-signaling mediators ERK1/2 and Akt. Using an algorithm similar to sections I and II of Table Box 1, 14 target genes were selected if their expression in dentate gyrus granule cells changed in the same direction in both schizophrenia cohorts, or were reported by others and found in at least one cohort to be altered in schizophrenia. The next level of priority was ascribed to disease signature genes that were closely related to a gene reported by others to change in the same direction in schizophrenia. Genes changed by insulin treatment of SH-SY5Y cells and in the opposite direction to that in schizophrenia brain were next most heavily weighted. Two control genes that did not change in schizophrenia or in response to insulin were chosen to provide normalization of the target genes (Figures 5 and 9).

Responses of the 14 target genes to insulin, first identified with microarrays, were verified in the MPHTS ${ }^{\mathrm{SM}}$ assay and by quantitative RT-PCR. With insulin serving as a positive control, 1940 pharmacologically defined compounds were screened for their mimicry of the insulin effect, and most were inactive. Interestingly, most of the active compounds were muscarinic agonists, and their effects on the schizophrenia genes were blocked by the muscarinic antagonists atropine and telenzepine (Altar et al, 2008). $\left[{ }^{3} \mathrm{H}\right]$ Pirenzepine binding to muscarinic receptors is lower within dentate gyrus and CA1, CA2, and CA3 neurons, and M4 expression is decreased in schizophrenic hippocampus (Scarr et al, 2007). These decreases are consistent with the ability of the M1/M4 muscarinic agonist xanomeline to improve the positive and negative symptoms of schizophrenia (Bymaster et al, 2002). These findings indicate that schizophrenics, or a sub-population of them, may have an insulin or IGF-1 signaling deficit in the brain. Increases in muscarinic or insulin/IGF-1 signaling may normalize genomic alterations in schizophrenia and better address its root causes.

$B P D$. Individuals with $B P D$ present initially with either a depressive or manic episode. The diagnosis of BPD type I follows a distinct period of mood change (elevated, expansive, or irritable) for at least a week, or shorter if hospitalization is required (DSM-IV criterion A). The manic episode can involve at least three or more items from the following (DSM-IV criterion B): inflated self-esteem or grandiosity, decreased sleep, more talkative or pressured speech, racing thoughts, distractibility, increased goaldirected activity, and excessive involvement in pleasurable activities. A hypomanic state, or BPD, type II, requires a shorter duration and severity of manic symptoms, and a depressive episode to have occurred (see Major Depressive Disorder below, for criteria). Diagnosis of BPD may require several years as a manic episode may not occur for several years after presentation. The prevalence of these DSM cases in the US National Epidemiological Catchment Area database is about 1.3\%; however, subthreshold bipolar spectrum cases are about $5 \%$ (Judd and Akiskal, 2003). The course of bipolar illness can be quite severe, including a 10fold increase in the risk of suicide above the general population, and a 20 -fold increase for patients not treated with lithium (Tong and Jahr, 1994). The brevity of the following section and the short list of genes reported for BPD in Table 2 reflect the smaller number of confirmatory studies for genes and targets identified in BPD.

Gene changes in bipolar brain: The 14-3-3 family protein YWHAQ is decreased in the prefrontal cortex (Elashoff et al, 2007; Vawter et al, 2006a) and hippocampus (Konradi 
et al, 2004) of bipolar cases. YWHAZ is decreased in bipolar DLPFC, as determined by a reanalysis of other studies (Elashoff et al, 2007), and in suicide subjects, in BA 46 (Klempan et al, 2007). YWHAE is decreased in cortexsuicide age-matched pairs (Sibille et al, 2004) and increased by lithium (McQuillin et al, 2007). There have, however, been negative reports of 14-3-3 family member changes in postmortem tissue (Dean et al, 2007; Wong et al, 2005).

The relevance of 14-3-3 proteins to BPD may also lie in their chaperone activity to enhance $\tau$ phosphorylation by glycogen synthase kinase 3 (GSK-3 $\beta$ ) (Agarwal-Mawal et al, 2003). The phosphorylation of the N-terminal serine 9 site of GSK-3 $\beta$ inhibits its activity, as induced by lithium, leading to neuroprotection (Bachmann et al, 2005). This is consistent with pharmaceutical industry efforts to develop selective GSK-3 $\beta$ inhibitors that mimic lithium. $\tau$ and GSK$3 \beta$ copurify with YWHAZ, and the association of phosphorylated GSK-3 $\beta$ with 14-3-3 in vitro prevents cell death (Mwangi et al, 2006; Henshall et al, 2002; Wang et al, 2007b). 14-3-3 family members also bind to the proapoptotic Bcl-2-associated death protein (BAD) to decrease cell death signaling (Henshall et al, 2002; Wang et al, 2007b; Shinoda et al, 2003).

Targets and drugs identified: The 14-3-3 gene expression studies in BPD reveal decreases in YWHA-Q, $-Z$, and E. It is interesting to speculate that the liability of SSRI drugs to precipitate a manic episode may result from their ability to induce YWHAZ and YWHAE, which has been reported for fluoxetine (Cecconi et al, 2007). Control of 143-3 proteins could strengthen effects of serotonin, GABA, and acetylcholine function in the nervous system to provide an alternative treatment for BPD. Deficiencies in GABA gene expression have been reported by several groups in the brains of suicide cases, BPD, and major depressive disorder (MDD) (Klempan et al, 2007; Sequeira and Turecki, 2006; Sequeira et al, 2007).

Niculescu and colleagues (Le-Niculescu et al, 2007; Ogden et al, 2004) have used convergent functional genomics (CFG) in mouse models to rank genes that are in close $(10 \mathrm{cM})$ proximity to bipolar risk candidate genes. The CFG paradigm cross-matches comprehensive animal model microarray gene expression data with human genetic linkage data, human postmortem gene expression data, and biological roles data. This Bayesian way of reducing uncertainty produces a short list of high-probability candidate genes, pathways, and mechanisms for complex genetic disorders, such as neuropsychiatric disorder (Bertsch et al, 2005).

The genes recently updated for BPD by the CFG approach include lysophospholipase I (LYPLA I), myocyte enhancer factor 2C (MEF2C), calcium/calmodulin-dependent protein kinase kinase 2, $\beta$ (CAMKK2), cyclin-dependent kinase 5, regulatory subunit 1 (p35) (CDK5R1), tachykinin, precursor 1 (TAC1), proenkephalin (PENK), protein phosphatase 1, regulatory (inhibitor) subunit $1 \mathrm{~B}, \mathrm{DA}$ - and cAMP-regulated phosphoprotein (DARPP-32), T-box, brain, 1 (TBR1), cholecystokinin (CCK), myelin-associated oligodendrocytic basic protein (MOBP), and GLUL (Le-Niculescu et al, 2007). The CFG approach has been applied to a DPB (D-boxbinding protein) knockout mouse model with features resembling BPD. The model was designed with information regarding blood-based biomarkers, QTL for behavioral changes, postmortem studies, and pharmacological and environmental stressors that induced gene expression changes (Le-Niculescu et al, 2007, 2008). The small number of samples used in these experiments, and the statistical likelihood that some disease- and drug-signature gene overlaps (Figure 1) is chance levels, requires that CFG associations be replicated.

Other gene changes between bipolar disease and drug paradigms include FGF2, for which increases were also reported in BPD (Shao and Vawter, 2008; Nakatani et al, 2006) and increased and decreased in subgroups of cocaine abusers (Lehrmann et al, 2003a,b). HINT1, summarized in the schizophrenia section, was decreased in a reanalysis of BPD microarray studies (Elashoff et al, 2007). Aldehyde dehydrogenase family 7 member A1 was increased in the DLPFC of schizophrenia and BPD in protein (Pennington et al, 2007) and mRNA measures (Shao and Vawter, 2008). Treatment of rats with lithium or valproate also increased hippocampal BAG-1 expression and BAG-1 protein (Zhou et al, 2005). GAD1 is decreased in the extracts of whole hippocampus (Konradi et al, 2004) but to a greater degree in stratum pyramidale and oriens of BPD cases, similar to GAD2 in stratum oriens (Benes et al, 2007).

Major depressive disorder. $\mathrm{MDD}$ is characterized by abnormal mood symptoms that occur during the same 2week period that results in clinically significant impairment. Five or more of the following criteria from DSM-IV must be met: depressed mood, diminished pleasure, decreased concentration, fatigue, feelings of worthlessness, weight or appetite disturbance, sleep disturbance, psychomotor disturbance, and recurrent thoughts of dying. Individuals with major depressive mood disorder will not have manic, mixed, or hypomanic episodes; however, if these occur and are not associated with antidepressant treatment, then a diagnosis of BPD is given. The risk of suicide is also high for individuals with severe MDD, but lithium (Guzzetta et al, 2007) and antidepressant treatments reduce but certainly do not eliminate this risk (Healy and Whitaker, 2003; Mann et al, 2005). Suicide rates can approach $20 \%$ among severely depressed men in some countries and are generally 3-5 times higher in men than women. Understanding the pathophysiology of depressive disorders and providing better treatments will improve mental health and quality of life for the largest number of individuals with psychiatric disease.

Gene changes in depressive disorder brain (Table 2): The enzyme GLUL is enriched in glia cells compared to neurons, where it converts glutamate to glutamine (ATP + L-glutamate $+\mathrm{NH}_{3} \Leftrightarrow \mathrm{ADP}+$ orthophosphate + L-glutamine) (Figure 10). GLUL is decreased in MDD (Choudary et al, 2005), BPD and schizophrenia (Shao and Vawter, 2008), and 


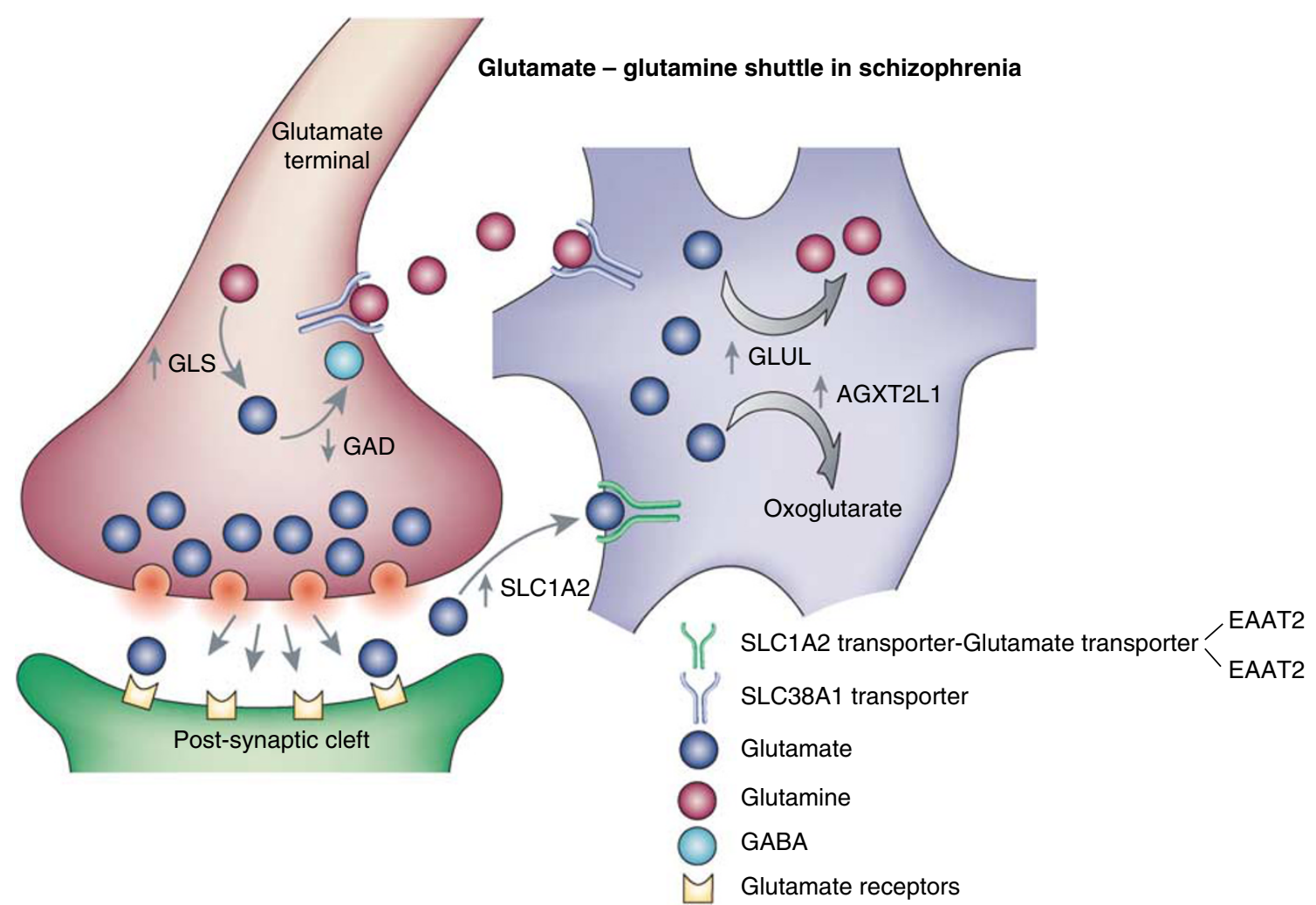

Figure 10. Glutamate-glutamine shuttle between glutamatergic nerve terminals and astroglia in the CNS. Increased expression of GLUL and SLC1A2 genes in schizophrenia and bipolar disorder (Shao and Vawter, 2008; Vawter et al, 2006a; Choudary et al, 2005; Beasley et al, 2006) and increased expression of GLS (Bruneau et al, 2005; Gluck et al, 2002) have been reported in schizophrenia, whereas decreased SLC1A2 and AGXT2L1 mRNA and GLUL mRNA and protein levels in major depressive disorder in the anterior cingulate were reported (Shao and Vawter, 2008; Vawter et al, 2006a; Choudary et al, 2005; Beasley et al, 2006). These molecules contribute to the transport, synthesis, and recycling of glutamate after synaptic release (Magistretti et al, 1999). Glutamate does not cross the blood-brain barrier and its presence in the CNS is from the glia-derived precursor, glutamine. SLC1A2 (solute carrier family 1 (glial high-affinity glutamate transporter, member 2)), AGXT2L1 (alanine-glyoxylate aminotransferase 2-like 1), GLUL (glutamate-ammonia ligase (glutamine synthetase)), SLC38A1 (solute carrier family 38, member 1), and GLS (glutaminase) are involved in this process and, as shown by arrows, are mostly increased in schizophrenia.

BPD and MDD (Vawter et al, 2006). GLUL expression is decreased by valproate administration (Bosetti et al, 2005) and is downregulated in 75\% of MDD-suicide pairs (Sibille et al, 2004), in schizophrenics who died from suicide (Kim et al, 2007), and in suicide cases from a Montreal cohort (Klempan et al, 2007).

Another potential pathway for intervention in glutamateglutamine metabolism is the shuttling of these compounds between astroglial end feet and neuronal processes (Figure 10) (Magistretti et al, 1999). The high-affinity glutamate transporter SLC1A2 (also known as EAAT2 or GLT) is brain enriched relative to peripheral organs (Berger and Hediger, 2006). Similar to GLUL, SLC1A2 is enriched in glial cells relative to neurons (Rothstein, 2003). It is decreased within the DLPFC in BPD and SZ (Shao and Vawter, 2008), in MDD (Choudary et al, 2005), in MDD-suicide cases (Klempan et al, 2007) and in $68 \%$ of MDD-suicide age-matched control pairs (Sibille et al, 2004). A note of caution has been raised regarding the specific isoform of importance because both EAAT2a and EAAT2b are alternatively spliced exons for the same SLC1A2 gene, and one study (Lauriat et al, 2006) failed to find changes in EAAT2, EAAT3, EAAT3b, or EAAT3 in DLPFC and visual cortex of schizophrenic cases.
EAAT2a is the predominant isoform in human brain (Lauriat et al, 2006). The ability of the NMDA antagonist riluzole (Frizzo et al, 2004) to upregulate EAAT2 gene and protein expression, and the antidepressant effects of riluzole in treatment-resistant patients (Sanacora et al, 2007; Zarate et al, 2005), is consistent with the EAAT2 decrease in MDD and suicide. The approval of riluzole for amyotrophic lateral sclerosis (Rothstein, 2003) may provide an opportunity to identify antidepressant effects in these patients as well. An experimental drug that has shown efficacy in treating schizophrenia, LY2140023, is an oral prodrug for LY404039, a metabotropic GluR2/3 receptor agonist (Patil et al, 2007). Similar to $\beta$-lactam antibiotics (Rothstein et al, 2005), LY404039 increases astrocyte glutamate uptake, thus providing another compound with which to stimulate glutamate uptake to test this approach for treating MDD.

Another gene related to glutamatergic function is alanineglyoxylate aminotransferase 2-like 1 (AGXT2L1), which participates in glutamate catabolism by transferring ammonia groups through alanine during glutamate-glutamine shuttling (Figure 10). A transaminase, AGXT2L1 promotes the conversion of L-alanine + glyoxylate $\Rightarrow$ pyruvate + glycine, and participates in the metabolism of L-glutamate and 
3-phosphonopyruvate $\Leftrightarrow 2$-amino-3-phosphonopropanoate +2 -oxoglutarate. This is consistent with its putative mitochondrial localization and with potential involvements in enzymatic amino-acid catabolism of glutamate, alanine, arginine, histidine, glutamine, and proline. AGXT2L1 is upregulated in BPD and schizophrenia (Shao and Vawter, 2008; Ryan et al, 2006) and downregulated in suicide completers (Kim et al, 2007) and in $72 \%$ of MDD-suicide cases when compared with age-matched controls (Sibille et al, 2004). Individuals with high AGXT2L1 appear to be at a higher risk of developing a psychiatric disorder, based on a highly significant odds ratio (Shao and Vawter, 2008). AGXT2L1 was the most upregulated gene in a genome-wide expression study of lithium administration to mice (McQuillin et al, 2007). Among schizophrenic cases, AGXT2L1 was decreased between the suicide completers $v s$ the non-suicide group (Kim et al, 2007). AGXT2L1 expression was decreased in atypical neuroleptic-treated patients with schizophrenia when compared with controls (Shao and Vawter, 2008). AGXT2L1 may withstand independent validation as a novel target of lithium and neuroleptics, thus providing greater relevance to its decreases in depression and suicide, and increases in BPD and schizophrenia.

In summary (Figure 10), SLC1A2 and GLUL have defined roles in glutamate neurotransmission and decreases are associated with MDD. AGXT2L1 has a putative role in glutamate-glutamine conversion and alanine-lactate shuttling between neurons and glia, and is decreased in MDD and suicide. Recent successes in treating depression (Zarate et al, 2005, 2006; Sanacora et al, 2007), schizophrenia (Patil et al, 2007), and BPD (Mathew et al, 2008) with drugs that augment several forms of glutamate neurotransmission increase interest in these genes and glutamatergic pathways. SLC1A2, GLUL, and AGXT2L1 may have an interactive effect on increasing the risk for MDD, BPD, or schizophrenia by altering the processing of glutamate by astrocytes. In vivo imaging of the anterior cingulate cortex has shown lower glutamine concentrations in non-medicated adolescents with BPD (Moore et al, 2007) and these results are consistent with abnormalities within glial cells of the anterior cingulate cortex in BPD (Vawter et al, 2000). However, increases in anterior cingulate cortex glutamine levels may not be sufficient to treat mood disorders. The antiepileptic drug, topiramate, raises glutamine levels in the anterior cingulate cortex in healthy men (Moore et al, 2006), but large clinical trials failed to show that it is an effective treatment for BPD (Goodnick, 2006; Johannessen Landmark, 2008). Instead, augmentation of other aspects of glutamate function compromised by deficient glutamate metabolism in astrocytes or neurons (Figure 10) may be therapeutic for MDD. NMDA antagonism by riluzole and ketamine may increase AMPA signaling relative to NMDA signaling to treat depression (Maeng et al, 2008), whereas direct mGlu2 receptor agonism may treat psychosis (Patil et al, 2007).
FGF. FGF family members have been found to be dysregulated in multiple studies of MDD, including genes for FGF1, acidic; FGF2, basic; keratinocyte growth factor (FGF7); and receptors FGFR1, FGFR2, and FGFR3 (Sibille et al, 2004; Evans et al, 2004; Aston et al, 2005; Tochigi et al, 2007). Interestingly, two studies reveal higher FGFR1 mRNA expression and reduced FGF2 mRNA in MDD hippocampus and PFC (Tochigi et al, 2007; Gaughran et al, 2006). These findings suggest decreased FGF synthesis, and possible compensatory increases in its receptor subtypes. Olanzapine is approved for mood stabilization in BPD and upregulates FGF3 and downregulates FGFR2 when administered to mice (Fatemi et al, 2006). These changes are in line with the FGF downregulation-receptor upregulation hypothesis we propose for mood disorder. It will be of interest to profile other drugs approved for bipolar mood stabilization, such as Abilify, valproate, carbamazepine, and lithium, to see whether there is a common effect on the FGF ligand and receptor system as described for olanzapine. Lithium also produces reciprocal changes by decreasing FGF3 and increasing its receptor, FGFR3, in neuronal cells (Yazlovitskaya et al, 2006). ECS, a model for electroshock therapy, increases cortical and hippocampal mRNA for the angiogenic factors VEGF, FGF, and neuropilin. These angiogenic factor increases are unexpected candidate targets for treating mood disorders including MDD and could underlie the antidepressant effects of ECT and exercise (Altar et al, 2005; Newton et al, 2003). Importantly, intracranial infusions of FGF reduce depressive-like behaviors in the forced swim test (Turner et al, 2006, 2008), and increase memory (Ishihara et al, 1992) and neurogenesis (Cheng et al, 2002; Matsuoka et al, 2003).

The FGF system offers additional therapeutic alternatives to the monoamine-based approaches that dominate treatment strategies for mood disorders (Turner et al, 2006). Peptide mimetics derived from the neural cell adhesion molecule (NCAM1) can also bind to and activate FGFR (Anderson et al, 2005; Berezin and Bock, 2004), (Figure 11). These NCAM1 mimetics enhance social memory retention (Secher et al, 2006), increase neurite outgrowth (Li et al, 2005), act as an antidepressant in animal models of depression (Turner et al, 2008), and are currently in clinical trials for AD (Anand et al, 2007). Similar to FGF, expression of the heterologous FGFR ligand, NCAM1, is decreased in MDD (Tochigi et al, 2007) and MDD-suicide pairs (Sibille et al, 2004), whereas proteolytically cleaved fragments of NCAM1 are elevated in BPD and schizophrenia (Vawter, 2000). Pathways that play roles in mood disorders, including MAP kinase and PI3/Akt signaling pathways, are modified by FGF-induced transcription factors that activate cadherin gene transcription or bind cadherin molecules (El-Hariry et al, 2001a,b; Boscher and Mege, 2008; Murakami et al, 2008). These interactions are summarized in Figure 11.

Other genes. G-protein-coupled receptor 37 endothelin receptor type B-like (GPR37) and G-protein-coupled receptor, family C, group 5, member B (GPRC5B) are decreased in the 


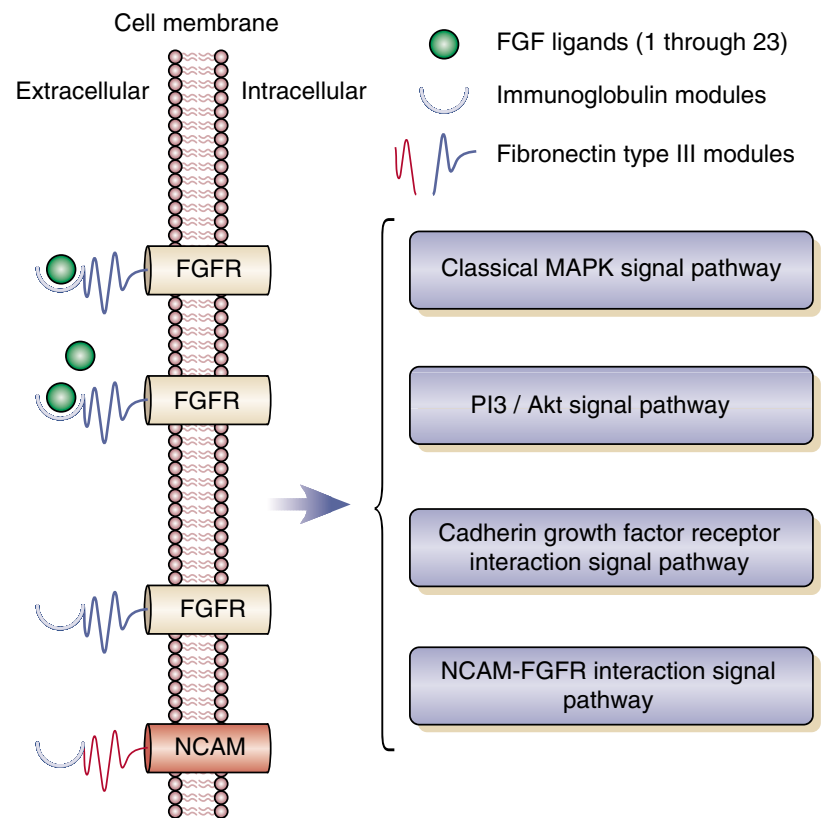

Figure 11. Fibroblast growth factor (FGF) signaling through diverse pathways. In total, 23 FGF family member ligands bind to four different FGF receptors (FGFR 1, 2, 3, and 4) and activate downstream signaling through FGFR homodimerization (shown by FGFR and FGFR). FGF signaling promotes the transcription of genes involved in proliferation, energy, growth, survival, angiogenesis, neurite extension, and growth cone motility. These signaling pathways can also be triggered by neural cell adhesion molecule (NCAM1) binding to an FGFR1 or FGFR2-NCAM heterodimer (Doherty and Walsh, 1996; Christensen et al, 2006). Peptide mimetics are being tested for their NCAM-like binding to FGFR1 or 2. Such agonism is anticipated to treat cognitive deficits, schizophrenia, and AD (Secher et al, 2006; Klementiev et al, 2007).

superior temporal gyrus in MDD (Aston et al, 2005) and in the prefrontal cortex of most MDD-suicide cases $v s$ age-matched controls (Sibille et al, 2004). These orphan GPCRs will require more investigation to determine endogenous ligands, functions, and possibly small molecules that interact with them.

Two microarray studies (Aston et al, 2005; Tochigi et al, 2007) independently found two genes, DIM1 dimethyladenosine transferase 1-like (DIMT1L) and PRP19/PSO4 pre-mRNA processing factor 19 homolog (PRPF19) to be decreased in MDD. Comparisons across microarray MDD studies showed NTRK2 (TrkB, the high-affinity receptor for BDNF and NT-3) to be decreased in more than one study, as did SSAT, CTSB, COPA, and PTP4A2 (Sequeira et al, 2006, 2007; Sequeira and Turecki, 2006; Choudary et al, 2005; Aston et al, 2005; Tochigi et al, 2007; Evans et al, 2003). Decreases in BDNF and TrkB have received additional confirmation by Dwivedi et al $(2003,2005)$.

Aquaporin 4 (AQP4), the predominant water-selective membrane channel in brain, is concentrated in astrocytic end feet and its expression is increased in the DLPFC of MDD and BPD cases (Iwamoto et al, 2005; Tochigi et al, 2007). Interestingly, AQP4 is reduced in rat brain by lithium (McQuillin et al, 2007) and valproate (Bosetti et al, 2005), and altered in $80 \%$ of MDD-suicide pairs (Sibille et al, 2004).
Gene effects of electroconvulsive seizure: ECT alleviates depression in the majority of drug-resistant patients with MDD or BPD. To discover targets for rapid pharmacological treatment of MDD, microarray-based genomic profiling studies of neocortex and hippocampus (Altar et al, 2004; Newton et al, 2003) have measured gene changes in rodent brain following ECS, a model of ECT. These findings have been compared with gene changes in the CNS in other antidepressant models, such as exercise (Ang and GomezPinilla, 2007; Molteni et al, 2002), or the administration of antidepressant drugs to animals or cultured neurons.

Many more genes were found to change to ECS in the hippocampus than in the neocortex, and a single ECS produced more changes than did 10 daily ECS administrations (Figure 12). Gene changes were ranked by an algorithm similar to that in Table Box 1 according to their statistical and biological significance, identification by other laboratories, and whether they changed in one or both tissues, or after one or both durations of ECS administration (Altar et al, 2004). This analysis identified 54 of the 88 mRNA or protein changes to ECS reported by others in rodent brain, and identified 101 novel genes.

In total, 30 genes that increased in response to ECS participate in biochemical pathways which have already been associated with the antidepressant efficacy (Altar et al, 2004; Newton et al, 2003) (Figure 13). These include genes involved in neurogenesis, neuritogenesis, neuropeptide synthesis, neurotransmitter signaling, angiogenesis, and arachidonic acid metabolism. Immediate-early genes increased by acute and chronic ECS include c-fos, jun, jun-B, Krox20, Nurr1, TGF $\beta$-inducible ERG (TIEG), the activity regulated cytoskeleton-associated growth factor (arc), NGF, and the activity and neurotransmitter-induced early gene proteins 4 (ania-4) and 3 (ania-3).

BDNF and TrkB message and protein are decreased in the postmortem neocortex and hippocampus of suicide cases (Dwivedi et al, 2003, 2005; Karege et al, 2005). Interestingly, decreases in BDNF and NT-3 were found in drug-free but not medicated suicides, suggesting upregulation of these factors by psychotropic agents (Karege et al, 2005). Consistent with this proposal, ECS elevated 17 genes along the BDNF/TrkB-stimulated MAP kinase pathway and its convergent, glutamate-coupled PKC pathway, and four additional genes of the ERK1,2-linked arachidonic acid pathway (Figure 13). ECS increases BDNF mRNA (Duman et al, 1997; Nibuya et al, 1995; Zetterstrom et al, 1998) and protein (Altar et al, 2003b) in rat neocortex and hippocampus. Several antidepressants or candidate drugs, including the glutamate release-augmenting drug riluzole (Katoh-Semba et al, 2002) and the AMPAkines LY 392098 or CX614 (Lauterborn et al, 2000), enhance BDNF expression and granule precursor cell proliferation in hippocampus. BDNF mRNA and protein, and TrkB mRNA, are increased in rat pups after 13 days of treatment with the SSRI escitalopram (Kozisek et al, 2008). The importance of TrkB phosphorylation and signaling (Saarelainen et al, 2000), and Grb-2 and RAS activation for antidepressant action, may occur through the 

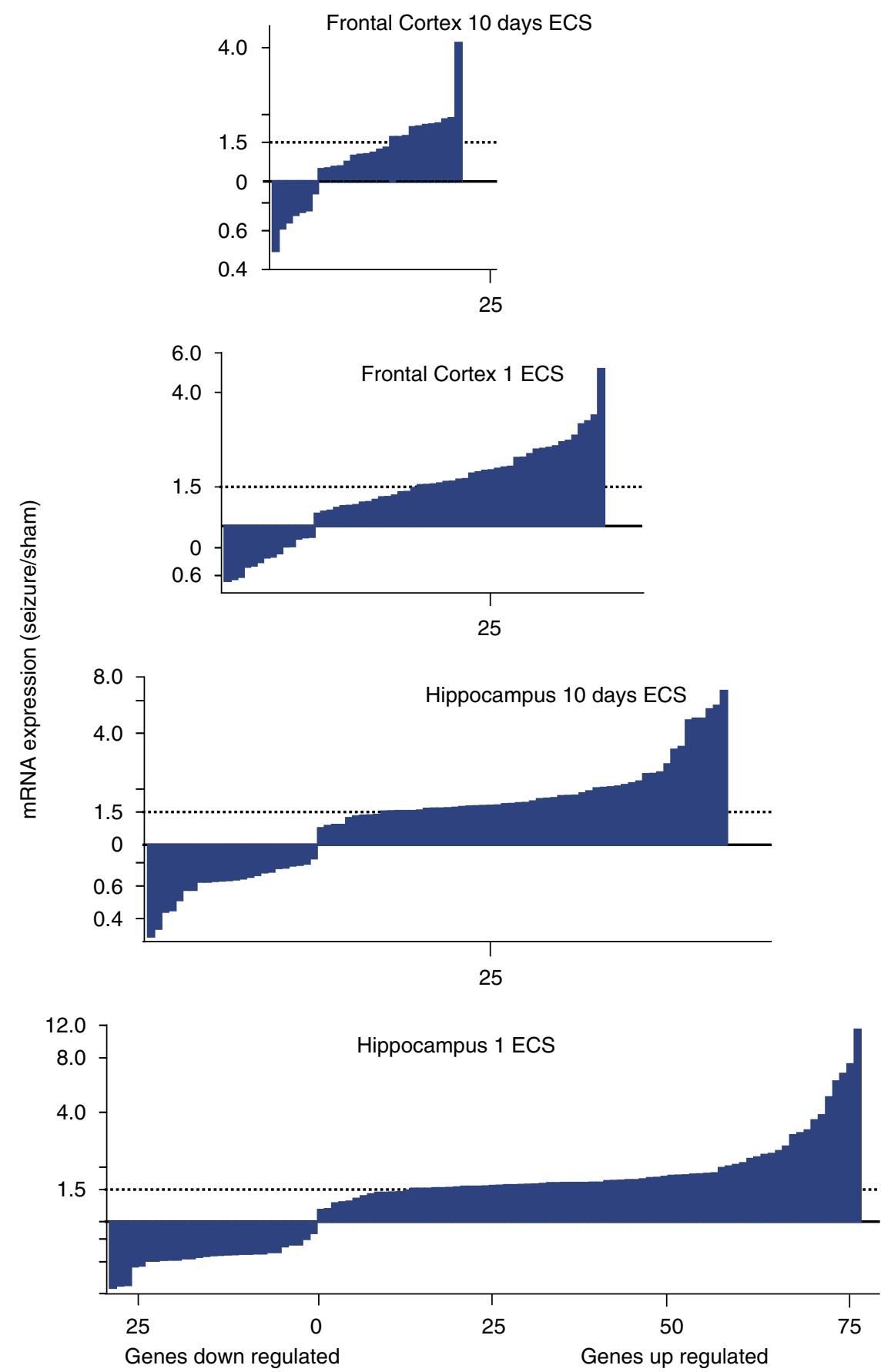

Figure 12. Cumulative number ( $X$ axis) and fold change ( $Y$ axis) of gene changes in the frontal cortex and hippocampus of rats treated with acute or chronic ECS. For all genes that changed $(p<0.05)$ from sham seizure control rats, the ratio of the mean expression in the ECS group over the control group is cumulated over the magnitude of change. In each graph, decreases are plotted below the unity line and increases are plotted above the line. The $X$ axes for all four graphs are aligned at ' 0 genes changed' and plotted at the same scale so that the width of the graph represents the number of genes that were significantly increased or decreased by ECS (Altar et al, 2004).

enhanced intracellular signaling through MAP kinase, RAS, and cAMP by antidepressant therapies (Mathew et al, 2008; Duman et al, 1997; Skolnick et al, 2001; Altar, 1999). These may represent novel targets for depression that avoid the nonspecific effects of ECT (Table Box 3).

ECS is also a potent inducer of hippocampal neurogenesis (Hellsten et al, 2002; Madsen et al, 2000) and ECS increases the sprouting of serotonin fibers (Madhav et al, 2001) and mossy fibers from dentate granule neurons (Chen et al, 2001). Twelve of the genes augmented by ECS might contribute to these actions. These include BDNF, TrkB, HES-1, neuritin, glypican, protein tyrosine phosphatase, Vesl/homer and its isoform, CREM, and neurofilament genes. Neuritin, similar to glypican, encodes a neuronal protein that promotes the outgrowth and branching of neuritic processes in hippocampal and cortical cells, where 


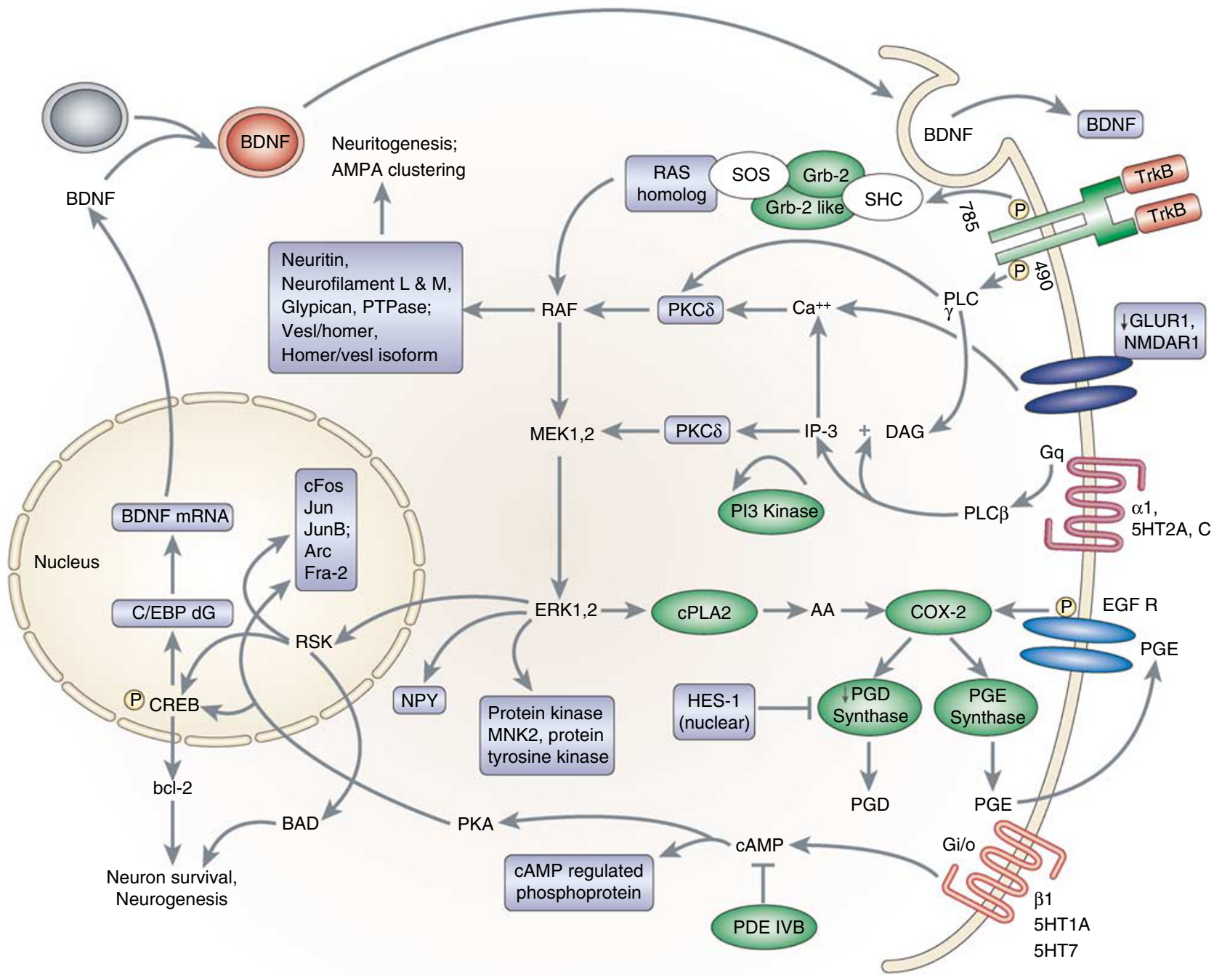

Figure 13. Biochemical pathways implicated in the responses to ECS, based on statistically significant increases in gene expression (colored rectangle or oval labels) in the rodent hippocampus and/or frontal cortex following chronic ECS (Altar et al, 2005). GLUR1 and PGD synthase were decreased by ECS. Also reported by other groups in response to ECS, these genes included those within neurotrophic signaling pathways, including those for BDNF/ MAP kinase, CAMP, and arachidonic acid signaling.

it is highly expressed (Naeve et al, 1997). Interestingly, dorsal raphe serotonin cell bodies are diminished by over $50 \%$ (Arango et al, 2001), and serotonergic axon densities are decreased by $24 \%$ in the deeper layers of DLPFC of suicide patients with MDD (Austin et al, 2002). The ability of BDNF (Mamounas et al, 1995) and ECS (Madhav et al, 2001) to augment serotonergic axon fiber densities in intact or fiber-lesioned rats is consistent with an antidepressant effect of BDNF (Siuciak et al, 1997) and may be mediated through a BDNF- and glutamate-stimulated neuritin/Vesl/ homer pathway (Altar, 1999; Naeve et al, 1997; Sato et al, 2001).

Eleven genes, including BDNF, Cox-2, Vesl/homer, VGF, NGF-inducible clone $\mathrm{C}$, are upregulated in rat hippocampus by exercise (Molteni et al, 2002; Russo-Neustadt et al, 1999; Tong et al, 2001) and by ECS in the hippocampus (Altar et al, 2004). These overlapping genes are of particular interest because of the moderate antidepressant and neurogenic effects of exercise (Craft et al, 2007; Labbe et al, 1988). VGF expression is decreased in the hippocampus of mice rendered helpless by forced swimming (Thakker-Varia et al, 2007). Similar to BDNF (Siuciak et al, 1997), intracranial infusions to mice of a synthetic VGF-derived peptide (Hunsberger et al, 2007) or VGF itself (Thakker-Varia et al, 2007) produce antidepressant-like responses in the forced swim and tail suspension tests. Mice lacking the VGF gene show a pro-depressant effect and an attenuated antidepressant-like response to exercise (Hunsberger et al, 2007). These findings, and the ability of imipramine as well as ECS to elevate arc and VGF protein levels in the hippocampus (Thakker-Varia et al, 2007), suggest that enhanced VGF expression by BDNF signaling could be a mechanism for antidepressant agents. BDNF induction of hippocampal VGF, arc, c-fos, EGR1, and other genes through MAP kinase (Alder et al, 2003) is consistent with this proposal. 
Table Box 3 Potential Antidepressant Pathways and Associated Gene Targets Based on the Predominant Pathways Summarized in Figure I3

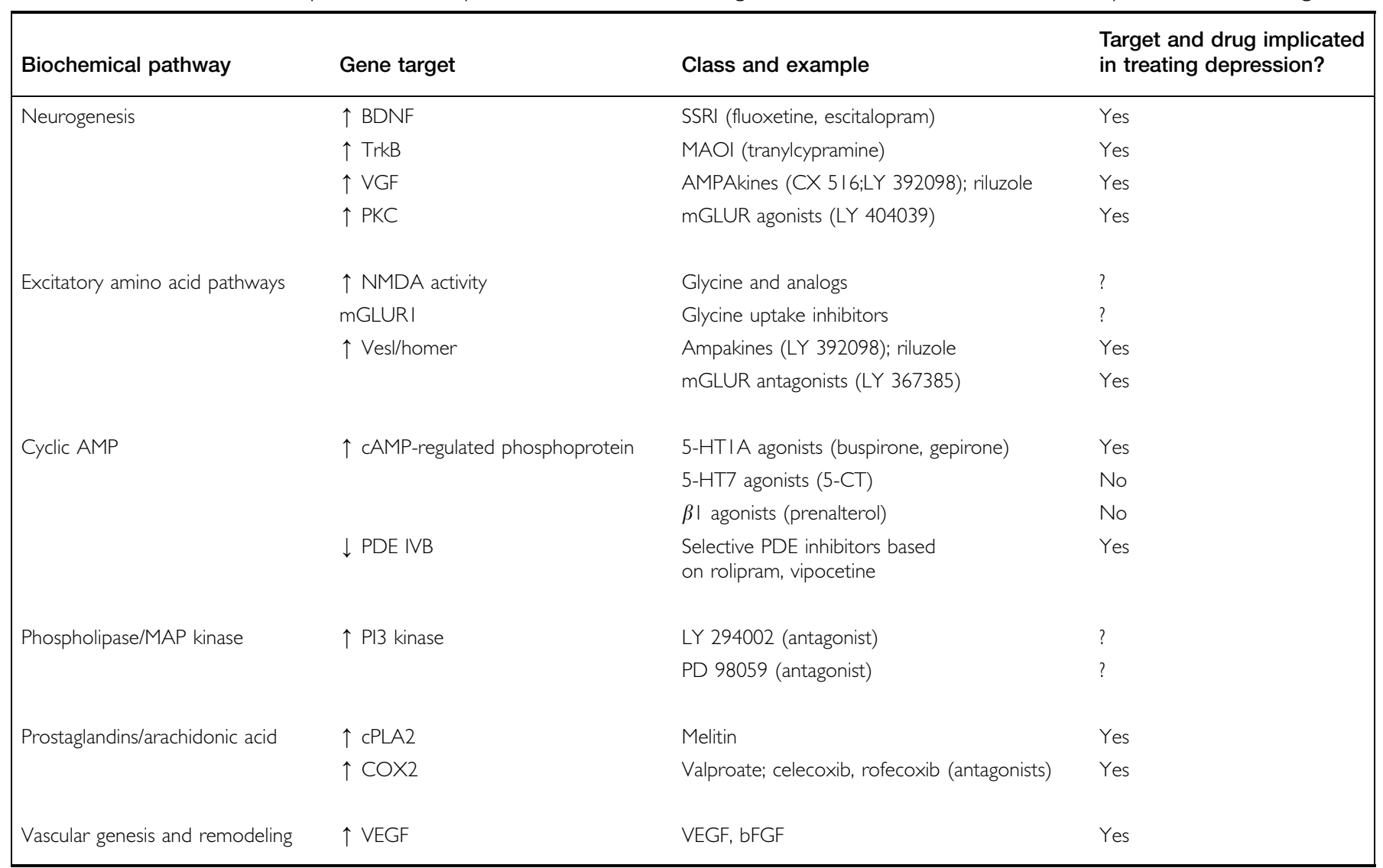

Validation by drugs used to treat depression is indicated in the last column.

\section{FUTURE RESEARCH DIRECTIONS}

The present review has identified genes and pathways as candidates for understanding psychiatric and neurodegenerative diseases, as well as possible targets for drug discovery. We reported findings from human brain tissues that were replicated in multiple cohorts of cases and by multiple laboratories, or were confirmed by protein-based immunohistochemistry, ELISA, or other detection methods, or by more precise RNA detection methods such as RTPCR. A far larger number of genes can be found in the literature that did not meet these criteria, and thus were not described here.

As exemplified by glutamate-glutamine shuttling, mitochondrial metabolic processes, FGF and neurotrophic factor signaling, responses to ECS, and pathways mediated by several G-protein-coupled receptors, multiple genes could be assembled into pathways. The aggregate functions of these pathways appear to be compromised in CNS disease. Some gene clusters seemed to be implicated in diverse diseases (eg, neurotransmitters, 14-3-3 proteins, glutamate binding and transport, metabolic dysfunction), but in general, each disease appears to involve distinct genes and pathways. These findings represent a start to a more complete picture of dysregulation. As new findings emerge, it is likely that some findings reported here will fall by the wayside, whereas others will be reinforced.

These multi-gene and pathway targets provide a novel approach to identify compounds based on their ability to alter genes in a desired manner. This screening approach (Figure 1) was demonstrated for schizophrenia and depression, where proven therapeutic approaches (muscarinic agonism and ECS, respectively) alter genes in neuron cultures or rodent brain in a reciprocal manner to their change in diseased brain, and in a similar manner to other therapeutic approaches, such as exercise for depression. It will be of interest to see whether new treatment modalities, such as transcranial magnetic stimulation for depression, or metabotropic GluR agonists for schizophrenia or anxiety, alter a subset of the same genes as do established therapies, or reciprocally alter disease signature genes.

Compounds identified by multi-gene screening will still require preclinical proof of concept through the use of in vivo models. In schizophrenia, these may include existing models, such as pre-pulse inhibition of startle responses, PCP models of psychosis, and models of working memory and cognition. But compounds discovered through actions on novel drug targets will probably require novel models, such as mice with heterozygous deletions or overexpression of receptors implicated in the identified pathways. It will 
also be valuable to determine proof of concept in animal models, such as in mouse strains prone to depressive-like behaviors, for which a manipulation by ECS or administration of the newly implicated factor, VGF, produces antidepressant-like effects.

An alternative proof-of-concept approach is to determine whether genes identified in the brains of affected patients are altered in a reciprocal manner in the homologous brain area of animals exposed to candidate and therapeutic compounds. For example, the rapid antidepressant response to intravenous injections of the NMDA antagonist ketamine (Zarate et al, 2006; Berman et al, 2000) increases interest in the genes in mood disorders (Vawter et al, 2006; Aston et al, 2005) that may also be affected by ketamine administration (Lowe et al, 2007). Such ketamine-responsive genes may help identify rapidly acting antidepressants (Zarate et al, 2006; Mathew et al, 2008; Maeng et al, 2008). In either case, lead compounds will need to be evaluated with more traditional ADME/toxicology and PK/PD models to satisfy FDA requirements for clinical testing prior to phase I and II trials. Measures of target mRNA changes in brain can be combined with traditional measures, such as in vivo binding or enzyme changes, to answer traditional questions in drug development such as blood-brain barrier penetration, oral availability, and dosing ranges. This information can be used to maximize efficacy in new behavioral tests.

The era of CNS functional genomics is in its infancy, but is starting to provide a list of options for rational drug design that go beyond the re-derivatization of marketed drugs that have modest effects. The discoveries of drug candidates that treat $\mathrm{AD}, \mathrm{PD}$, depression, psychosis, and BPD through interactions with non-monoaminergic targets provide an exciting opportunity to reconcile their novel mechanisms with genes reported here, and with the gene effects of anti-Parkinsonian drugs, antidepressants, antipsychotics, and mood stabilizers. In the interim, gene discovery may reinforce targets that are already being pursued, and help guide the selection of secondary models. Only by testing in humans will the validity of the CNS pharmacogenomic approach to drug discovery be determined.

\section{ACKNOWLEDGEMENTS}

Dr Vawter received funding from NIMH Biomarker Grant, NIMH Conte Center For Genetics of Depression, Pritzker Neuropsychiatric Disorders Research Consortium, and William Lion Penzner Foundation. Dr Ginsberg is supported by grants NS48447, AG14449, AG17617, and the Alzheimer's Association.

\section{DISCLOSURE/CONFLICT OF INTEREST}

Dr Marquis Vawter is a co-inventor on three patent applications regarding gene expression for several genes described in this article. If any of the pending patent applications are accepted, Dr Vawter could eventually receive a partial share of royalties. Otherwise, the authors declare that, except for income received from our primary employers, no financial support or compensation has been received from any individual or corporate entity over the past three years, and no personal financial holdings exist, that could be perceived as constituting a potential conflict of interest.

\section{REFERENCES}

Abe T, Tohgi $H$, Isobe C, Murata T, Sato C (2002). Remarkable increase in the concentration of 8-hydroxyguanosine in cerebrospinal fluid from patients with Alzheimer's disease. J Neurosci Res 70: 447-450.

$\mathrm{ABI}$ (2004). Guide to Performing Relative Quantitation of Gene Expression Using Real-Time Quantitative PCR. Applied Biosystems Inc., Foster City, CA, Product Guide. pp 1-60.

Addington AM, Gornick M, Duckworth J, Sporn A, Gogtay N, Bobb A et al (2005). GAD1 (2q31.1) which encodes glutamic acid decarboxylase (GAD67), is associated with childhood-onset schizophrenia and cortical gray matter volume loss. Mol Psychiatry 10: 581-588.

Agarwal-Mawal A, Qureshi HY, Cafferty PW, Yuan Z, Han D, Lin R et al (2003). 14-33 connects glycogen synthase kinase-3 beta to tau within a brain microtubuleassociated tau phosphorylation complex. J Biol Chem 278: 12722-12728.

Akbarian S, Kim JJ, Potkin SG, Hagman JO, Tafazzoli A, Bunney Jr WE et al (1995). Gene expression for glutamic acid decarboxylase is reduced without loss of neurons in prefrontal cortex of schizophrenics. Arch Gen Psychiatry 52 258-266

Alder J, Thakker-Varia S, Bangasser DA, Kuroiwa M, Plummer MR, Shors TJ et al (2003). Brain-derived neurotrophic factor-induced gene expression reveals nove actions of VGF in hippocampal synaptic plasticity. J Neurosci 23: 10800-10808.

Altar CA (1999). Neurotrophins and depression. Trends Pharmacol Sci 20: 59-61.

Altar CA, Hunt RA, Jurata LW, Webster MJ, Derby E, Gallagher P et al (2008). Insulin, IGF-1, and muscarinic agonists modulate schizophrenia-associated genes in human neuroblastoma cells. Biol Psychiatry (in press).

Altar CA, Jurata LW, Charles V, Lemire A, Liu P, Bukhman Y et al (2005). Deficient hippocampal neuron expression of proteasome, ubiquitin, and mitochondrial genes in multiple schizophrenia cohorts. Biol Psychiatry 58: 85-96.

Altar CA, Laeng P, Jurata LW, Brockman JA, Lemire A, Bullard J et al (2004). Electroconvulsive seizures regulate gene expression of distinct neurotrophic signaling pathways. J Neurosci 24: 2667-2677.

Altar CA, Marshall JF (1988). Neostriatal dopamine uptake and reversal of agerelated movement disorders with dopamine-uptake inhibitors. Ann NY Acad Sci 515: 343-354.

Altar CA, Martin A, Thurkauf A (2003a). Antipsychotic agents. In: Abraham DJ (ed). Burger's Medicinal Chemistry and Drug Discovery. Wiley \& Sons: Hoboken. pp 599-672.

Altar CA, Wasley AM, Neale RF, Stone GA (1986). Typical and atypical antipsychotic occupancy of D2 and S2 receptors: an autoradiographic analysis in rat brain. Brain Res Bull 16: 517-525.

Altar CA, Whitehead RE, Chen R, Wortwein G, Madsen TM (2003b). Effects of electroconvulsive seizures and antidepressant drugs on brain-derived neurotrophic factor protein in rat brain. Biol Psychiatry 54: 703-709.

Amenta F, Mignini F, Ricci A, Sabbatini M, Tomassoni D, Tayebati SK (2001). Agerelated changes of dopamine receptors in the rat hippocampus: a light microscope autoradiography study. Mech Ageing Dev 122: 2071-2083.

Anand R, Seiberling M, Kamtchoua T, Pokorny R (2007). Tolerability, safety and pharmacokinetics of the FGLL peptide, a novel mimetic of neural cell adhesion molecule, following intranasal administration in healthy volunteers. Clin Pharmacokinet 46: 351-358.

Andersen CL, Jensen JL, Orntoft TF (2004). Normalization of real-time quantitative reverse transcription-PCR data: a model-based variance estimation approach to identify genes suited for normalization, applied to bladder and colon cancer data sets. Cancer Res 64: 5245-5250.

Anderson AA, Kendal CE, Garcia-Maya M, Kenny AV, Morris-Triggs SA, Wu T et al (2005). A peptide from the first fibronectin domain of NCAM acts as an inverse agonist and stimulates FGF receptor activation, neurite outgrowth and survival J Neurochem 95: 570-583.

Andorfer C, Acker CM, Kress Y, Hof PR, Duff K, Davies P (2005). Cell-cycle reentry and cell death in transgenic mice expressing nonmutant human tau isoforms. J Neurosci 25: 5446-5454. 
Andreu P, Colnot S, Godard C, Laurent-Puig P, Lamarque D, Kahn A et al (2006). Identification of the IFITM family as a new molecular marker in human colorectal tumors. Cancer Res 66: 1949-1955.

Ang ET, Gomez-Pinilla F (2007). Potential therapeutic effects of exercise to the brain. Curr Med Chem 14: 2564-2571.

Aoyama S, Koga K, Mori A, Miyaji H, Sekine S, Kase H et al (2002). Distribution of adenosine $\mathrm{A}(2 \mathrm{~A})$ receptor antagonist $\mathrm{KW}-6002$ and its effect on gene expression in the rat brain. Brain Res 953: 119-125.

Arango V, Underwood MD, Boldrini M, Tamir H, Kassir SA, Hsiung S et al (2001). Serotonin $1 \mathrm{~A}$ receptors, serotonin transporter binding and serotonin transporter mRNA expression in the brainstem of depressed suicide victims. Neuropsychopharmacology 25: 892-903.

Arion D, Unger T, Lewis DA, Levitt P, Mirnics K (2007). Molecular evidence for increased expression of genes related to immune and chaperone function in the prefrontal cortex in schizophrenia. Biol Psychiatry 62: 711-721.

Aston C, Jiang L, Sokolov BP (2004). Microarray analysis of postmortem temporal cortex from patients with schizophrenia. J Neurosci Res 77: 858-866.

Aston C, Jiang L, Sokolov BP (2005). Transcriptional profiling reveals evidence for signaling and oligodendroglial abnormalities in the temporal cortex from patients with major depressive disorder. Mol Psychiatry 10: 309-322.

Austin MC, Whitehead RE, Edgar CL, Janosky JE, Lewis DA (2002). Localized decrease in serotonin transporter-immunoreactive axons in the prefrontal cortex of depressed subjects committing suicide. Neuroscience 114: 807-815.

Bachmann RF, Schloesser RJ, Gould TD, Manji HK (2005). Mood stabilizers target cellular plasticity and resilience cascades: implications for the development of novel therapeutics. Mol Neurobiol 32: 173-202.

Bahn S, Augood SJ, Ryan M, Standaert DG, Starkey M, Emson PC (2001). Gene expression profiling in the post-mortem human brain-no cause for dismay. J Chem Neuroanat 22: 79-94.

Baker C, Belbin O, Kalsheker N, Morgan K (2007). SERPINA3 (aka alpha-1antichymotrypsin). Front Biosci 12: 2821-2835.

Barbier E, Zapata A, Oh E, Liu Q, Zhu F, Undie A et al (2007). Supersensitivity to amphetamine in protein kinase-C interacting protein/HINT1 knockout mice. Neuropsychopharmacology 32: 1774-1782.

Barja G (2004). Free radicals and aging. Trends Neurosci 27: 595-600.

Barton AJL, Pearson RCA, Najlerahim A, Harrison PJ (1993). Pre- and postmortem influences on brain RNA. J Neurochem 61: 1-11.

Bartus RT (2000). On neurodegenerative diseases, models, and treatment strategies: lessons learned and lessons forgotten a generation following the cholinergic hypothesis. Exp Neurol 163: 495-529.

Beasley CL, Pennington K, Behan A, Wait R, Dunn MJ, Cotter D (2006). Proteomic analysis of the anterior cingulate cortex in the major psychiatric disorders: evidence for disease-associated changes. Proteomics 6: 3414-3425.

Beasley CL, Reynolds GP (1997). Parvalbumin-immunoreactive neurons are reduced in the prefrontal cortex of schizophrenics. Schizophr Res 24: 349-355.

Behan A, Byrne C, Dunn MJ, Cagney G, Cotter DR (2008). Proteomic analysis of membrane microdomain-associated proteins in the dorsolateral prefrontal cortex in schizophrenia and bipolar disorder reveals alterations in LAMP, STXBP1 and BASP1 protein expression. Mol Psychiatry.

Bell R, Munro J, Russ C, Powell JF, Bruinvels A, Kerwin RW et al (2000). Systematic screening of the 14-3-3 eta (eta) chain gene for polymorphic variants and casecontrol analysis in schizophrenia. Am J Med Genet 96: 736-743.

Benes FM, Berretta S (2000). Amygdalo-entorhinal inputs to the hippocampal formation in relation to schizophrenia. Ann NY Acad Sci 911: 293-304.

Benes FM, Lim B, Matzilevich D, Walsh JP, Subburaju S, Minns M (2007). Regulation of the GABA cell phenotype in hippocampus of schizophrenics and bipolars. Proc Natl Acad Sci USA 104: 10164-10169.

Bennett DA, Wilson RS, Schneider JA, Evans DA, Beckett LA, Aggarwal NT et al (2002). Natural history of mild cognitive impairment in older persons. Neurology 59: 198-205.

Berezin V, Bock E (2004). NCAM mimetic peptides: pharmacological and therapeutic potential. J Mol Neurosci 22: 33-39.

Berg D, Holzmann C, Riess O (2003). 14-3-3 proteins in the nervous system. Nat Rev Neurosci 4: 752-762.

Berger UV, Hediger MA (2006). Distribution of the glutamate transporters GLT-1 (SLC1A2) and GLAST (SLC1A3) in peripheral organs. Anat Embryol (Berl) 211: 595-606.

Berman RM, Cappiello A, Anand A, Oren DA, Heninger GR, Charney DS et al (2000). Antidepressant effects of ketamine in depressed patients. Biol Psychiatry 47: 351-354.

Bertram L, McQueen MB, Mullin K, Blacker D, Tanzi RE (2007). Systematic metaanalyses of Alzheimer disease genetic association studies: the AlzGene database. Nat Genet 39: 17-23.
Bertsch B, Ogden CA, Sidhu K, Le-Niculescu H, Kuczenski R, Niculescu AB (2005) Convergent functional genomics: a Bayesian candidate gene identification approach for complex disorders. Methods 37: 274-279.

Beveridge NJ, Tooney PA, Carroll AP, Gardiner E, Bowden N, Scott RJ et al (2008). Dysregulation of miRNA $181 \mathrm{~b}$ in the temporal cortex in schizophrenia. Hum Mol Genet 17: 1156-1168.

Blalock EM, Chen KC, Sharrow K, Herman JP, Porter NM, Foster TC et al (2003). Gene microarrays in hippocampal aging: statistical profiling identifies novel processes correlated with cognitive impairment. J Neurosci 23: 3807-3819.

Blalock EM, Geddes JW, Chen KC, Porter NM, Markesbery WR, Landfield PW (2004). Incipient Alzheimer's disease: microarray correlation analyses reveal major transcriptional and tumor suppressor responses. Proc Natl Acad Sci USA 101: 2173-2178.

Bleuler E (1950). Dementia Praecox or the Group of Schizophrenias. International Universities Press: New York.

Boissiere F, Faucheux B, Ruberg M, Agid Y, Hirsch EC (1997). Decreased TrkA gene expression in cholinergic neurons of the striatum and basal forebrain of patients with Alzheimer's disease. Exp Neurol 145: 245-252.

Bonner RF, Emmert-Buck M, Cole K, Pohida T, Chuaqui R, Goldstein S et al (1997). Laser capture microdissection: molecular analysis of tissue. Science $\mathbf{2 7 8}$ 1481-1483.

Boscher C, Mege RM (2008). Cadherin-11 interacts with the FGF receptor and induces neurite outgrowth through associated downstream signalling. Cell Signal 20: 1061-1072.

Bosetti F, Bell JM, Manickam P (2005). Microarray analysis of rat brain gene expression after chronic administration of sodium valproate. Brain Res Bull 65 : 331-338.

Brenner C (2002). Hint, Fhit, and GalT: function, structure, evolution, and mechanism of three branches of the histidine triad superfamily of nucleotide hydrolases and transferases. Biochemistry 41: 9003-9014.

Bridges D, Moorhead GB (2005). 14-3-3 proteins: a number of functions for a numbered protein. Sci STKE 2005: re10.

Brooks WM, Lynch PJ, Ingle CC, Hatton A, Emson PC, Faull RL et al (2007). Gene expression profiles of metabolic enzyme transcripts in Alzheimer's disease. Brain Res 1127: 127-135.

Brown PO, Botstein D (1999). Exploring the new world of the genome with DNA microarrays. Nat Genet 21: 33-37.

Bruneau EG, McCullumsmith RE, Haroutunian V, Davis KL, Meador-Woodruff JH (2005). Increased expression of glutaminase and glutamine synthetase mRNA in the thalamus in schizophrenia. Schizophr Res 75: 27-34.

Bunney WE, Bunney BG, Vawter MP, Tomita H, Li J, Evans SJ et al (2003). Microarray technology: a review of new strategies to discover candidate vulnerability genes in psychiatric disorders. Am J Psychiatry 160: 657-666.

Burbaeva GS, Boksha IS, Turishcheva MS, Vorobyeva EA, Savushkina OK, Tereshkina EB (2003). Glutamine synthetase and glutamate dehydrogenase in the prefrontal cortex of patients with schizophrenia. Prog Neuropsychopharmacol Biol Psychiatry 27: 675-680.

Bustany P, Trenque T, Crambes O, Moulin M (1995). Restoration of brain protein synthesis in mature and aged rats by a DA agonist, piribedil. Fundam Clin Pharmacol 9: 458-468.

Bustin SA (2002). Quantification of mRNA using real-time reverse transcription PCR (RT-PCR): trends and problems. J Mol Endocrinol 29: 23-39.

Bymaster FP, Felder C, Ahmed S, McKinzie D (2002). Muscarinic receptors as a target for drugs treating schizophrenia. Curr Drug Targets CNS Neurol Disord 1: 163-181.

Callahan LM, Vaules WA, Coleman PD (1999). Quantitative decrease in synaptophysin message expression and increase in cathepsin D message expression in Alzheimer disease neurons containing neurofibrillary tangles. J Neuropathol Exp Neurol 58: 275-287.

Carson R, Craig D, McGuinness B, Johnston JA, O'Neill FA, Passmore AP et al (2008). Alpha7 nicotinic acetylcholine receptor gene and reduced risk of Alzheimer's disease. J Med Genet 45: 244-248.

Carter TL, Rissman RA, Mishizen-Eberz AJ, Wolfe BB, Hamilton RL, Gandy S et al (2004). Differential preservation of AMPA receptor subunits in the hippocampi of Alzheimer's disease patients according to Braak stage. Exp Neurol 187: 299-309.

Cecconi D, Mion S, Astner H, Domenici E, Righetti PG, Carboni L (2007). Proteomic analysis of rat cortical neurons after fluoxetine treatment. Brain Res 1135: 41-51.

Chen AC, Shin KH, Duman RS, Sanacora G (2001). ECS-Induced mossy fiber sprouting and BDNF expression are attenuated by ketamine pretreatment. J ECT 17: $27-32$.

Chen JH, Hales CN, Ozanne SE (2007). DNA damage, cellular senescence and organismal ageing: causal or correlative? Nucleic Acids Res 35 7417-7428. 
Cheng MC, Liao DL, Hsiung CA, Chen CY, Liao YC, Chen CH (2008). Chronic treatment with aripiprazole induces differential gene expression in the rat frontal cortex. Int J Neuropsychopharmacol 11: 207-216.

Cheng Y, Black IB, DiCicco-Bloom E (2002). Hippocampal granule neuron production and population size are regulated by levels of bFGF. Eur $\mathrm{J}$ Neurosci 15: 3-12.

Chin MH, Qian WJ, Wang H, Petyuk VA, Bloom JS, Sforza DM et al (2008). Mitochondrial dysfunction, oxidative stress, and apoptosis revealed by proteomic and transcriptomic analyses of the striata in two mouse models of Parkinson's disease. J Proteome Res 4: 4.

Choi J, Levey Al, Weintraub ST, Rees HD, Gearing M, Chin LS et al (2004). Oxidative modifications and down-regulation of ubiquitin carboxyl-terminal hydrolase L1 associated with idiopathic Parkinson's and Alzheimer's diseases. J Biol Chem 279: 13256-13264.

Chong VZ, Thompson M, Beltaifa S, Webster MJ, Law AJ, Weickert CS (2008). Elevated neuregulin-1 and ErbB4 protein in the prefrontal cortex of schizophrenic patients. Schizophr Res 100: 270-280.

Chou TF, Wagner CR (2007). Lysyl-tRNA synthetase-generated lysyl-adenylate is a substrate for histidine triad nucleotide binding proteins. J Biol Chem 282 4719-4727.

Choudary PV, Molnar M, Evans SJ, Tomita H, Li JZ, Vawter MP et al (2005). Altered cortical glutamatergic and GABAergic signal transmission with glial involvement in depression. Proc Natl Acad Sci USA 102: 15653-15658.

Christensen C, Lauridsen JB, Berezin V, Bock E, Kiselyov WV (2006). The neural cell adhesion molecule binds to fibroblast growth factor receptor 2. FEBS Lett 580: 3386-3390.

Chu Y, Le W, Kompoliti K, Jankovic J, Mufson EJ, Kordower JH (2006). Nurr1 in Parkinson's disease and related disorders. J Comp Neurol 494: 495-514.

Colangelo V, Schurr J, Ball MJ, Pelaez RP, Bazan NG, Lukiw WJ (2002). Gene expression profiling of 12633 genes in Alzheimer hippocampal CA1: transcription and neurotrophic factor down-regulation and up-regulation of apoptotic and proinflammatory signaling. J Neurosci Res 70: 462-473.

Counts SE, He B, Che S, Ikonomovic MD, Dekosky ST, Ginsberg SD et al (2007). \{alpha\}7 Nicotinic receptor up-regulation in cholinergic basal forebrain neurons in Alzheimer disease. Arch Neurol 64: 1771-1776.

Couve A, Kittler JT, Uren JM, Calver AR, Pangalos MN, Walsh FS et al (2001). Association of GABA(B) receptors and members of the 14-3-3 family of signaling proteins. Mol Cell Neurosci 17: 317-328.

Craft LL, Freund KM, Culpepper L, Perna FM (2007). Intervention study of exercise for depressive symptoms in women. J Womens Health 16: 1499-1509.

Crino PB, Khodakhah K, Becker K, Ginsberg SD, Hemby S, Eberwine JH (1998). Presence and phosphorylation of transcription factors in dendrites. Proc Nat Acad Sci USA 95: 2313-2318.

de Magalhaes JP (2004). From cells to ageing: a review of models and mechanisms of cellular senescence and their impact on human ageing. Exp Cell Res 300: $1-10$

de Magalhaes JP, Costa J, Toussaint O (2005). HAGR: the Human Ageing Genomic Resources. Nucleic Acids Res 33(Database issue): D537-D543.

Dean B, Boer SA, Mackinnon A, Berk M (2007). CNS 14-3-3zeta: changes with sex but not psychiatric diagnoses or psychotropic drug treatment. Schizophr Res 93 $51-57$

Dickey CA, Loring JF, Montgomery J, Gordon MN, Eastman PS, Morgan D (2003). Selectively reduced expression of synaptic plasticity-related genes in amyloid precursor protein+presenilin-1 transgenic mice. J Neurosci 23 5219-5226.

Doherty P, Walsh FS (1996). CAM-FGF receptor interactions: a model for axonal growth. Mol Cell Neurosci 8: 99-111.

Duan S, Gao R, Xing Q, Du J, Liu Z, Chen Q et al (2005). A family-based association study of schizophrenia with polymorphisms at three candidate genes. Neurosci Lett 379: 32-36.

Duke DC, Moran LB, Kalaitzakis ME, Deprez M, Dexter DT, Pearce RK et al (2006). Transcriptome analysis reveals link between proteasomal and mitochondrial pathways in Parkinson's disease. Neurogenetics 7: 139-148.

Duman RS, Heninger GR, Nestler EJ (1997). A molecular and cellular theory of depression. Arch Gen Psychiatry 54: 597-606.

Dwivedi Y, Mondal AC, Rizavi HS, Conley RR (2005). Suicide brain is associated with decreased expression of neurotrophins. Biol Psychiatry 58: 315-324.

Dwivedi Y, Rizavi HS, Conley RR, Roberts RC, Tamminga CA, Pandey GN (2003). Altered gene expression of brain-derived neurotrophic factor and receptor tyrosine kinase B in postmortem brain of suicide subjects. Arch Gen Psychiatry 60: 804-815.

Eberwine J, Kacharmina JE, Andrews C, Miyashiro K, Mclntosh T, Becker K et al (2001). mRNA expression analysis of tissue sections and single cells. J Neurosci 21: 8310-8314.
Eells JB, Lipska BK, Yeung SK, Misler JA, Nikodem VM (2002). Nurr1-null heterozygous mice have reduced mesolimbic and mesocortical dopamine levels and increased stress-induced locomotor activity. Behav Brain Res 136: 267-275.

Ehrenreich H, Bartels C, Sargin D, Stawicki S, Krampe H (2008). Recombinant human erythropoietin in the treatment of human brain disease: focus on cognition. J Ren Nutr 18: 146-153.

Ehrenreich H, Degner D, Meller J, Brines M, Behe M, Hasselblatt M et al (2004). Erythropoietin: a candidate compound for neuroprotection in schizophrenia. $\mathrm{Mol}$ Psychiatry 9: 42-54.

El-Hariry I, Pignatelli M, Lemoine NR (2001a). FGF-1 and FGF-2 modulate the Ecadherin/catenin system in pancreatic adenocarcinoma cell lines. $\mathrm{Br} J$ Cancer 84: 1656-1663.

El-Hariry I, Pignatelli M, Lemoine NR (2001b). FGF-1 and FGF-2 regulate the expression of E-cadherin and catenins in pancreatic adenocarcinoma. Int $J$ Cancer 94: 652-661.

Elashoff M, Higgs BW, Yolken RH, Knable MB, Weis S, Webster MJ et al (2007). Meta-analysis of 12 genomic studies in bipolar disorder. J Mol Neurosci 31: 221-243.

Emmert-Buck MR, Bonner RF, Smith PD, Chuaqui RF, Zhuang Z, Goldstein SR et al (1996). Laser capture microdissection. Science 274: 998-1001.

Evans SJ, Choudary PV, Neal CR, Li JZ, Vawter MP, Tomita H et al (2004) Dysregulation of the fibroblast growth factor system in major depression. Proc Natl Acad Sci USA 101: 15506-15511.

Evans SJ, Choudary PV, Vawter MP, Li J, Meador-Woodruff JH, Lopez JF et al (2003). DNA microarray analysis of functionally discrete human brain regions reveals divergent transcriptional profiles. Neurobiol Dis 14: 240-250.

Eyles D, Almeras L, Benech P, Patiatian A, Mackay-Sim A, McGrath J et al (2007). Developmental vitamin $D$ deficiency alters the expression of genes encoding mitochondrial, cytoskeletal and synaptic proteins in the adult rat brain. $J$ Steroid Biochem Mol Biol 103: 538-545.

Faber R, Trimble MR (1991). Electroconvulsive therapy in Parkinson's disease and other movement disorders. Mov Disord 6: 293-303.

Fatemi SH, Reutiman TJ, Folsom TD, Bell C, Nos L, Fried P et al (2006). Chronic olanzapine treatment causes differential expression of genes in frontal cortex of rats as revealed by DNA microarray technique. Neuropsychopharmacology 31 1888-1899.

Fearnley JM, Lees AJ (1991). Ageing and Parkinson's disease: substantia nigra regional selectivity. Brain 114: 2283-2301.

Fend F, Emmert-Buck MR, Chuaqui R, Cole K, Lee J, Liotta LA et al (1999). Immuno-LCM: laser capture microdissection of immunostained frozen sections for mRNA analysis. Am J Pathol 154: 61-66.

Fenu S, Pinna A, Ongini E, Morelli M (1997). Adenosine A2A receptor antagonism potentiates L-DOPA-induced turning behaviour and c-fos expression in 6 hydroxydopamine-lesioned rats. Eur J Pharmacol 321: 143-147.

Freeman WM, Hemby SE (2004). Proteomics for protein expression profiling in neuroscience. Neurochem Res 29: 1065-1081.

Frizzo ME, Dall'Onder LP, Dalcin KB, Souza DO (2004). Riluzole enhances glutamate uptake in rat astrocyte cultures. Cell Mol Neurobiol 24: 123-128.

Galvin JE, Ginsberg SD (2005). Expression profiling in the aging brain: a perspective. Ageing Res Rev 4: 529-547.

Ganguly S, Gastel JA, Weller JL, Schwartz C, Jaffe H, Namboodiri MA et al (2001). Role of a pineal CAMP-operated arylalkylamine $N$-acetyltransferase/14-3-3 binding switch in melatonin synthesis. Proc Natl Acad Sci USA 98: 8083-8088.

Garver DL, Tamas RL, Holcomb JA (2003). Elevated interleukin-6 in the cerebrospinal fluid of a previously delineated schizophrenia subtype. Neuropsychopharmacology 28: 1515-1520.

Gaughran F, Payne J, Sedgwick PM, Cotter D, Berry M (2006). Hippocampal FGF-2 and FGFR1 mRNA expression in major depression, schizophrenia and bipolar disorder. Brain Res Bull 70: 221-227.

Gems D, McElwee JJ (2003). Ageing: microarraying mortality. Nature 424 259-261.

Ginsberg SD (2007). Expression profile analysis of brain aging. In: Riddle DR (ed). Brain Aging: Models, Methods and Mechanisms. CRC Press: New York. pp 159-185.

Ginsberg SD, Che S, Counts SE, Mufson EJ (2006a). Shift in the ratio of threerepeat tau and four-repeat tau mRNAs in individual cholinergic basal forebrain neurons in mild cognitive impairment and Alzheimer's disease. J Neurochem 96 1401-1408.

Ginsberg SD, Che S, Counts SE, Mufson EJ (2006b). Single cell gene expression profiling in Alzheimer's disease. NeuroRx 3: 302-318.

Ginsberg SD, Che S, Wuu J, Counts SE, Mufson EJ (2006c). Down regulation of trk but not p75 gene expression in single cholinergic basal forebrain neurons mark the progression of Alzheimer's disease. J Neurochem 97: 475-487.

Ginsberg SD, Crino PB, Hemby SE, Weingarten JA, Lee VM-Y, Eberwine JH et al (1999a). Predominance of neuronal mRNAs in individual Alzheimer's disease senile plaques. Ann Neurol 45: 174-181. 
Ginsberg SD, Crino PB, Lee VM-Y, Eberwine JH, Trojanowski JQ (1997). Sequestration of RNA in Alzheimer's disease neurofibrillary tangles and senile plaques. Ann Neurol 41: 200-209.

Ginsberg SD, Elarova I, Ruben M, Tan F, Counts SE, Eberwine JH et al (2004). Single cell gene expression analysis: implications for neurodegenerative and neuropsychiatric disorders. Neurochem Res 29: 1054-1065.

Ginsberg SD, Galvin JE, Chiu T-S, Lee VM-Y, Masliah E, Trojanowski JQ (1998). RNA sequestration to pathological lesions of neurodegenerative disorders. Acta Neuropathol 96: 487-494.

Ginsberg SD, Hemby SE, Lee VM-Y, Eberwine JH, Trojanowski JQ (2000). Expression profile of transcripts in Alzheimer's disease tangle-bearing CA1 neurons. Ann Neurol 48: 77-87.

Ginsberg SD, Hemby SE, Mufson EJ, Martin LJ (2006d). Cell and tissue microdissection in combination with genomic and proteomic applications. In: Zaborszky L, Wouterlood FG, Lanciego JL (eds). Neuroanatomical Tract Tracing 3: Molecules, Neurons, and Systems. Springer: New York. pp 109-141.

Ginsberg SD, Mirnics K (2006). Functional genomic methodologies. Prog Brain Res 158: $15-40$.

Ginsberg SD, Schmidt ML, Crino PB, Eberwine JH, Lee VM-Y, Trojanowski JQ (1999b). Molecular pathology of Alzheimer's disease and related disorders. In: Peters A, Morrison JH (eds). Cerebral Cortex. Neurodegenerative and AgeRelated Changes in Structure and Function of Cerebral Cortex, vol. 14 Kluwer Academic/Plenum: New York. pp 603-653.

Gluck MR, Thomas RG, Davis KL, Haroutunian V (2002). Implications for altered glutamate and GABA metabolism in the dorsolateral prefrontal cortex of aged schizophrenic patients. Am J Psychiatry 159: 1165-1173.

Goedert M, Jakes R (2005). Mutations causing neurodegenerative tauopathies. Biochim Biophys Acta 1739: 240-250.

Golden TR, Melov S (2004). Microarray analysis of gene expression with age in individual nematodes. Aging Cell 3: 111-124.

Goldsworthy SM, Stockton PS, Trempus CS, Foley JF, Maronpot RR (1999). Effects of fixation on RNA extraction and amplification from laser capture microdissected tissue. Mol Carcinog 25: 86-91.

Goodnick PJ (2006). Anticonvulsants in the treatment of bipolar mania. Expert Opin Pharmacother 7: 401-410.

Gotz J (2001). Tau and transgenic animal models. Brain Res Brain Res Rev 35: 266-286.

Gould TD, Quiroz JA, Singh J, Zarate CA, Manji HK (2004). Emerging experimental therapeutics for bipolar disorder: insights from the molecular and cellular actions of current mood stabilizers. Mol Psychiatry 9: 734-755.

Granata R, Wenning GK, Jolkkonen J, Jenner P, Marsden CD (1996). Effect of repeated administration of dopamine agonists on striatal neuropeptide mRNA expression in rats with a unilateral nigral 6-hydroxydopamine lesion. J Neural Transm 103: 249-260.

Gray L, Scarr E, Dean B (2006). N-Ethylmaleimide sensitive factor in the cortex of subjects with schizophrenia and bipolar I disorder. Neurosci Lett 391: 112-115.

Greene JG, Dingledine R, Greenamyre JT (2005). Gene expression profiling of rat midbrain dopamine neurons: implications for selective vulnerability in Parkinsonism. Neurobiol Dis 18: 19-31.

Grunblatt E, Mandel S, Jacob-Hirsch J, Zeligson S, Amariglo N, Rechavi G et al (2004). Gene expression profiling of parkinsonian substantia nigra pars compacta; alterations in ubiquitin-proteasome, heat shock protein, iron and oxidative stress regulated proteins, cell adhesion/cellular matrix and vesicle trafficking genes. J Neural Transm 111: 1543-1573.

Grunblatt E, Mandel S, Maor G, Youdim MB (2001). Gene expression analysis in Nmethyl-4-phenyl-1,2,3,6-tetrahydropyridine mice model of Parkinson's disease using cDNA microarray: effect of R-apomorphine. J Neurochem 78: 1-12.

Guang W, Wang H, Su T, Weinstein IB, Wang JB (2004). Role of mPKCl, a novel mu-opioid receptor interactive protein, in receptor desensitization, phosphorylation, and morphine-induced analgesia. Mol Pharmacol 66: 1285-1292.

Guidotti A, Auta J, Davis JM, Di-Giorgi-Gerevini V, Dwivedi Y, Grayson DR et al (2000). Decrease in reelin and glutamic acid decarboxylase67 (GAD67) expression in schizophrenia and bipolar disorder: a postmortem brain study. Arch Gen Psychiatry 57: 1061-1069.

Gutala RV, Reddy PH (2004). The use of real-time PCR analysis in a gene expression study of Alzheimer's disease post-mortem brains. J Neurosci Methods 132: 101-107.

Guzzetta F, Tondo L, Centorrino F, Baldessarini RJ (2007). Lithium treatment reduces suicide risk in recurrent major depressive disorder. $J$ Clin Psychiatry 68: 380-383.

Hakak Y, Walker JR, Li C, Wong WH, Davis KL, Buxbaum JD et al (2001). Genomewide expression analysis reveals dysregulation of myelination-related genes in chronic schizophrenia. Proc Natl Acad Sci USA 98: 4746-4751.

Hanson DR, Gottesman II (2005). Theories of schizophrenia: a genetic-inflammatory-vascular synthesis. BMC Med Genet 6: 7.
Haroutunian V, Katsel P, Dracheva S, Stewart DG, Davis KL (2007). Variations in oligodendrocyte-related gene expression across multiple cortical regions: implications for the pathophysiology of schizophrenia. Int $J$ Neuropsychopharmacol 10: 565-573.

Hashimoto T, Arion D, Unger T, Maldonado-Aviles JG, Morris HM, Volk DW et al (2008). Alterations in GABA-related transcriptome in the dorsolateral prefrontal cortex of subjects with schizophrenia. Mol Psychiatry 13: 147-161.

Hashimoto T, Bergen SE, Nguyen QL, Xu B, Monteggia LM, Pierri JN et al (2005). Relationship of brain-derived neurotrophic factor and its receptor TrkB to altered inhibitory prefrontal circuitry in schizophrenia. J Neurosci 25: 372-383.

Hashimoto T, Volk DW, Eggan SM, Mirnics K, Pierri JN, Sun Z et al (2003). Gene expression deficits in a subclass of GABA neurons in the prefrontal cortex of subjects with schizophrenia. J Neurosci 23: 6315-6326.

Hata R, Masumura M, Akatsu H, Li F, Fujita H, Nagai Y et al (2001). Up-regulation of calcineurin Abeta mRNA in the Alzheimer's disease brain: assessment by cDNA microarray. Biochem Biophys Res Commun 284: 310-316.

Hauser ER, Pericak-Vance MA (2000). Genetic analysis for common complex disease. Am Heart J 140: S36-S44.

Hauser MA, Li YJ, Xu H, Noureddine MA, Shao YS, Gullans SR et al (2005). Expression profiling of substantia nigra in Parkinson disease, progressive supranuclear palsy, and frontotemporal dementia with Parkinsonism. Arch Neurol 62: 917-921.

Hayakawa T, Ishiguro $H$, Toru M, Hamaguchi $H$, Arinami T (1998). Systematic search for mutations in the 14-3-3 eta chain gene on chromosome 22 in schizophrenics. Psychiatr Genet 8: 33-36.

Healy D, Whitaker C (2003). Antidepressants and suicide: risk-benefit conundrums. J Psychiatry Neurosci 28: 331-337.

Heffernan JM, Eastwood SL, Nagy Z, Sanders MW, McDonald B, Harrison PJ (1998). Temporal cortex synaptophysin mRNA is reduced in Alzheimer's disease and is negatively correlated with the severity of dementia. Exp Neurol 150 235-239.

Hellsten J, Wennstrom M, Mohapel P, Ekdahl CT, Bengzon J, Tingstrom A (2002). Electroconvulsive seizures increase hippocampal neurogenesis after chronic corticosterone treatment. Eur J Neurosci 16: 283-290.

Hemby SE, Ginsberg SD, Brunk B, Arnold SE, Trojanowski JQ, Eberwine JH (2002). Gene expression profile for schizophrenia: discrete neuron transcription patterns in the entorhinal cortex. Arch Gen Psychiatry 59: 631-640.

Hemby SE, Trojanowski JQ, Ginsberg SD (2003). Neuron-specific age-related decreases in dopamine receptor subtype mRNAs. J Comp Neurol 456: 176-183.

Henshall DC, Araki T, Schindler CK, Lan JQ, Tiekoter KL, Taki W et al (2002). Activation of $\mathrm{Bcl}-2$-associated death protein and counter-response of Akt within cell populations during seizure-induced neuronal death. J Neurosci 22: 84588465.

Higgs BW, Elashoff M, Richman S, Barci B (2006). An online database for brain disease research. BMC Genomics 7: 70.

Ho L, Guo Y, Spielman L, Petrescu O, Haroutunian V, Purohit D et al (2001). Altered expression of a-type but not b-type synapsin isoform in the brain of patients at high risk for Alzheimer's disease assessed by DNA microarray technique. Neurosci Lett 298: 191-194.

Hosack DA, Dennis Jr G, Sherman BT, Lane HC, Lempicki RA (2003). Identifying biological themes within lists of genes with EASE. Genome Biol 4: R70.

Hunsberger JG, Newton SS, Bennett AH, Duman CH, Russell DS, Salton SR et al (2007). Antidepressant actions of the exercise-regulated gene VGF. Nat Med 13 1476-1482.

Hunt-Newbury R, Viveiros R, Johnsen R, Mah A, Anastas D, Fang L et al (2007). High-throughput in vivo analysis of gene expression in Caenorhabditis elegans. PLoS Biol 5: e237.

Hyman BT, Trojanowski JQ (1997). Consensus recommendations for the postmortem diagnosis of Alzheimer disease from the National Institute on Aging and the Reagan Institute Working Group on diagnostic criteria for the neuropathological assessment of Alzheimer disease. J Neuropathol Exp Neurol 56: 1095-1097.

Hyman BT, Van Hoesen GW, Damasio AR, Barnes CL (1984). Alzheimer's disease: cell-specific pathology isolates the hippocampal formation. Science 225: 1168-1170.

Hynd MR, Lewohl JM, Scott HL, Dodd PR (2003). Biochemical and molecular studies using human autopsy brain tissue. J Neurochem 85: 543-562.

Ikonomovic MD, Sheffield R, Armstrong DM (1995). AMPA-selective glutamate receptor subtype immunoreactivity in the hippocampal formation of patients with Alzheimer's disease. Hippocampus 5: 469-486.

Imai C, Sugai T, Iritani S, Niizato K, Nakamura R, Makifuchi T et al (2001). A quantitative study on the expression of synapsin II and $N$-ethylmaleimidesensitive fusion protein in schizophrenic patients. Neurosci Lett 305: 185-188.

Ishihara A, Saito H, Nishiyama N (1992). Basic fibroblast growth factor ameliorates learning deficits in basal forebrain-lesioned mice. Jpn J Pharmacol 59: 7-13. 
Iwamoto K, Bundo M, Kato T (2005). Altered expression of mitochondria-related genes in postmortem brains of patients with bipolar disorder or schizophrenia, as revealed by large-scale DNA microarray analysis. Hum Mol Genet 14: 241-253.

Iwamoto K, Kato T (2006). Gene expression profiling in schizophrenia and related mental disorders. Neuroscientist 12: 349-361.

Iwata S, Nomoto M, Miyata A (2007). Microarray analysis of laser capture microdissected substantia nigra pars compacta after a single administration of MPTP in common marmosets. Nihon Shinkei Seishin Yakurigaku Zasshi 27: 161-166.

Jacob CP, Koutsilieri E, Bartl J, Neuen-Jacob E, Arzberger T, Zander N et al (2007). Alterations in expression of glutamatergic transporters and receptors in sporadic Alzheimer's disease. J Alzheimers Dis 11: 97-116.

Jang SW, Okada M, Sayeed I, Xiao G, Stein D, Jin P et al (2007). Gambogic amide, a selective agonist for TrkA receptor that possesses robust neurotrophic activity, prevents neuronal cell death. Proc Natl Acad Sci USA 2: 2.

Jeanclos EM, Lin L, Treuil MW, Rao J, DeCoster MA, Anand R (2001). The chaperone protein 14-3-3eta interacts with the nicotinic acetylcholine receptor alpha 4 subunit. Evidence for a dynamic role in subunit stabilization. J Biol Chem 276: 28281-28290.

Jia Y, Yu X, Zhang B, Yuan Y, Xu Q, Shen Y (2004). An association study between polymorphisms in three genes of 14-3-3 (tyrosine 3-monooxygenase/tryptophan 5-monooxygenase activation protein) family and paranoid schizophrenia in northern Chinese population. Eur Psychiatry 19: 377-379.

Johannessen Landmark C (2008). Antiepileptic drugs in non-epilepsy disorders: relations between mechanisms of action and clinical efficacy. CNS Drugs 22: 27-47.

Johnston NL, Cervenak J, Shore AD, Torrey EF, Yolken RH (1997). Multivariate analysis of RNA levels from postmortem human brains as measured by three different methods of RT-PCR. Stanley Neuropathology Consortium. J NeurosCi Methods 77: 83-92.

Joyce JN, Kaeger C, Ryoo H, Goldsmith S (1993). Dopamine D2 receptors in the hippocampus and amygdala in Alzheimer's disease. Neurosci Lett 154: 171-174.

Judd LL, Akiskal HS (2003). The prevalence and disability of bipolar spectrum disorders in the US population: re-analysis of the ECA database taking into account subthreshold cases. J Affect Disord 73: 123-131.

Jurata LW, Bukhman YV, Charles V, Capriglione F, Bullard J, Lemire AL et al (2004). Comparison of microarray-based mRNA profiling technologies for identification of psychiatric disease and drug signatures. J Neurosci Methods 138: 173-188.

Kaminski N, Friedman N (2002). Practical approaches to analyzing results of microarray experiments. Am J Respir Cell Mol Biol 27: 125-132.

Kaplan DR, Miller FD (2000). Neurotrophin signal transduction in the nervous system. Curr Opin Neurobiol 10: 381-391.

Karege F, Vaudan G, Schwald M, Perroud N, La Harpe R (2005). Neurotrophin levels in postmortem brains of suicide victims and the effects of antemortem diagnosis and psychotropic drugs. Brain Res Mol Brain Res 136: 29-37.

Kato T, Monji A, Hashioka S, Kanba S (2007). Risperidone significantly inhibits interferon-gamma-induced microglial activation in vitro. Schizophr Res 92: 108-115.

Katoh-Semba R, Asano T, Ueda H, Morishita R, Takeuchi IK, Inaguma Yet al (2002). Riluzole enhances expression of brain-derived neurotrophic factor with consequent proliferation of granule precursor cells in the rat hippocampus. FASEB J 16: 1328-1330

Katsel P, Davis KL, Gorman JM, Haroutunian V (2005a). Variations in differential gene expression patterns across multiple brain regions in schizophrenia. Schizophr Res 77: 241-252.

Katsel PL, Davis KL, Haroutunian V (2005b). Large-scale microarray studies of gene expression in multiple regions of the brain in schizophrenia and Alzheimer's disease. Int Rev Neurobiol 63: 41-82.

Katz I, de Deyn PP, Mintzer J, Greenspan A, Zhu Y, Brodaty H (2007). The efficacy and safety of risperidone in the treatment of psychosis of Alzheimer's disease and mixed dementia: a meta-analysis of 4 placebo-controlled clinical trials. Int J Geriatr Psychiatry 22: 475-484.

Kenyon C, Chang J, Gensch E, Rudner A, Tabtiang R (1993). A C. elegans mutant that lives twice as long as wild type. Nature 366: 461-464.

Kim S, Choi KH, Baykiz AF, Gershenfeld HK (2007). Suicide candidate genes associated with bipolar disorder and schizophrenia: an exploratory gene expression profiling analysis of post-mortem prefrontal cortex. BMC Genomics 8: 413 .

Kirkwood TB (2005). Understanding the odd science of aging. Cell 120: 437-447.

Klementiev B, Novikova T, Novitskaya V, Walmod PS, Dmytriyeva O, Pakkenberg B et al (2007). A neural cell adhesion molecule-derived peptide reduces neuropathological signs and cognitive impairment induced by Abeta25-35. Neuroscience 145: 209-224.

Klempan TA, Sequeira A, Canetti L, Lalovic A, Ernst C, Ffrench-Mullen $J$ et al (2007). Altered expression of genes involved in ATP biosynthesis and GABAergic neurotransmission in the ventral prefrontal cortex of suicides with and without major depression. Mol Psychiatry.

Knable MB, Barci BM, Bartko JJ, Webster MJ, Torrey EF (2002). Molecular abnormalities in the major psychiatric illnesses: classification and regression tree (CRT) analysis of post-mortem prefrontal markers. Mol Psychiatry 7: 392-404.

Konig R, Baldessari D, Pollet N, Niehrs C, Eils R (2004). Reliability of gene expression ratios for CDNA microarrays in multiconditional experiments with a reference design. Nucleic Acids Res 32: e29.

Konradi C, Eaton M, MacDonald ML, Walsh J, Benes FM, Heckers S (2004). Molecular evidence for mitochondrial dysfunction in bipolar disorder. Arch Gen Psychiatry 61: 300-308.

Kothapalli R, Yoder SJ, Mane S, Loughran Jr TP (2002). Microarray results: how accurate are they? BMC Bioinformatics 3: 22.

Kozisek ME, Middlemas D, Bylund DB (2008). The differential regulation of BDNF and TrkB levels in juvenile rats after four days of escitalopram and desipramine treatment. Neuropharmacology 54: 251-257.

Kraeplin E (1919). Dementia Praecox and Paraphrenia. RE Krieger Publishing: Huntington.

Kuo WP, Jenssen TK, Butte AJ, Ohno-Machado L, Kohane IS (2002). Analysis of matched mRNA measurements from two different microarray technologies. Bioinformatics 18: 405-412.

Labbe EE, Welsh MC, Delaney D (1988). Effects of consistent aerobic exercise on the psychological functioning of women. Percept Mot Skills 67: 919-925.

Lauriat TL, Dracheva S, Chin B, Schmeidler J, Mclnnes LA, Haroutunian V (2006). Quantitative analysis of glutamate transporter mRNA expression in prefrontal and primary visual cortex in normal and schizophrenic brain. Neuroscience 137: 843-851.

Lauterborn JC, Lynch G, Vanderklish P, Arai A, Gall CM (2000). Positive modulation of AMPA receptors increases neurotrophin expression by hippocampal and cortical neurons. J Neurosci 20: 8-21.

Le-Niculescu H, Kurian SM, Yehyawi N, Dike C, Patel SD, Edenberg HJ et al (2008). Identifying blood biomarkers for mood disorders using convergent functional genomics. Mol Psychiatry 26: 26.

Le-Niculescu H, McFarland MJ, Mamidipalli S, Ogden CA, Kuczenski R, Kurian SM et al (2007). Convergent functional genomics of bipolar disorder: from anima model pharmacogenomics to human genetics and biomarkers. Neurosci Biobehav Rev 31: 897-903.

Lee CK, Weindruch R, Prolla TA (2000). Gene-expression profile of the ageing brain in mice. Nat Genet 25: 294-297.

Lee HJ, Song JY, Kim JW, Jin SY, Hong MS, Park JK et al (2005). Association study of polymorphisms in synaptic vesicle-associated genes, SYN2 and CPLX2, with schizophrenia. Behav Brain Funct 1: 15

Lee J, Gomez-Ramirez J, Johnston TH, Visanji N, Brotchie JM (2008). Receptoractivity modifying protein 1 expression is increased in the striatum following repeated L-DOPA administration in a 6-hydroxydopamine lesioned rat model of Parkinson's disease. Synapse 62: 310-313.

Lehrmann E, Hyde TM, Vawter MP, Becker KG, Kleinman JE, Freed WJ (2003a). The use of microarrays to characterize neuropsychiatric disorders: postmortem studies of substance abuse and schizophrenia. Curr Mol Med 3: 437-446.

Lehrmann E, Oyler J, Vawter MP, Hyde TM, Kolachana B, Kleinman JE et al (2003b). Transcriptional profiling in the human prefrontal cortex: evidence for two activational states associated with cocaine abuse. Pharmacogenomics J 3: 27-40.

Lewis DA, Moghaddam B (2006). Cognitive dysfunction in schizophrenia: convergence of gamma-aminobutyric acid and glutamate alterations. Arch Neurol 63: 1372-1376.

Li JZ, Vawter MP, Walsh DM, Tomita H, Evans SJ, Choudary PV et al (2004) Systematic changes in gene expression in postmortem human brains associated with tissue $\mathrm{pH}$ and terminal medical conditions. Hum Mol Genet 13: 609-616.

Li S, Kolkova K, Rudenko O, Soroka V, Poulsen FM, Bock E et al (2005). Triple effect of mimetic peptides interfering with neural cell adhesion molecule homophilic cis interactions. Biochemistry 44: 5034-5040.

Lipton SA (2007). Pathologically activated therapeutics for neuroprotection. Nat Rev Neurosci 8: 803-808

Liu Q, Puche AC, Wang JB (2008). Distribution and expression of protein kinase C interactive protein (PKCl/HINT1) in mouse central nervous system (CNS) Neurochem Res 33: 1263-1276.

Liu Y, Fallon L, Lashuel HA, Liu Z, Lansbury Jr PT (2002). The UCH-L1 gene encodes two opposing enzymatic activities that affect alpha-synuclein degradation and Parkinson's disease susceptibility. Cell 111: 209-218.

Lockhart DJ, Dong H, Byrne MC, Follettie MT, Gallo MV, Chee MS et al (1996). Expression monitoring by hybridization to high density oligonucleotide arrays. Nat Biotechnol 14: 1675-1680.

Loring JF, Wen X, Lee JM, Seilhamer J, Somogyi R (2001). A gene expression profile of Alzheimer's disease. DNA Cell Biol 20: 683-695.

Lowe XR, Lu X, Marchetti F, Wyrobek AJ (2007). The expression of Troponin T1 gene is induced by ketamine in adult mouse brain. Brain Res 1174: 7-17. 
Lu T, Pan Y, Kao SY, Li C, Kohane I, Chan J et al (2004). Gene regulation and DNA damage in the ageing human brain. Nature 429: 883-891.

Lukiw WJ (2004). Gene expression profiling in fetal, aged, and Alzheimer hippocampus: a continuum of stress-related signaling. Neurochem Res 29: 1287-1297.

Luo L, Salunga RC, Guo H, Bittner A, Joy KC, Galindo JE et al (1999). Gene expression profiles of laser-captured adjacent neuronal subtypes. Nat Med $\mathbf{5}$ : 117-122.

Madhav TR, Pei Q, Zetterstrom TS (2001). Serotonergic cells of the rat raphe nuclei express mRNA of tyrosine kinase $B$ (trkB), the high-affinity receptor for brain derived neurotrophic factor (BDNF). Brain Res Mol Brain Res 93: 56-63.

Madsen TM, Treschow A, Bengzon J, Bolwig TG, Lindvall O, Tingstrom A (2000). Increased neurogenesis in a model of electroconvulsive therapy. Biol Psychiatry 47: 1043-1049.

Maeng S, Zarate Jr CA, Du J, Schloesser RJ, McCammon J, Chen G et al (2008). Cellular mechanisms underlying the antidepressant effects of ketamine: role of alpha-amino-3-hydroxy-5-methylisoxazole-4-propionic acid receptors. Biol Psychiatry 63: 349-352.

Magistretti PJ, Pellerin L, Rothman DL, Shulman RG (1999). Energy on demand. Science 283: 496-497.

Mamounas LA, Blue ME, Siuciak JA, Altar CA (1995). Brain-derived neurotrophic factor promotes the survival and sprouting of serotonergic axons in rat brain. J Neurosci 15: 7929-7939.

Manczak M, Park BS, Jung Y, Reddy PH (2004). Differential expression of oxidative phosphorylation genes in patients with Alzheimer's disease: implications for early mitochondrial dysfunction and oxidative damage. Neuromolecular Med 5: 147-162.

Mandel S, Weinreb O, Youdim M (2003). Using cDNA microarray to assess Parkinson's disease models and the effects of neuroprotective drugs. Trends Pharmacol Sci 24: 184-191.

Mann JJ, Apter A, Bertolote J, Beautrais A, Currier D, Haas A et al (2005). Suicide prevention strategies: a systematic review. JAMA 294: 2064-2074.

Martel RR, Botros IW, Rounseville MP, Hinton JP, Staples RR, Morales DA et al (2002). Multiplexed screening assay for mRNA combining nuclease protection with luminescent array detection. Assay Drug Dev Technol 1: 61-71.

Martin H, Rostas J, Patel Y, Aitken A (1994). Subcellular localisation of 14-3-3 isoforms in rat brain using specific antibodies. J Neurochem 63: 2259-2265.

Mathew SJ, Manji HK, Charney DS (2008). Novel drugs and therapeutic targets for severe mood disorders. Neuropsychopharmacology 33: 2080-2092.

Matsuoka N, Nozaki K, Takagi Y, Nishimura M, Hayashi J, Miyatake S et al (2003). Adenovirus-mediated gene transfer of fibroblast growth factor-2 increases BrdU-positive cells after forebrain ischemia in gerbils. Stroke 34: 1519-1525.

Matzilevich DA, Rall JM, Moore AN, Grill RJ, Dash PK (2002). High density microarray analysis of hippocampal gene expression following experimental brain injury. J Neurosci Res 67: 646-663.

McCullumsmith RE, Gupta D, Beneyto M, Kreger E, Haroutunian V, Davis KL et al (2007). Expression of transcripts for myelination-related genes in the anterior cingulate cortex in schizophrenia. Schizophr Res 90: 15-27.

McQuillin A, Rizig M, Gurling HM (2007). A microarray gene expression study of the molecular pharmacology of lithium carbonate on mouse brain mRNA to understand the neurobiology of mood stabilization and treatment of bipolar affective disorder. Pharmacogenet Genomics 17: 605-617.

Medhurst AD, Zeng BY, Charles KJ, Gray J, Reavill C, Hunter AJ et al (2001). Upregulation of secretoneurin immunoreactivity and secretogranin ॥ mRNA in rat striatum following 6-hydroxydopamine lesioning and chronic L-DOPA treatment. Neuroscience 105: 353-364.

Mexal S, Frank M, Berger R, Adams CE, Ross RG, Freedman R et al (2005). Differential modulation of gene expression in the NMDA postsynaptic density of schizophrenic and control smokers. Brain Res Mol Brain Res 139: 317-332.

Middleton FA, Mirnics K, Pierri JN, Lewis DA, Levitt P (2002). Gene expression profiling reveals alterations of specific metabolic pathways in schizophrenia. $J$ Neurosci 22: 2718-2729.

Middleton FA, Peng L, Lewis DA, Levitt P, Mirnics K (2005). Altered expression of 14-3-3 genes in the prefrontal cortex of subjects with schizophrenia. Neuropsychopharmacology 30: 974-983.

Mikel UV, Becker Jr RL (1991). A comparative study of quantitative stains for DNA in image cytometry. Analyt Quant Cytol Histol 13: 253-260.

Miller JA, Oldham MC, Geschwind DH (2008). A systems level analysis of transcriptional changes in Alzheimer's disease and normal aging. J Neurosci 28: 1410-1420.

Miller RM, Callahan LM, Casaceli C, Chen L, Kiser GL, Chui B et al (2004). Dysregulation of gene expression in the 1-methyl-4-phenyl-1,2,3,6-tetrahydropyridine-lesioned mouse substantia nigra. J Neurosci 24: 7445-7454.
Miller RM, Kiser GL, Kaysser-Kranich TM, Lockner RJ, Palaniappan C, Federoff HJ (2006). Robust dysregulation of gene expression in substantia nigra and striatum in Parkinson's disease. Neurobiol Dis 21: 305-313.

Mirnics K, Lewis DA (2001). Genes and subtypes of schizophrenia. Trends Mol Med 7: $281-283$.

Mirnics K, Middleton FA, Marquez A, Lewis DA, Levitt P (2000). Molecular characterization of schizophrenia viewed by microarray analysis of gene expression in prefrontal cortex. Neuron 28: 53-67.

Mirnics K, Middleton FA, Stanwood GD, Lewis DA, Levitt P (2001). Disease-specific changes in regulator of G-protein signaling 4 (RGS4) expression in schizophrenia. Mol Psychiatry 6: 293-301.

Mirnics ZK, Mirnics K, Terrano D, Lewis DA, Sisodia SS, Schor NF (2003). DNA microarray profiling of developing PS1-deficient mouse brain reveals complex and coregulated expression changes. Mol Psychiatry 8: 863-878.

Mirra SS, Heyman A, McKeel D, Sumi SM, Crain BJ, Brownlee LM et al (1991). The consortium to establish a registry for Alzheimer's Disease (CERAD). Part II. Standardization of the neuropathologic assessment of Alzheimer's disease. Neurology 41: 479-486.

Mocanu MM, Nissen A, Eckermann K, Khlistunova I, Biernat J, Drexler D et al (2008). The potential for beta-structure in the repeat domain of tau protein determines aggregation, synaptic decay, neuronal loss, and coassembly with endogenous Tau in inducible mouse models of tauopathy. $J$ Neurosci 28: 737-748.

Molteni R, Ying Z, Gomez-Pinilla F (2002). Differential effects of acute and chronic exercise on plasticity-related genes in the rat hippocampus revealed by microarray. Eur J Neurosci 16: 1107-1116.

Moore CM, Frazier JA, Glod CA, Breeze JL, Dieterich M, Finn CT et al (2007). Glutamine and glutamate levels in children and adolescents with bipolar disorder: a 4.0-T proton magnetic resonance spectroscopy study of the anterior cingulate cortex. J Am Acad Child Adolesc Psychiatry 46: 524-534.

Moore CM, Wardrop M, de BFB, Renshaw PF (2006). Topiramate raises anterior cingulate cortex glutamine levels in healthy men; a 4.0T magnetic resonance spectroscopy study. Psychopharmacology (Berl) 188: 236-243.

Moots RJ, Al-Saffar Z, Hutchinson D, Golding SP, Young SP, Bacon PA et al (1999). Old drug, new tricks: haloperidol inhibits secretion of proinflammatory cytokines. Ann Rheum Dis 58: 585-587.

Morse JK, Wiegand SJ, Anderson K, You Y, Cai N, Carnahan J et al (1993). Brain-derived neurotrophic factor (BDNF) prevents the degeneration of medial septal cholinergic neurons following fimbria transection. J Neurosci 13: 4146-4156.

Mufson EJ, Counts SE, Fahnestock M, Ginsberg SD (2007a). NGF family of neurotrophins and their receptors: early involvement in the progression of Alzheimer's disease. In: Dawbarn D, Allen SJ (eds). Neurobiology of Alzheimer's Disease, 3rd edn. Oxford University Press: Oxford. pp 283-321.

Mufson EJ, Counts SE, Fahnestock M, Ginsberg SD (2007b). Cholinotrophic molecular substrates of mild cognitive impairment in the elderly. Curr Alzheimer Res 4: 340-350.

Mufson EJ, Ginsberg SD, Ikonomovic MD, DeKosky ST (2003). Human cholinergic basal forebrain: chemoanatomy and neurologic dysfunction. J Chem Neuroanat 26: 233-242.

Mullis KB (1990). The unusual origin of the polymerase chain reaction. Sci Am 262 56-65.

Murakami M, Elfenbein A, Simons M (2008). Non-canonical fibroblast growth factor signalling in angiogenesis. Cardiovasc Res 78: 223-231.

Mwangi S, Anitha M, Fu H, Sitaraman SV, Srinivasan S (2006). Glial cell line-derived neurotrophic factor-mediated enteric neuronal survival involves glycogen synthase kinase-3beta phosphorylation and coupling with 14-3-3. Neuroscience 143: $241-251$

Naeve GS, Ramakrishnan M, Kramer R, Hevroni D, Citri Y, Theill LE (1997). Neuritin: a gene induced by neural activity and neurotrophins that promotes neuritogenesis. Proc Natl Acad Sci USA 94: 2648-2653.

Nakatani N, Hattori E, Ohnishi T, Dean B, Iwayama Y, Matsumoto I et al (2006). Genome-wide expression analysis detects eight genes with robust alterations specific to bipolar I disorder: relevance to neuronal network perturbation. Hum Mol Genet 15: 1949-1962.

Napolitano M, Centonze D, Calce A, Picconi B, Spiezia S, Gulino A et al (2002). Experimental Parkinsonism modulates multiple genes involved in the transduction of dopaminergic signals in the striatum. Neurobiol Dis 10: 387-395.

Napolitano M, Picconi B, Centonze D, Bernardi G, Calabresi P, Gulino A (2006). L-DOPA treatment of parkinsonian rats changes the expression of Src, Lyn and PKC kinases. Neurosci Lett 398: 211-214.

Newton SS, Collier EF, Hunsberger J, Adams D, Terwilliger R, Selvanayagam E et al (2003). Gene profile of electroconvulsive seizures: induction of neurotrophic and angiogenic factors. J Neurosci 23: 10841-10851. 
Nibuya M, Morinobu S, Duman RS (1995). Regulation of BDNF and trkB mRNA in rat brain by chronic electroconvulsive seizure and antidepressant drug treatments. J Neurosci 15: 7539-7547.

Novikova SI, He F, Cutrufello NJ, Lidow MS (2006). Identification of protein biomarkers for schizophrenia and bipolar disorder in the postmortem prefrontal cortex using SELDI-TOF-MS ProteinChip profiling combined with MALDI-TOFPSD-MS analysis. Neurobiol Dis 23: 61-76.

Obsil T, Ghirlando R, Klein DC, Ganguly S, Dyda F (2001). Crystal structure of the 14-3-3zeta:serotonin $\mathrm{N}$-acetyltransferase complex. A role for scaffolding in enzyme regulation. Cell 105: 257-267.

Ogden CA, Rich ME, Schork NJ, Paulus MP, Geyer MA, Lohr JB et al (2004). Candidate genes, pathways and mechanisms for bipolar (manic-depressive) and related disorders: an expanded convergent functional genomics approach. Mol Psychiatry 9: 1007-1029.

Ohl F, Jung M, Xu C, Stephan C, Rabien A, Burkhardt M et al (2005). Gene expression studies in prostate cancer tissue: which reference gene should be selected for normalization? J Mol Med 83: 1014-1024.

Palfreyman MG, Hook DJ, Klimczak LJ, Brockman JA, Evans DM, Altar CA (2002). Novel directions in antipsychotic target identification using gene arrays. Curr Drug Targets CNS Neurol Disord 1: 227-238.

Pan T, Xie W, Jankovic J, Le W (2005). Biological effects of pramipexole on dopaminergic neuron-associated genes: relevance to neuroprotection. Neurosci Lett 377: 106-109.

Patel S, Singh K, Singh S, Singh MP (2008). Gene expression profiles of mouse striatum in control and maneb+paraquat-induced Parkinson's disease phenotype: validation of differentially expressed energy metabolizing transcripts. Mol Biotechnol 2: 2.

Patil ST, Zhang L, Martenyi F, Lowe SL, Jackson KA, Andreev BV et al (2007). Activation of mGlu2/3 receptors as a new approach to treat schizophrenia: a randomized phase 2 clinical trial. Nat Med 13: 1102-1107.

Paulson L, Martin P, Persson A, Nilsson CL, Ljung E, Westman-Brinkmalm A et al (2003). Comparative genome- and proteome analysis of cerebral cortex from MK-801-treated rats. J Neurosci Res 71: 526-533.

Pennington K, Beasley CL, Dicker P, Fagan A, English J, Pariante CM et al (2007). Prominent synaptic and metabolic abnormalities revealed by proteomic analysis of the dorsolateral prefrontal cortex in schizophrenia and bipolar disorder. $\mathrm{MO}$ Psychiatry.

Peretti CS, Gierski F, Harrois S (2004). Cognitive skill learning in healthy older adults after 2 months of double-blind treatment with piribedil. Psychopharmacology (Berl) 176: 175-181.

Pericak-Vance MA, Grubber J, Bailey LR, Hedges D, West S, Santoro L et al (2000). Identification of novel genes in late-onset Alzheimer's disease. Exp Geronto/ 35 1343-1352.

Phillips J, Eberwine JH (1996). Antisense RNA amplification: a linear amplification method for analyzing the mRNA population from single living cells. Methods Enzymol Suppl 10: 283-288.

Plassman BL, Langa KM, Fisher GG, Heeringa SG, Weir DR, Ofstedal MB et al (2007). Prevalence of dementia in the United States: the aging, demographics, and memory study. Neuroepidemiology 29: 125-132.

Pletcher SD, Stumpf MP (2002). Population genomics: ageing by association. Curr Biol 12: R328-R330.

Plomin R, McClearn GE (1993). Nature, Nurture and Psychology. American Psychological Association: Washington, DC.

Pozuelo Rubio M, Geraghty KM, Wong BH, Wood NT, Campbell DG, Morrice N et al (2004). 14-3-3-Affinity purification of over 200 human phosphoproteins reveals new links to regulation of cellular metabolism, proliferation and trafficking. Biochem J 379(Part 2): 395-408.

Prabakaran S, Swatton JE, Ryan MM, Huffaker SJ, Huang JT, Griffin JL et al (2004). Mitochondrial dysfunction in schizophrenia: evidence for compromised brain metabolism and oxidative stress. Mol Psychiatry 9: 684-697, 643.

Prolla TA (2002). DNA microarray analysis of the aging brain. Chem Senses 27 299-306.

Pulver AE (2000). Search for schizophrenia susceptibility genes. Biol Psychiatry 47: 221-230.

Raghothama C, Harsha HC, Prasad CK, Pandey A (2005). Bioinformatics and proteomics approaches for aging research. Biogerontology 6: 227-232.

Reddy PH, McWeeney S, Park BS, Manczak M, Gutala RV, Partovi D et al (2004). Gene expression profiles of transcripts in amyloid precursor protein transgenic mice: up-regulation of mitochondrial metabolism and apoptotic genes is an early cellular change in Alzheimer's disease. Hum Mol Genet 13: 1225-1240.

Reiner A, Yekutieli D, Benjamini Y (2003). Identifying differentially expressed genes using false discovery rate controlling procedures. Bioinformatics 19: 368-375.

Rinne JO, Lonnberg P, Marjamaki P (1990). Age-dependent decline in human brain dopamine D1 and D2 receptors. Brain Res 508: 349-352.
Rogers A, Antoshechkin I, Bieri T, Blasiar D, Bastiani C, Canaran P et al (2008). WormBase 2007. Nucleic Acids Res 36: D612-D617.

Rome S, Clement K, Rabasa-Lhoret R, Loizon E, Poitou C, Barsh GS et al (2003). Microarray profiling of human skeletal muscle reveals that insulin regulates approximately 800 genes during a hyperinsulinemic clamp. J Biol Chem 278 : 18063-18068.

Roth BL, Sheffler DJ, Kroeze WK (2004). Magic shotguns versus magic bullets: selectively non-selective drugs for mood disorders and schizophrenia. Nat Rev Drug Discov 3: 353-359.

Rothstein JD (2003). Of mice and men: reconciling preclinical ALS mouse studies and human clinical trials. Ann Neurol 53: 423-426.

Rothstein JD, Patel S, Regan MR, Haenggeli C, Huang YH, Bergles DE et al (2005). Beta-lactam antibiotics offer neuroprotection by increasing glutamate transporter expression. Nature 433: 73-77.

Russo-Neustadt A, Beard RC, Cotman CW (1999). Exercise, antidepressant medications, and enhanced brain derived neurotrophic factor expression Neuropsychopharmacology 21: 679-682.

Ryan MM, Lockstone HE, Huffaker SJ, Wayland MT, Webster MJ, Bahn S (2006). Gene expression analysis of bipolar disorder reveals downregulation of the ubiquitin cycle and alterations in synaptic genes. Mol Psychiatry 11 965-978.

Ryoo HL, Joyce JN (1994). Loss of dopamine D2 receptors varies along the rostrocaudal axis of the hippocampal complex in Alzheimer's disease. J Comp Neurol 348: 94-110.

Saarelainen T, Pussinen R, Koponen E, Alhonen L, Wong G, Sivio J et al (2000). Transgenic mice overexpressing truncated trkB neurotrophin receptors in neurons have impaired long-term spatial memory but normal hippocampal LTP. Synapse 38: 102-104.

Saetre P, Emilsson L, Axelsson E, Kreuger J, Lindholm E, Jazin E (2007). Inflammation-related genes up-regulated in schizophrenia brains. BMC Psychiatry 7: 46.

Sanacora G, Kendell SF, Levin Y, Simen AA, Fenton LR, Coric V et al (2007). Preliminary evidence of riluzole efficacy in antidepressant-treated patients with residual depressive symptoms. Biol Psychiatry 61: 822-825.

Sastry PS, Sita Ratna W (2004). Intrathecal therapy with trastuzumab may be beneficial in cases of refractory schizophrenia. Med Hypotheses 62 $542-545$

Sato M, Suzuki K, Nakanishi S (2001). NMDA receptor stimulation and brainderived neurotrophic factor upregulate homer 1a mRNA via the mitogenactivated protein kinase cascade in cultured cerebellar granule cells. J Neurosci 21: 3797-3805.

Saviouk V, Moreau MP, Tereshchenko IV, Brzustowicz LM (2007). Association of synapsin 2 with schizophrenia in families of Northern European ancestry. Schizophr Res 96: 100-111.

Scarr E, Sundram S, Keriakous D, Dean B (2007). Altered hippocampal muscarinic M4, but not M1, receptor expression from subjects with schizophrenia. Biol Psychiatry 61: 1161-1170.

Schena M, Shalon D, Davis RW, Brown PO (1995). Quantitative monitoring of gene expression patterns with a complementary DNA microarray. Science 270: 467-470.

Secher T, Novitskaia V, Berezin V, Bock E, Glenthoj B, Klementiev B (2006). A neural cell adhesion molecule-derived fibroblast growth factor receptor agonist, the FGL-peptide, promotes early postnatal sensorimotor development and enhances social memory retention. Neuroscience 141: 1289-1299.

Selkoe DJ (1997). Alzheimer's disease: genotypes, phenotypes, and treatments. Science 275: 630-631.

Sequeira A, Gwadry FG, Ffrench-Mullen JM, Canetti L, Gingras Y, Casero Jr RA et al (2006). Implication of SSAT by gene expression and genetic variation in suicide and major depression. Arch Gen Psychiatry 63: 35-48.

Sequeira A, Klempan T, Canetti L, ffrench-Mullen J, Benkelfat C, Rouleau GA et al (2007). Patterns of gene expression in the limbic system of suicides with and without major depression. Mol Psychiatry 12: 640-655.

Sequeira A, Turecki G (2006). Genome wide gene expression studies in mood disorders. Omics 10: 444-454.

Serrano F, Klann E (2004). Reactive oxygen species and synaptic plasticity in the aging hippocampus. Ageing Res Rev 3: 431-443.

Shan X, Tashiro H, Lin CL (2003). The identification and characterization of oxidized RNAs in Alzheimer's disease. J Neurosci 23: 4913-4921.

Shao L, Martin MV, Watson SJ, Schatzberg A, Akil H, Myers RM et al (2008). Mitochondrial involvement in psychiatric disorder. Ann Med 40: 281-295

Shao L, Vawter MP (2008). Shared gene expression alterations in schizophrenia and bipolar disorder. Biol Psychiatry 64: 89-97.

Sheedy D, Garrick T, Dedova I, Hunt C, Miller R, Sundqvist N et al (2008). An Australian brain bank: a critical investment with a high return!. Cell Tissue Bank 10: 10. 
Shimohama S, Kamiya S, Taniguchi T, Akagawa K, Kimura J (1997). Differential involvement of synaptic vesicle and presynaptic plasma membrane proteins in Alzheimer's disease. Biochem Biophys Res Comm 236: 239-242.

Shinoda S, Schindler CK, Quan-Lan J, Saugstad JA, Taki W, Simon RP et al (2003). Interaction of 14-3-3 with Bid during seizure-induced neuronal death. J Neurochem 86: 460-469.

Sibille E, Arango V, Galfalvy HC, Pavlidis P, Erraji-Benchekroun L, Ellis SP et al (2004). Gene expression profiling of depression and suicide in human prefrontal cortex. Neuropsychopharmacology 29: 351-361.

Simone NL, Remaley AT, Charboneau L, Petricoin III EF, Glickman JW, EmmertBuck MR et al (2000). Sensitive immunoassay of tissue cell proteins procured by laser capture microdissection. Am J Pathol 156: 445-452.

Siuciak JA, Lewis DR, Wiegand SJ, Lindsay RM (1997). Antidepressant-like effect of brain-derived neurotrophic factor (BDNF). Pharmacol Biochem Behav 56: 131-137.

Skaper SD (2008). The biology of neurotrophins, signalling pathways, and functional peptide mimetics of neurotrophins and their receptors. CNS Neurol Disord Drug Targets 7: 46-62.

Skolnick P, Legutko B, Li X, Bymaster FP (2001). Current perspectives on the development of non-biogenic amine-based antidepressants. Pharmacol Res 43: 411-423.

Sofroniew MV, Howe CL, Mobley WC (2001). Nerve growth factor signaling, neuroprotection, and neural repair. Annu Rev Neurosci 24: 1217-1281.

Sohal RS, Weindruch R (1996). Oxidative stress, caloric restriction, and aging. Science 273: 59-63.

Song C, Lin A, Kenis G, Bosmans E, Maes M (2000). Immunosuppressive effects of clozapine and haloperidol: enhanced production of the interleukin-1 receptor antagonist. Schizophr Res 42: 157-164.

Straub RE, Lipska BK, Egan MF, Goldberg TE, Callicott JH, Mayhew MB et al (2007). Allelic variation in GAD1 (GAD67) is associated with schizophrenia and influences cortical function and gene expression. Mol Psychiatry 12: 854-869.

Svenningsson P, Arts J, Gunne L, Andren PE (2002). Acute and repeated treatment with L-DOPA increase c-jun expression in the 6-hydroxydopamine-lesioned forebrain of rats and common marmosets. Brain Res 955: 8-15.

Swerdlow RH (2007). Is aging part of Alzheimer's disease, or is Alzheimer's disease part of aging? Neurobiol Aging 28: 1465-1480.

Sze Cl, Bi H, Kleinschmidt-DeMasters BK, Filley CM, Martin LJ (2000). Selective regional loss of exocytotic presynaptic vesicle proteins in Alzheimer's disease brains. J Neurol Sci 175: 81-90.

Sze Cl, Troncoso JC, Kawas C, Mouton P, Price DL, Martin LJ (1997). Loss of the presynaptic vesicle protein synaptophysin in hippocampus correlates with cognitive decline in Alzheimer disease. J Neuropathol Exp Neurol 56: 933-944.

Taya S, Shinoda T, Tsuboi D, Asaki J, Nagai K, Hikita Tet al (2007). DISC1 regulates the transport of the NUDEL/LIS1/14-3-3epsilon complex through kinesin-1. $J$ Neurosci 27: 15-26.

Taylor M, Shajahan P, Lawrie SM (2008). Comparing the use and discontinuation of antipsychotics in clinical practice: an observational study. J Clin Psychiatry 69: 240-245.

Thakker-Varia S, Krol JJ, Nettleton J, Bilimoria PM, Bangasser DA, Shors TJ et al (2007). The neuropeptide VGF produces antidepressant-like behavioral effects and enhances proliferation in the hippocampus. J Neurosci 27: 12156-12167.

Tkachev D, Mimmack ML, Ryan MM, Wayland M, Freeman T, Jones PB et al (2003). Oligodendrocyte dysfunction in schizophrenia and bipolar disorder. Lancet 362: 798-805.

Tochigi M, Iwamoto K, Bundo M, Sasaki T, Kato N, Kato T (2008). Gene expression profiling of major depression and suicide in the prefrontal cortex of postmortem brains. Neurosci Res 60: 184-191.

Tomita H, Vawter MP, Walsh DM, Evans SJ, Choudary PV, Li J et al (2004). Effect of agonal and postmortem factors on gene expression profile: quality control in microarray analyses of postmortem human brain. Biol Psychiatry 55: 346-352.

Tong G, Jahr CE (1994). Block of glutamate transporters potentiates postsynaptic excitation. Neuron 13: 1195-1203.

Tong L, Shen H, Perreau VM, Balazs R, Cotman CW (2001). Effects of exercise on gene-expression profile in the rat hippocampus. Neurobiol Dis 8: 1046-1056.

Torrey EF, Barci BM, Webster MJ, Bartko JJ, Meador-Woodruff JH, Knable MB (2005). Neurochemical markers for schizophrenia, bipolar disorder, and major depression in postmortem brains. Biol Psychiatry 57: 252-260.

Torrey EF, Webster M, Knable M, Johnston N, Yolken RH (2000). The Stanley Foundation Brain Collection and Neuropathology Consortium. Schizophr Res 44: 151-155.

Toyooka K, Muratake T, Tanaka T, Igarashi S, Watanabe H, Takeuchi H et al (1999). 14-3-3 protein eta chain gene (YWHAH) polymorphism and its genetic association with schizophrenia. Am J Med Genet 88: 164-167.

Traina G, Valleggi S, Bernardi R, Rizzo M, Calvani M, Nicolai R et al (2004). Identification of differentially expressed genes induced in the rat brain by acetyl-L- carnitine as evidenced by suppression subtractive hybridisation. Brain Res $\mathrm{Mol}$ Brain Res 132: 57-63.

Trojanowski JQ, Lee VM (2005). The Alzheimer's brain: finding out what's broken tells us how to fix it. Am J Pathol 167: 1183-1188.

Tronci E, Simola N, Borsini F, Schintu N, Frau L, Carminati P et al (2007). Characterization of the antiparkinsonian effects of the new adenosine A2A receptor antagonist ST1535: acute and subchronic studies in rats. Eur $J$ Pharmacol 566: 94-102.

Tsuang MT, Stone WS, Faraone SV (1999). The genetics of schizophrenia. Curr Psychiatry Rep 1: 20-24.

Turner CA, Akil H, Watson SJ, Evans SJ (2006). The fibroblast growth factor system and mood disorders. Biol Psychiatry 59: 1128-1135.

Turner CA, Gula EL, Taylor LP, Watson SJ, Akil H (2008). Antidepressant-like effects of intracerebroventricular FGF2 in rats. Brain Res 1224: 63-68.

Tuszynski MH (2007). Nerve growth factor gene therapy in Alzheimer disease. Alzheimer Dis Assoc Disord 21: 179-189.

Van Deerlin VMD, Ginsberg SD, Lee VM-Y, Trojanowski JQ (2002). The use of fixed human post mortem brain tissue to study mRNA expression in neurodegenerative diseases: applications of microdissection and mRNA amplification. In: Geschwind DH, Gregg JP (eds). Microarrays for the Neurosciences: AN Essential Guide. MIT Press: Boston. pp 201-235.

Vawter MP (2000). Dysregulation of the neural cell adhesion molecule and neuropsychiatric disorders. Eur J Pharmacol 405: 385-395.

Vawter MP, Atz ME, Rollins BL, Cooper-Casey KM, Shao L, Byerley WF (2006a). Genome scans and gene expression microarrays converge to identify gene regulatory loci relevant in schizophrenia. Hum Genet 119: 558-570.

Vawter MP, Barrett T, Cheadle C, Sokolov BP, Wood III WH, Donovan DM et al (2001). Application of cDNA microarrays to examine gene expression differences in schizophrenia. Brain Res Bull 55: 641-650.

Vawter MP, Crook JM, Hyde TM, Kleinman JE, Weinberger DR, Becker KG et al (2002a). Microarray analysis of gene expression in the prefrontal cortex in schizophrenia: a preliminary study. Schizophrenia Res 58: 11-20.

Vawter MP, Evans S, Choudary P, Tomita H, Meador-Woodruff J, Molnar M et al (2004a). Gender-specific gene expression in post-mortem human brain: localization to sex chromosomes. Neuropsychopharmacology 29 373-384.

Vawter MP, Freed WJ, Kleinman JE (2000). Neuropathology of bipolar disorder. Biol Psychiatry 48: 486-504.

Vawter MP, Shannon Weickert C, Ferran E, Matsumoto M, Overman K, Hyde TM et al (2004b). Gene expression of metabolic enzymes and a protease inhibitor in the prefrontal cortex are decreased in schizophrenia. Neurochem Res 29 1245-1255.

Vawter MP, Thatcher L, Usen N, Hyde TM, Kleinman JE, Freed WJ (2002b). Reduction of synapsin in the hippocampus of patients with bipolar disorder and schizophrenia. Mol Psychiatry 7: 571-578.

Vawter MP, Tomita H, Meng F, Bolstad B, Li J, Evans S et al (2006b). Mitochondrialrelated gene expression changes are sensitive to agonal-pH state: implications for brain disorders. Mol Psychiatry 11: 615, 663-679.

Vijg J, Suh Y (2005). Genetics of longevity and aging. Annu Rev Med 56: 193-212.

Vincent VA, DeVoss JJ, Ryan HS, Murphy Jr GM (2002). Analysis of neuronal gene expression with laser capture microdissection. J Neurosci Res 69: 578-586.

Vogt IR, Lees AJ, Evert BO, Klockgether T, Bonin M, Wullner U (2006). Transcriptional changes in multiple system atrophy and Parkinson's disease putamen. Exp Neurol 199: 465-478.

Volkow ND, Ding YS, Fowler JS, Wang GJ, Logan J, Gatley SJ et al (1996). Dopamine transporters decrease with age. J Nucl Med 37: 554-559.

Vonsattel JP, Amaya MD, Cortes EP, Mancevska K, Keller CE (2008). Twenty-first century brain banking: practical prerequisites and lessons from the past: the experience of New York Brain Bank, Taub Institute, Columbia University. Cell Tissue Bank 26: 26.

Wang H, Katz J, Dagostino P, Soghomonian JJ (2007a). Unilateral 6-hydroxydopamine lesion of dopamine neurons and subchronic L-DOPA administration in the adult rat alters the expression of the vesicular GABA transporter in different subsets of striatal neurons and in the substantia nigra, pars reticulata. Neuroscience 145: 727-737

Wang HS, Duan SW, Xing QH, Du J, Li XW, Xu YF et al (2005). Association study between NPY and YWHAH gene polymorphisms and schizophrenia. Yi Chuan Xue Bao 32: 1235-1240.

Wang XT, Pei DS, Xu J, Guan QH, Sun YF, Liu XM et al (2007b). Opposing effects of Bad phosphorylation at two distinct sites by Akt1 and JNK1/2 on ischemic brain injury. Cell Signal 19: 1844-1856.

Weickert CS, Hyde TM, Lipska BK, Herman MM, Weinberger DR, Kleinman JE (2003). Reduced brain-derived neurotrophic factor in prefrontal cortex of patients with schizophrenia. Mol Psychiatry 8: 592-610. 
Westphalen RI, Scott HL, Dodd PR (2003). Synaptic vesicle transport and synaptic membrane transporter sites in excitatory amino acid nerve terminals in Alzheimer disease. J Neural Transm 110: 1013-1027.

Whatley SA, Curti D, Marchbanks RM (1996). Mitochondrial involvement in schizophrenia and other functional psychoses. Neurochem Res 21: 995-1004.

Whitehouse PJ, Price DL, Struble RG, Clark AW, Coyle JT, Delong MR (1982). Alzheimer's disease and senile dementia: loss of neurons in the basal forebrain. Science 215: 1237-1239.

Wimo A, Winblad B, Jönsson L (2007). An estimate of the total worldwide societal costs of dementia in 2005. Alzheimer Dement 3: 81-91.

Winge I, McKinney JA, Ying M, D'Santos CS, Kleppe R, Knappskog PM et al (2008). Activation and stabilization of human tryptophan hydroxylase 2 by phosphorylation and 14-3-3 binding. Biochem J 410: 195-204.

Wong AH, Likhodi O, Trakalo J, Yusuf M, Sinha A, Pato CN et al (2005). Genetic and post-mortem mRNA analysis of the 14-3-3 genes that encode phosphoserine/ threonine-binding regulatory proteins in schizophrenia and bipolar disorder. Schizophr Res 78: 137-146.

Wong AH, Macciardi F, Klempan T, Kawczynski W, Barr CL, Lakatoo S et al (2003). Identification of candidate genes for psychosis in rat models, and possible association between schizophrenia and the 14-3-3eta gene. Mol Psychiatry 8 156-166.

Woodward ND, Purdon SE, Meltzer HY, Zald DH (2005). A meta-analysis of neuropsychological change to clozapine, olanzapine, quetiapine, and risperidone in schizophrenia. Int J Neuropsychopharmacol 8: 457-472.

Yang YH, Dudoit S, Luu P, Lin DM, Peng V, Ngai J et al (2002). Normalization for CDNA microarray data: a robust composite method addressing single and multiple slide systematic variation. Nucleic Acids Res 30: e15.

Yao PJ, Zhu M, Pyun El, Brooks Al, Therianos S, Meyers VE et al (2003). Defects in expression of genes related to synaptic vesicle trafficking in frontal cortex of Alzheimer's disease. Neurobiol Dis 12: 97-109.

Yasuda RP, Ikonomovic MD, Sheffield R, Rubin RT, Wolfe BB, Armstrong DM (1995). Reduction of AMPA-selective glutamate receptor subunits in the entorhinal cortex of patients with Alzheimer's disease pathology: a biochemical study. Brain Res 678: 161-167.

Yazlovitskaya EM, Edwards E, Thotala D, Fu A, Osusky KL, Whetsell Jr WO et al (2006). Lithium treatment prevents neurocognitive deficit resulting from cranial irradiation. Cancer Res 66: 11179-11186.

Yechoor VK, Patti ME, Saccone R, Kahn CR (2002). Coordinated patterns of gene expression for substrate and energy metabolism in skeletal muscle of diabetic mice. Proc Natl Acad Sci USA 99: 10587-10592.

Zarate Jr CA, Quiroz JA, Singh JB, Denicoff KD, De Jesus G, Luckenbaugh DA et al (2005). An open-label trial of the glutamate-modulating agent riluzole in combination with lithium for the treatment of bipolar depression. Biol Psychiatry 57: 430-432.

Zarate Jr CA, Singh JB, Carlson PJ, Brutsche NE, Ameli R, Luckenbaugh DA et al (2006). A randomized trial of an N-methyl-D-aspartate antagonist in treatmentresistant major depression. Arch Gen Psychiatry 63: 856-864.

Zeng BY, Jolkkonen J, Jenner P, Marsden CD (1995). Chronic L-DOPA treatment differentially regulates gene expression of glutamate decarboxylase, preproenkephalin and preprotachykinin in the striatum of 6-hydroxydopamine-lesioned rat. Neuroscience 66: 19-28.

Zetterstrom TS, Pei Q, Grahame-Smith DG (1998). Repeated electroconvulsive shock extends the duration of enhanced gene expression for BDNF in rat brain compared with a single administration. Brain Res Mol Brain Res 57: 106-110.

Zhao Z, Ksiezak-Reding H, Riggio S, Haroutunian V, Pasinetti GM (2006). Insulin receptor deficits in schizophrenia and in cellular and animal models of insulin receptor dysfunction. Schizophr Res 84: 1-14

Zhou R, Gray NA, Yuan P, Li X, Chen J, Chen G et al (2005). The anti-apoptotic, glucocorticoid receptor cochaperone protein BAG-1 is a long-term target for the actions of mood stabilizers. J Neurosci 25: 4493-4502.

Zink M, Schmitt A, May B, Muller B, Demirakca T, Braus DF et al (2004). Differential effects of long-term treatment with clozapine or haloperidol on GABAA receptor binding and GAD67 expression. Schizophr Res 66: 151-157.

Zucchero T, Ahmed S (2006). Genetics of proliferative aging. Exp Gerontol 41: 992-1000.
APPENDIX A: Representative brain banks for neurodegenerative and psychiatric disease cases

\begin{tabular}{|c|c|}
\hline Brain bank & Website \\
\hline $\begin{array}{l}\text { Center for Neurodegenerative Disease Research, } \\
\text { University of Pennsylvania }\end{array}$ & http://www.med.upenn.edu/cndr/ \\
\hline $\begin{array}{l}\text { Cognitive Neurology and Azheimer's Disease } \\
\text { Center at Northwestern University }\end{array}$ & $\begin{array}{l}\text { http://mww.brain.northwestern.edu/mdad/ } \\
\text { neuropathology.html }\end{array}$ \\
\hline Columbia University & http://uww.nybb.hs.columbia.edu/ \\
\hline Harvard Brain Tissue Resource Center & http://www. brainbank.mclean.org/ \\
\hline Multiple Sclerosis Brain Bank & http://www.msbrainbank.org.au/ \\
\hline New South Wales Brain Bank & $\begin{array}{l}\text { http://umw.florey. edu. au/support/australian- } \\
\text { brain-bank-network/ }\end{array}$ \\
\hline NINDS Web site & $\begin{array}{l}\text { http://www.ninds.nih.gov/funding/research/ } \\
\text { parkinsonsweb/brainbanks.htm }\end{array}$ \\
\hline Rush Alzheimer's Disease Center & $\begin{array}{l}\text { http://unw.rush.edu/rumc/page- } \\
\text { R12388.html }\end{array}$ \\
\hline Stanley Medical Research Institute & $\begin{array}{l}\text { http://mww. stanleyresearch.org/dnn/Brain } \\
\text { ResearchCollection/tabid/83/Default.aspx }\end{array}$ \\
\hline University of Miami Brain Endowment Bank & http://brainbank.med.miami.edu/ \\
\hline $\begin{array}{l}\text { University of Pittsburgh Alzheimer Disease } \\
\text { Research Center Brain Bank }\end{array}$ & \\
\hline
\end{tabular}

APPENDIX B: Commercial and non-commercial microarray platforms and software sources used to conduct microarray gene expression studies.

\begin{tabular}{|l|l|}
\hline Platform vendor & Websites for information on products \\
\hline Affymetrix & www.affymetrix.com/index.affx \\
\hline Exon Hit & www.exonhit.com/index.php?page=1 \\
\hline Agilent & www.chem.agilent.com494 www.chem.agilent.com/ \\
\hline & Scripts/PCol.asp?Page=494 \\
\hline Illumina & www.illumina.com/ \\
\hline $\begin{array}{l}\text { Applied Microarray (formerly } \\
\text { Codelink GE Amersham) }\end{array}$ & www.appliedmicroarrays.com/Human.html \\
\hline Roche Nimblegen & www.nimblegen.com/products/exp/index.html \\
\hline Software analysis vendor & \\
\hline Partek Genomic Solutions & www.partek.com \\
\hline Agilent GeneSpring & www.chem.agilent.com/Scripts/PDS.asp?/Page=27881 \\
\hline dCHIP & biosun1.harvard.edu/complab/dchip/ \\
\hline RMA & www.bioconductor.org/ \\
\hline MAS 5 Affymetrix & www.affymetrix.com/index.affx \\
\hline Bioconductor & www.bioconductor.org/ \\
\hline Bioinformatics vendor & \\
\hline Ingenuity & www.ingenuity.com \\
\hline Transfac & www.gene-regulation.com/pub/databases.html \\
\hline DAVID/EASE & david.abcc.ncifcrf.gov/ \\
\hline Gene Expression Omnibus & www.ncbi.nlm.nih.gov/geo/ \\
\hline KEGG & www.genome.jp/kegg/ \\
\hline GenMAPP & www.genmapp.org/ \\
\hline Novartis SymAtlas & symatlas.gnf.org/SymAtlas/ \\
\hline Microarray World & $\begin{array}{l}\text { www.microarrayworld.com/SoftwarePage.html } \\
\text { (listing of software, platform, and other tools) }\end{array}$ \\
\hline
\end{tabular}

